\title{
FOOD ONLINE
}

PhD thesis on food legal and civil law requirements for digital contracts regarding food purchases by consumers in the Netherlands 


\section{Food Online}

Lomme C. van der Veer 


\section{Thesis Committee}

\section{Promotor}

Prof. dr. Bernhard M.J. van der Meulen

Professor of Food Law

Wageningen University and Research

\section{Other members}

Prof. dr. S.W.F. Omta, Wageningen University and Research

Prof. dr. I. Härtel, Europa Universität Viadrina, Frankfurt a.d. Oder

Prof. dr. D.W. Bruil, University of Groningen

Dr. J.A. Jurriëns, Avans University of applied sciences 


\section{Food Online}

Lomme C. van der Veer

\section{Thesis}

submitted in fulfilment of the requirements for the degree of doctor at Wageningen University

by the authority of the Rector Magnificus

Prof. dr. A.P.J. Mol,

In the presence of the Academic Board

to be defended in public

on Friday 3 November 2017

at 11.00 a.m. in the Aula. 
Lomme C. van der Veer

Food Online : PhD thesis on food legal and civil law requirements for digital contracts regarding food purchases by consumers in the Netherlands, 153 pages.

PhD thesis, Wageningen University, Wageningen, the Netherlands (2017)

With references, with summary in English

ISBN 978-94-6343-712-7

DOI https://doi.org/10.18174/425634 


\section{TABLE OF CONTENTS}

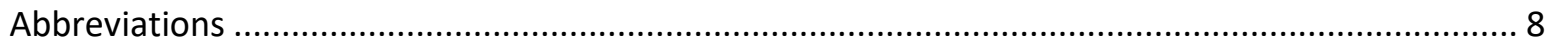

Preface

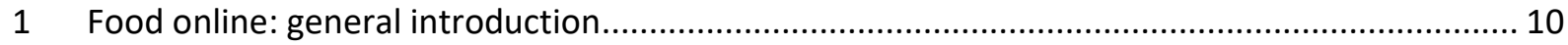

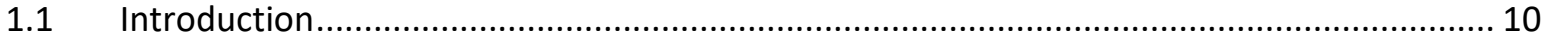

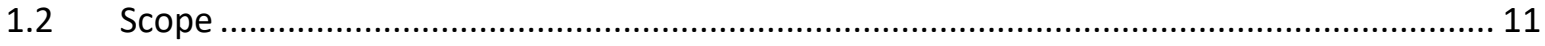

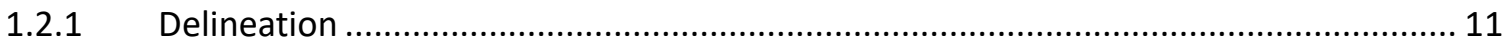

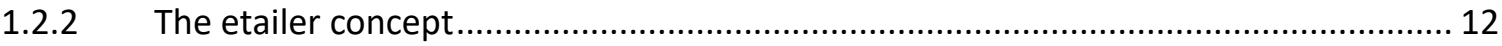

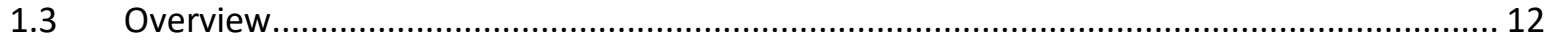

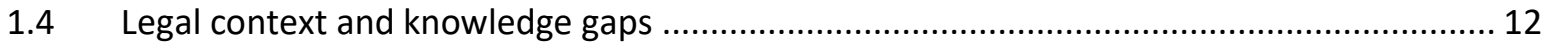

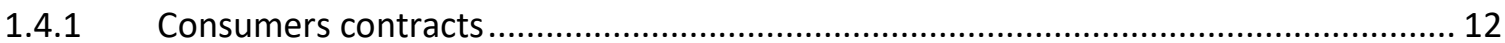

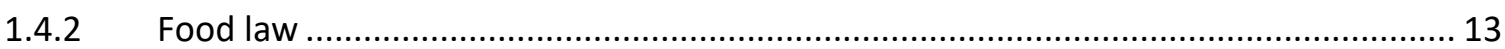

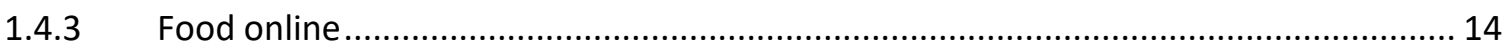

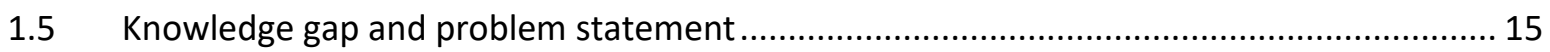

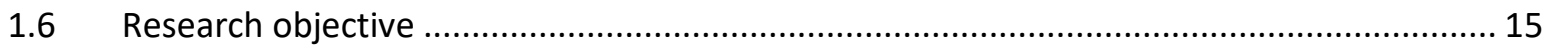

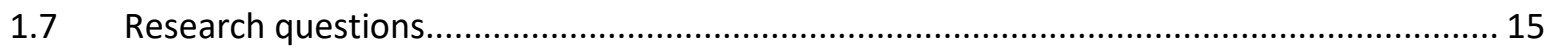

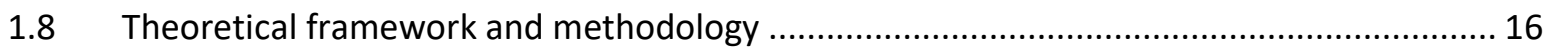

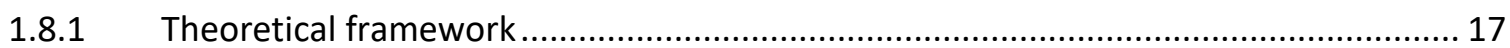

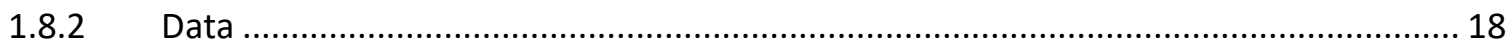

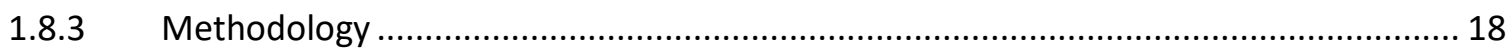

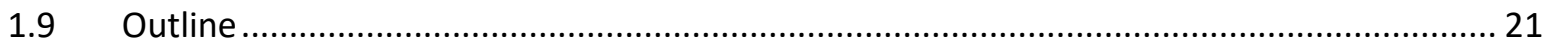

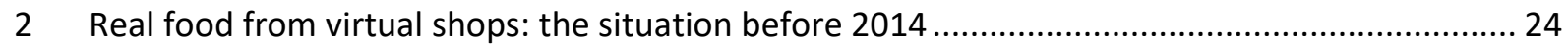

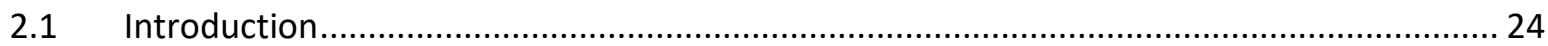

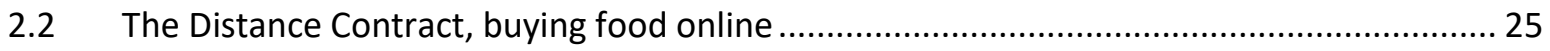

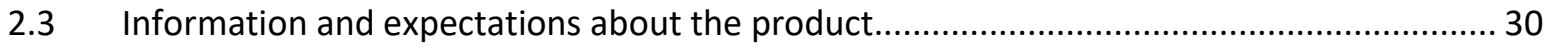

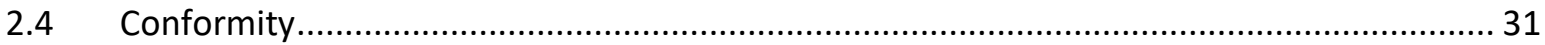

2.5 Conformity requirement and Distance Contracts .............................................................. 35

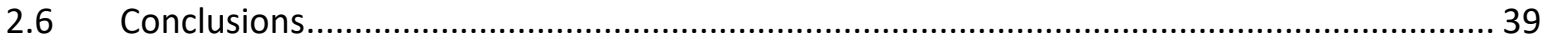

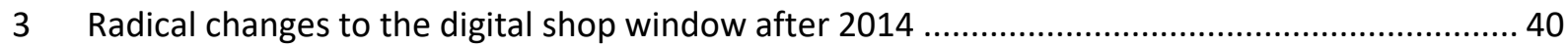

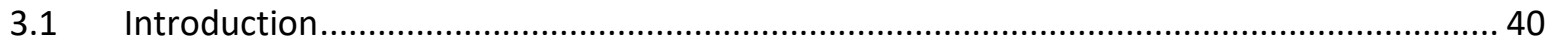

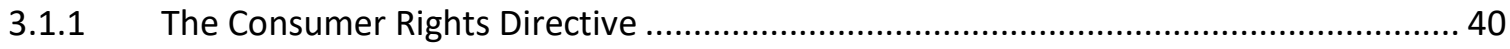

3.1.2 The Food Information for Consumers Regulation ........................................................ 41

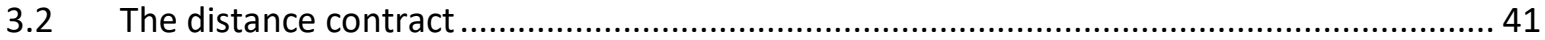




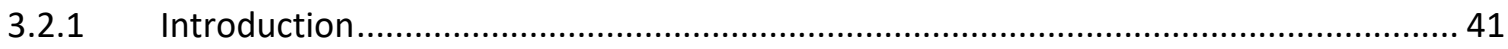

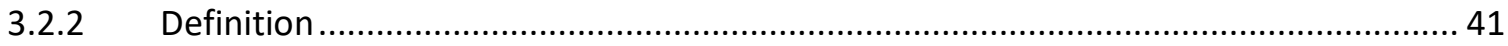

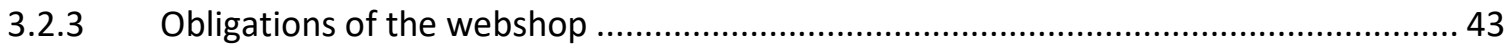

3.2.4 Obligations relating to the provision of information in the webshop ........................... 43

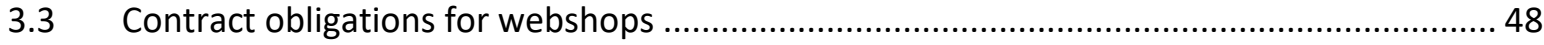

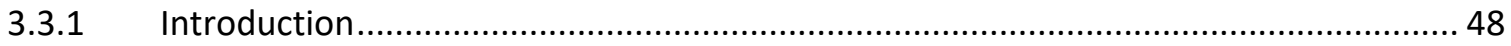

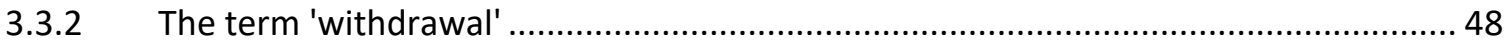

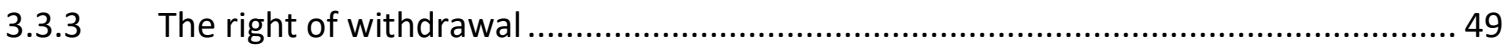

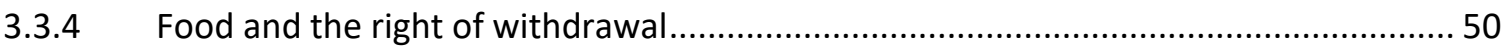

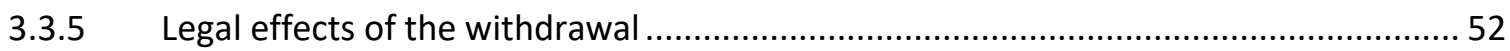

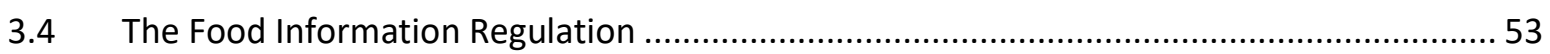

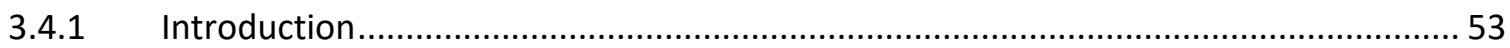

3.4.2 The Food Information Regulation and the responsible operator ................................ 54

3.4.3 The webshop's obligation to provide food information ............................................... 55

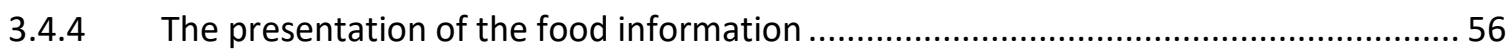

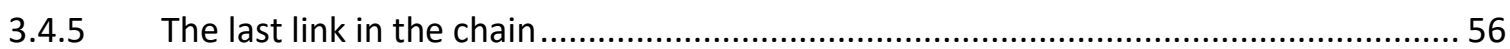

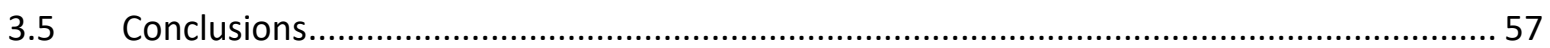

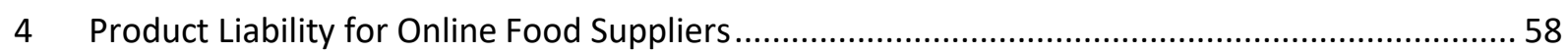

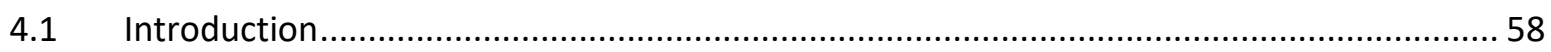

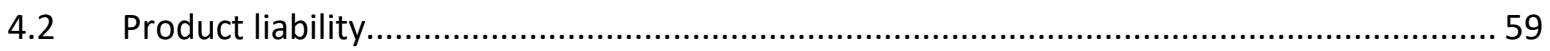

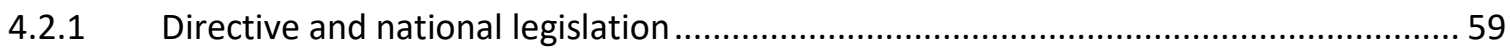

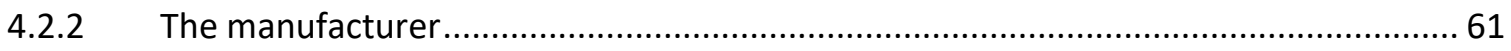

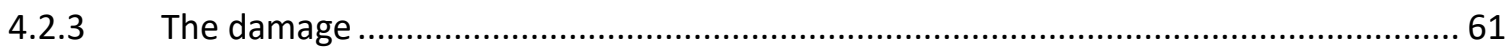

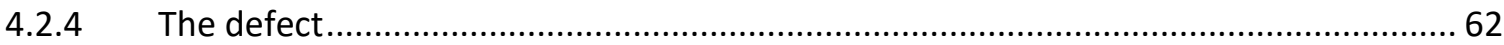

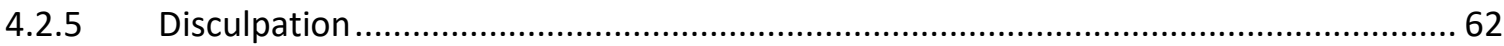

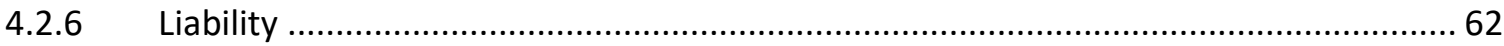

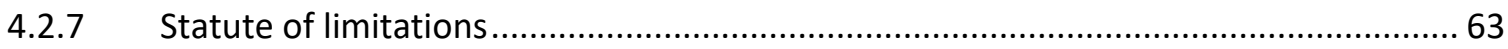

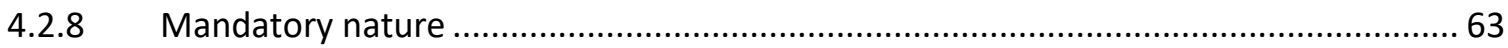

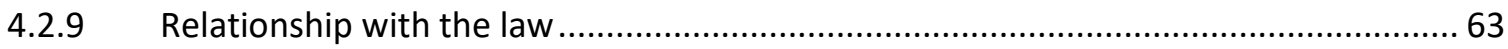

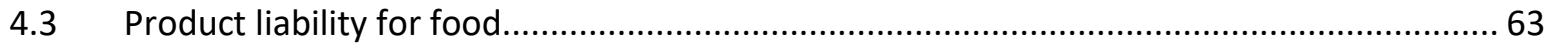

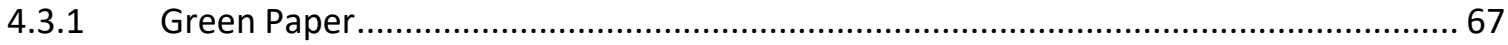

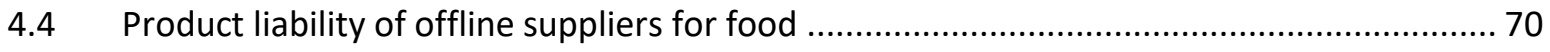

4.5 Product liability of online suppliers for food ................................................................... 75

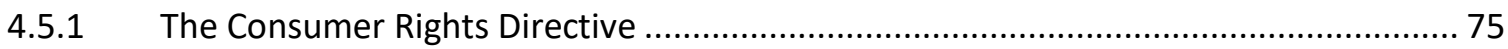

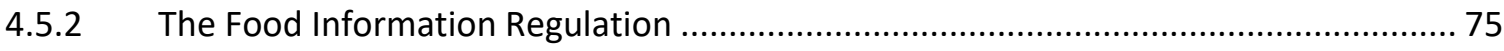

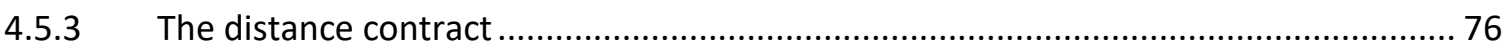




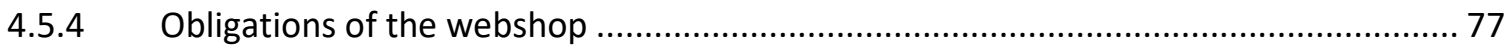

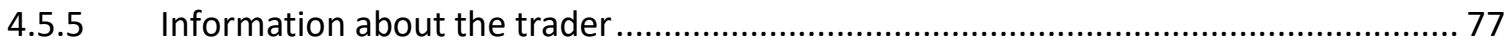

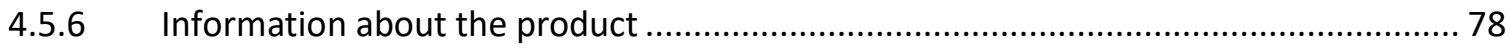

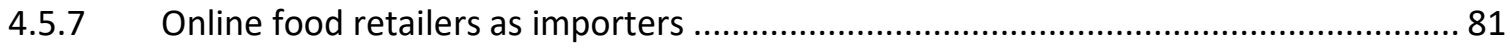

4.6 From liability to the obligation to pay compensation ....................................................... 81

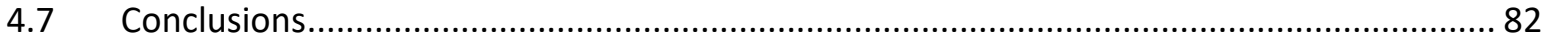

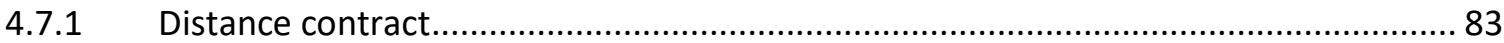

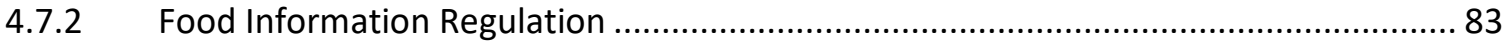

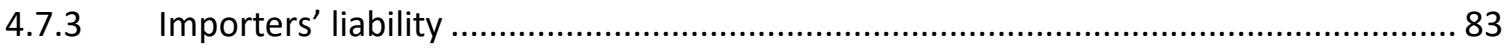

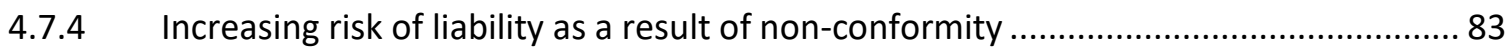

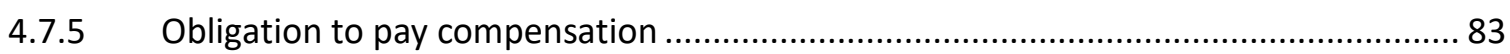

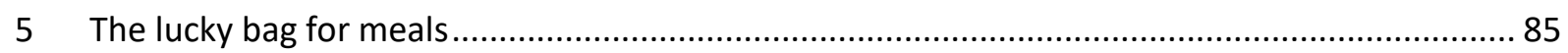

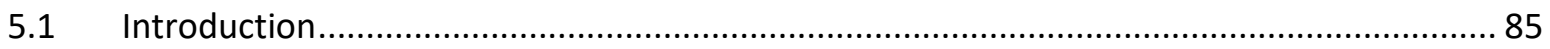

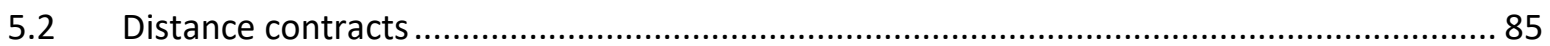

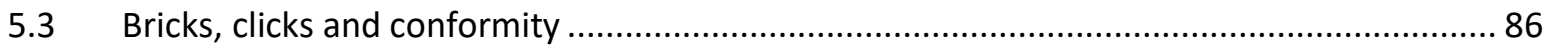

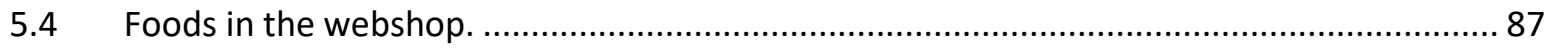

5.5 The relation between the Consumer Rights Directive and the Food Information Regulation 88

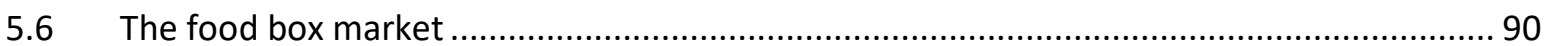

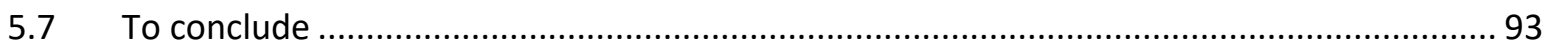

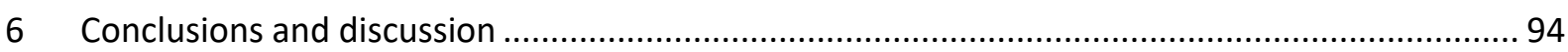

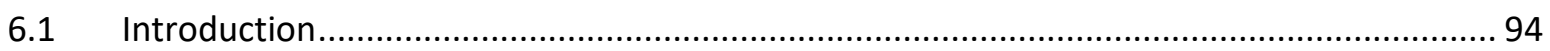

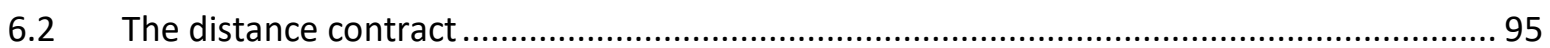

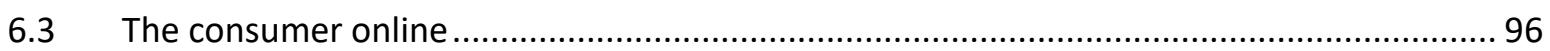

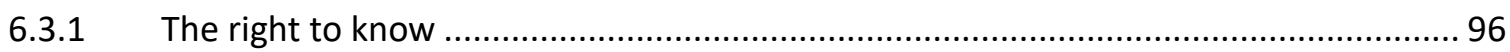

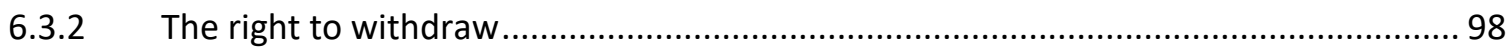

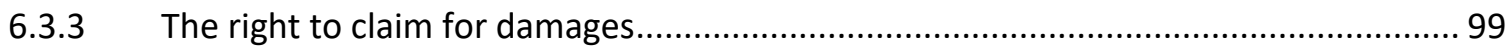

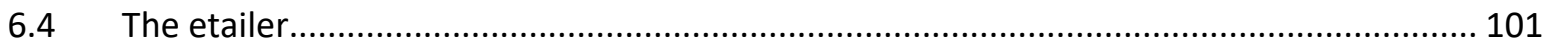

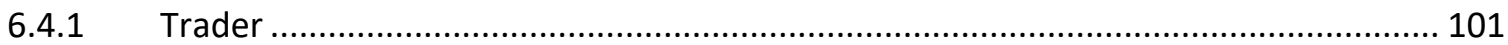

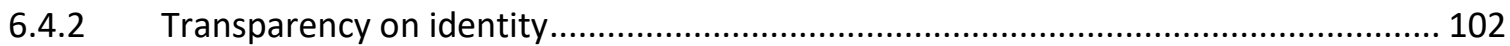

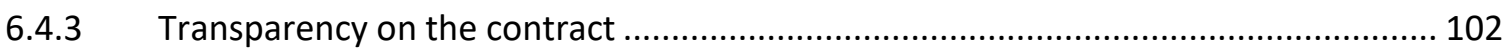

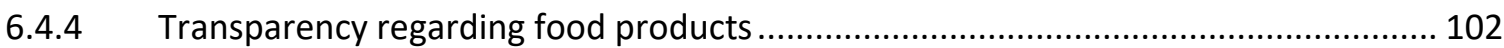

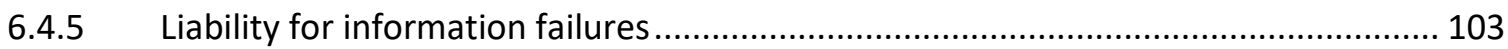

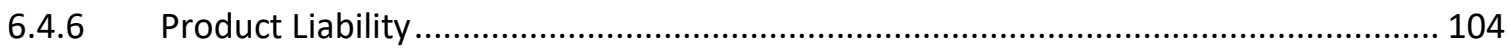

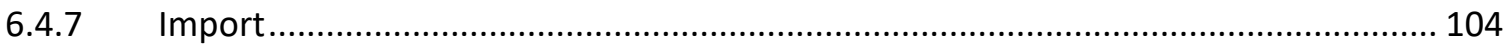


6.5 Is the new legal framework for food online adequate in view of the new market shapes? 104

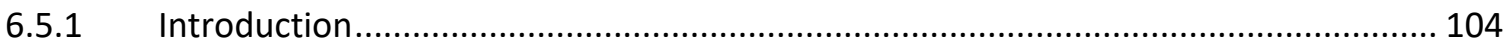

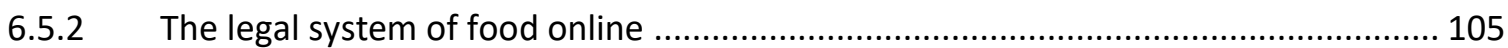

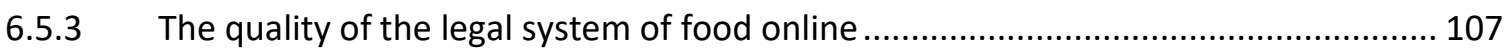

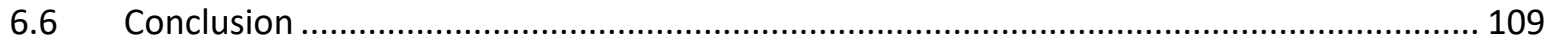

6.7 Discussion and recommendations for further research............................................... 110

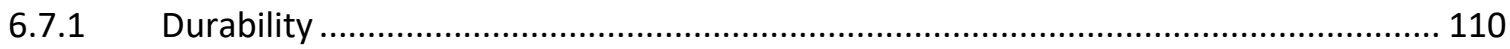

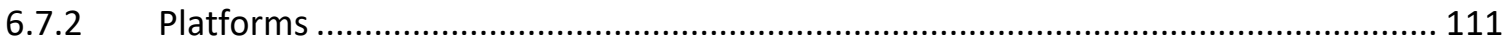

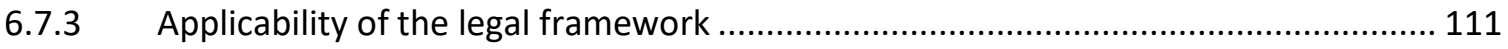

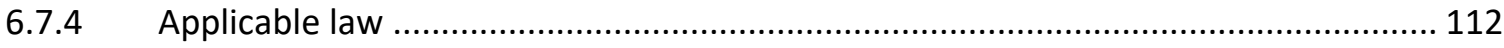

6.7.5 Discrepancies between information online and on the label .................................... 113

6.7.6 Article 14 of the Food Information Regulation ....................................................... 113

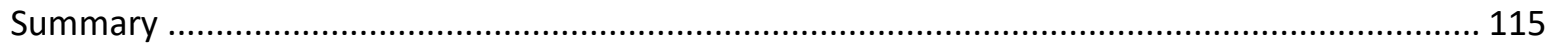

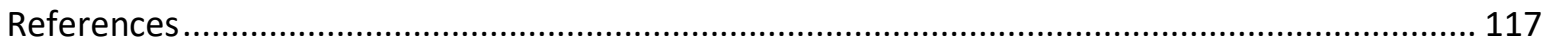

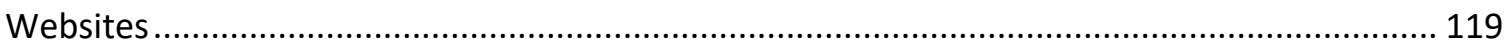

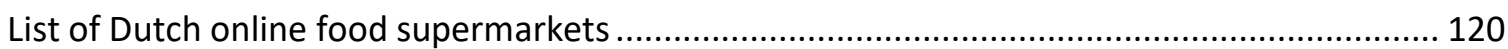

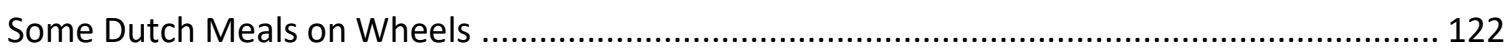

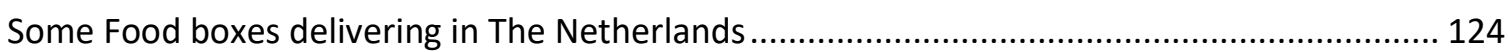




\section{ABBREVIATIONS}

The use of abbreviations is kept to a minimum. A few however occur in the thesis.

\begin{tabular}{|c|c|c|}
\hline ACM & - & Authority for Consumer and Market \\
\hline BSE & - & Bovine Spongiform Encephalopathy \\
\hline CC & - & Civil Code \\
\hline COM & - & Commission of the European Union (Communities) \\
\hline EC & - & European Commission or European Community \\
\hline ECJ & - & European Court of Justice \\
\hline EEA & - & European Economic Area \\
\hline EEC & - & European Economic Community \\
\hline EFFL & - & European Food and Feed Law \\
\hline EFSA & - & European Food Safety Authority \\
\hline EU & - & European Union \\
\hline FIR & - & Food Information Regulation (Regulation (EU) 1169/2011) \\
\hline GATT & - & General Agreement on Tariffs and Trade \\
\hline GFL & - & General Food Law (Regulation (EC) 178/2002) \\
\hline NVWA & - & Dutch food safety authority \\
\hline OJ & - & Official Journal of the European Union \\
\hline RASFF & - & Rapid Alert System for Food and Feed \\
\hline WHO & - & World Health Organization \\
\hline
\end{tabular}




\section{PREFACE}

As a child, I worked in a tree nursery. The work involved crawling on my knees between the rows of plants while pulling out weeds by hand. The rows were long and the landscape sloped gently, which made it impossible to see the end of the row. And there is the parallel.

That I now find myself at the end of the row with grazed knees, is due to certain organisations and individuals. I would like to briefly mention the most important ones.

\section{Windesheim University of Applied Sciences}

Windesheim has facilitated me in a way that allowed me to write this thesis besides doing my work in the legal profession. The organization followed my activities from a distance, with understanding and patience.

\section{$\underline{\text { dr. J.L.F. Hagelaar }}$}

Geoffrey taught me the principles of scientific research. Each time I presented him with a tangle of research details, he took a step back to regain the overview I had lost in the process. I owe him a great debt of gratitude.

prof. dr. mr. B.M.J. van der Meulen

As a promotor, Bernd forced me time and again to stay focused. In over 20 years of working in the legal profession - in which every period of 6 minutes is accounted for - an inevitable urge to produce emerged, even at the expense of quality. Every time I thought I could get away with that, Bernd effortlessly put his finger on the sore spot. Therefore, much of the ultimate result should be attributed to him. I owe him a world of thanks.

\section{$\underline{\text { Bernadette Brefeld }}$}

Bernadet is my wife. Initially, she gave up a small part of her studio, so I could place a cupboard and a desk to write at. Over the years, I increasingly filled her studio space with laptops, books, magazines, and loads of paper. My expansion was tolerated warm-heartedly and patiently. It is with love and gratitude that I now return your studio to you.

Giethoorn, July 2017 


\section{FOOD ONLINE: GENERAL INTRODUCTION}

\subsection{INTRODUCTION}

Within the time span of a single generation, ${ }^{1}$ the digital revolution has fundamentally altered the way human relations are shaped in form as well as in content; private relations as well as business relations. A parallel virtual universe has emerged where people meet and do business. ${ }^{2}$

Even though food can never be fully virtual nor downloadable, ${ }^{3}$ this revolution has not bypassed the food sector. Quite on the contrary; increasingly, consumers order food online. Figures for the Netherlands indicate that in 2017 one in every six consumers orders food and drink in an online supermarket. ${ }^{4}$ This rapidly expanding market enjoys unrestrained attention of economists ${ }^{5}$ and financial analysts, ${ }^{6}$ not in the last place because the mayor players compete to life or death mindful of the internet adage 'the winner takes it all'.

Established and emerging parties beset online consumers with existing and innovative food products. ${ }^{7}$ All major supermarket chains in the Netherlands offer their products online. Some provide pick up spots other deliver at home. ${ }^{8}$ Other food businesses attempt to bypass the supermarket by posting their offers to the consumer along the digital highway. ${ }^{9}$

Form and content usually influence each other. ${ }^{10}$ While digital trade seems to be purely form, it appears to affect the content of the transactions as well. Food trade online acquires interactive traits. For example, consumers by combining various ingredients can compose their own pizza before actually ordering it. Also food boxes have made their appearance. Seen from the perspective of products shaped by the consumers themselves, food boxes form the other side of the spectrum. The supplier unilaterally decides on the content of the box that has already been sold. For the consumer the content already bought remains a surprise until after delivery. The new online food market indeed is 'food for thought' for marketers and economists.

Despite the undisputable societal relevance of this phenomenon that in this thesis is labelled 'food online' and all the attention given to the economic and financial aspects, so far scholarly analysis of the legal dimensions of this booming market is absent. The legal dimensions are multidimensional. Existing legal frameworks apply to contractual relations between consumers and food traders in the Netherlands. This framework consists of existing contract law and food law both national and European. The legislators both at national level and EU level, both in civil law and in food law

\footnotetext{
${ }^{1}$ Personal computers became generally available in the 1980 s.

${ }^{2}$ The word 'social media' encompasses communication tools, like twitter, whatsapp, wechat, chatboxes, dating-sites and whatnot. Good and services are provided online.

${ }^{3}$ It remains to be seen to what extent the appearance of 3D food printers will affect even this state of affairs.

${ }^{4}$ CBS report 2017.

${ }^{5}$ Google present 28 million hits on 'food online and economy'.

${ }^{6}$ Google presents 63 milion hits on 'food online and finance'.

${ }^{7} \mathrm{New}$ is for example the later discussed food box.

${ }^{8}$ Most supermarkets in the Netherlands like Albert Heijn, Jumbo, Dirk do both.

${ }^{9}$ Unilever has since April 2017 a partnership with Alibaba daughter Lazada for the development of e-commerce activities.

${ }^{10}$ According to Van Eikema Hommes, the interdependence between form and matter was already an issue of keen awareness in ancient Greek thinking prior to Plato (H.J. van Eikema Hommes, Hoofdlijnen van de geschiedenis der rechtsfilosofie, $2^{\text {nd }}$ ed. Kluwer Deventer 1981, p. 3-5).
} 
respond to the new developments by providing new constructs intended to deal with 'food online'. Generally the objective is to increase protection for the online consumer of food. The purpose of this thesis is to lay the foundation for research on the emerging legal framework for food online in the Netherlands. It addresses the reinforced position of the consumer as well as the consequences for the Dutch market.

In so far as the relevant elements of the legal framework originate at EU level - directly through regulations or indirectly through directives - the findings will be relevant as well for other member states in the EU. In the concluding chapter recommendations are provided how the findings of this thesis can be used to inform legal research in other jurisdictions.

As will become apparent in the research chapters, the intention of the new national and European rules and requirements is to reinforce the position of consumers by providing them a variety of tools and instruments. It seems likely that this fortification will have consequences elsewhere in the chain as well. After all, how else can rights of the last link in the chain be reinforced than by heaping obligations upon the one but last link in the chain towards the last link? Which legal consequences the law to be discussed in this thesis has for consumers is likely to be apparent. After all, the strongly modifying and mandatory legislation has been designed specifically with these consequences in mind. However, the research in this theses starts from the assumption that the consequences of this consumer protecting framework for the retailer online are less considered. This thesis aims to contribute to reconsidering this aspect.

\subsection{SCOPE}

\subsubsection{Delineation}

This research focuses on the legal rules and regulations in the Netherlands that apply in the context of food purchases by consumers that are concluded online. By consequence the essence of this research is of a civil law ${ }^{11}$ nature as purchases by definition amount to contracts. Within civil law, the focus is on the law pertaining to obligations. However, civil law relations are also influenced by public law regulation. These elements of public law are included.

Elements of an exclusively public law nature are excluded from the scope of this research. In particular outside the scope of this research are sanctioning of infringements on public law requirements and supervision by the Netherlands' Food and Consumer Product Safety Authority ${ }^{12}$ and by the Authority for Consumers and Markets. ${ }^{13}$ The new regulation on official controls ${ }^{14}$ that comes into force on 14 December 2019, provides these agencies some specific competences regarding food online. Article 36 of this regulation addresses: 'Sampling of animals and goods offered for sale by means of distance communication'. It authorises authorities to engage in mystery shopping, identifying themselves only afterwards. Further delegated acts to address this issue can be adopted by the European Commission. ${ }^{15}$

\footnotetext{
${ }^{11}$ As opposed to public law, not to common law.

${ }^{12}$ Its official name and acronym in Dutch are: Nederlandse Voedsel- en Warenautoriteit / NVWA.

${ }^{13}$ Its official name and acronym in Dutch are: Autoriteit Consument en Markt / ACM.

${ }^{14}$ Regulation (EU) 2017/625 on official controls and other official activities performed to ensure the application of food and feed law, rules on animal health and welfare, plant health and plant protection products, OJ 7.4.2017 L 95/1-142.

${ }^{15}$ Article 77 Regulation (EU) 2017/625.
} 
The thesis in particular singles out for research those elements in the law where it makes a difference if the purchasing takes place through the Internet rather than by other means. First and foremost, these are the rules and regulations that are expressly designed to deal with online trading.

As indicated above, law in the Netherlands is not only created from national law sources, but also from European Union law sources. These parts of EU law are in the scope of the research, indeed they form the largest part. This fact notwithstanding the disciplinary embedding of this research is Dutch law, not EU law.

\subsubsection{The etailer concept}

In this thesis the label 'etailer' - a common epithet on the internet - is used to designate a food business that provides food products to consumers through electronic media. Usually, this will be a retail or catering business. In the course of the argument, laid out in the research chapters, the notion of 'etailer' will develop into one of the leading concepts of 'food online'.

\subsection{OVERVIEW}

The current chapter is organised as follows. Section 1.4 provides the legal context to the research, leading up to the formulation of the problem statement in section 1.5. The problem statement in turn leads to the objective of the research (section 1.6) and the research questions to be answered in order to achieve this objective (section 1.7).

Legal research which is normative in nature just like empirical/quantitative research requires a methodological and theoretical basis to ensure the research and its findings are valid by legal standards and embedded in a clear structure. Section 1.8 sets out and justifies the methods and theory.

Section 1.9 introduces the research chapters that set out and give meaning to the data. Finally, this section looks ahead towards the final chapter (chapter 6) which provides the conclusions of this research, recommendations regarding their application in legal practice, current scholarship and future research and a reflective discussion.

\subsection{LEGAL CONTEXT AND KNOWLEDGE GAPS}

\subsubsection{Consumers contracts}

The underlying principle ruling any contractual relation from Roman times onwards up to and including contemporary law is the 'freedom of contract'. Parties bind themselves exclusively through their agreement. ${ }^{16}$ This principle is under non-relenting pressure from the legislators' propensity to interfere with legal relations and - thus - limiting the scope of the freedom of contract. This propensity increases according to the level of power imbalance between the parties. Parties structurally suffering from information asymmetries or from a structurally weaker negation position require codified support to be able to come to equitable contractual agreements. Legislatures may want to interfere to restore a level playing field. As first example of such legislation in the

\footnotetext{
${ }^{16}$ The legally binding nature of agreements is expressed in the classic Latin adage 'pacta sunt servanda'.
} 
Netherlands is considered an act dating back to 1874 proposed by Minister van Houten on the protection of children, popularly known as Van Houten's children's act. ${ }^{17}$ After Van Houten's children's act cleared the way to limiting contractual freedom with a view to protecting the weaker party, increasingly protective legislation has been put into place concerning qualified stakeholders like wage workers, tenants and consumers.

The emergence of online concluded sales contracts between businesses and final users of food products, has prompted European and national legislatures to considerably interfere with the freedom of contract. The final purchasers at the end of the food chain ${ }^{18}$ in their many guises appear as the weakest party to be protected. Almost by definition consumers' knowledge regarding the food product at issue falls short of the knowledge of the supplier. The food business operator is under legal obligation to provide information on composition and ingredients list ${ }^{19}$ and to ensure the safety of the product ${ }^{20}$ - therefore, to have the related knowledge. The consumer, at best, has assumptions regarding these aspects.

Additionally, as a rule consumers will also have less knowledge regarding the conclusion of contracts than the opposing contract party who concludes contracts professionally and for profit. When these transactions are performed on the virtual market place these disparities may be magnified prompting the legislatures to interfere even deeper with the freedom of contract.

As from 13 June 2014 the Dutch Civil Code includes provisions implementing the Consumer Rights Directive. ${ }^{21}$ Half a year later the Food information to consumers Regulation ${ }^{22}$ entered into force. Thus, both from the side of contract law and from the side of food law, contributions are made to increase the protection of consumers of food online. In this research these two areas of law meet. These areas of law are very different in nature and so are the scholars engaged in studying them. Would this explain why so far so little attention has been given to the way in which these two legal worlds jointly or at least concurrently operate on this type of legal relation contract that meanwhile has become rather frequent; the sale-and-purchase contract online regarding food products?

\subsubsection{Food law}

With the exception of a limited number of works addressing product liability, ${ }^{23}$ treatises on food law focus on the public law aspects. Attention to consumer contracts seems to be fully absent in the leading literature on food law. ${ }^{24}$ Atwood and Painter (2000), ${ }^{25}$ Broberg (2008), ${ }^{26}$ Costato and Albisinni

\footnotetext{
${ }^{17}$ The act 'Wet houdende maatregelen to het tegengaan van overmatigen arbeid en verwaarlozing van kinderen' came into force in 1874 to prevent some forms of child labour.

${ }^{18}$ The term 'food chain' is too attractive to bypass.

${ }^{19}$ See Regulation (EU) 1169/2011.

${ }^{20}$ See Article 14 of Regulation (EC) 178/2002.

${ }^{21}$ See Directive 2011/83/EU. The Netherlands were half a year too late.

${ }^{22}$ Regulations have a direct effect in the member states.

${ }^{23}$ R. O'Rourke, Food Safety and Product Liability, Palladin Law Publishing, 200, Heereluurt Heeres, Productaansprakelijkheid voor levensmiddelen, Sdu The Hague 2004 (in later editions the title has been changed to; Productverantwoordelijkheid voor levensmiddelen), Klaus Pichhardt, Produkthaftung und Produktsicherheit im Lebensmittelbereich. Rechtsfolgen fehlerhafter Lebensmittel, Springer 1999.

${ }^{24}$ With the exception of a publication of my own: L.C. van der Veer, Contracteren in de voedselketen, in: B.M.J. van der Meulen, Voer voor advocaten, BJu The Hague 2009, p. 90-99.

${ }^{25}$ Atwood B. and Painter A.A., Butterworths Food Law, $2^{\text {nd }}$ Edition, Butterworths, Reed Elsevier (UK), 2000.

${ }^{26}$ Broberg, M.P. Transforming the European Community's Regulation of Food Safety, Sieps Stockholm 2008

$<$ http://www.sieps.se/en/publications/rapporter/transforming-the-european-communitys-regulation-of-foodsafety.html $>$.
} 
(2012), ${ }^{27}$ Goodburn (2001), ${ }^{28}$ Holland and Pope (2004), ${ }^{29}$ Lauterburg (2001), ${ }^{30}$ MacMaolain (2007), ${ }^{31}$ O'Rourke (2005), ${ }^{32}$ neither of these dedicates a single word to consumer contracts. Most striking, however, is the position taken by Van der Meulen. This author has coined the concept 'Private food law'. ${ }^{33}$ However, he seems to have reserved this concept for the use of private law instruments by private sector actors to regulate national and international food chains. It is all about private standards, audits and certification. Consumer contracts are not mentioned. In fact, in the influential 'EU Food Law Handbook' he explicitly takes the position that food law does not provide consumers any legal instruments. In the chapter addressing consumers aptly called 'For you, about you, over you, without you', this author states among other things: 'Even though the first and foremost objectives of EU food law are to protect consumers' health and other consumers' interests, no provision can be found actually granting the individual consumer a right $\mathrm{s} /$ he can uphold in a court of law.' This position seems difficult to reconcile with the definition this author proposes of food law as a functional field of law. According to Van der Meulen the field of food law is not delineated by the inner logic of the law but by its relevance to the food sector. All rules pertaining to food, regardless if they are public or private, national, European or international, belong to food law. If, therefore, in the interplay between the law of obligations, consumer law and food information law a set of rules emerges that is specific for the legal position of the consumer of food product, than this is food law. Nevertheless, this part of food law so far has remained completely outside the scope of scholarly attention.

\subsubsection{Food online}

Even more so, the particular influence exercised on food law by digitalisation of civil food law has remained terra incognita. A systematic analysis ${ }^{34}$ of the most influential journal on food law in Europe - the European Food and Feed Law Review (EFFL) - revealed that in the years from the creation of the journal in 2006 until the finalisation of the current text in 2017 only articles included as research chapters in this thesis (and a few short references to these articles) pay any attention to this topic. A similar analysis of Waar \& Wet - the Dutch journal addressing food law, did not provide any hits. ${ }^{35}$

\footnotetext{
${ }^{27}$ Costato, Luigi and Albisinni, Ferdinando (eds.), European Food Law, Wolters Kluwer Italia, 2012.

${ }^{28}$ Goodburn, K. (ed.), EU food law. A practical guide, Cambridge (UK), 2001.

${ }^{29}$ Holland, Debra and Pope, Helen, EU Food Law and Policy, Kluwer Law International 2004.

${ }^{30}$ Lauterburg, D. Food Law: Policy and Ethics, Routledge-Cavendish, 2001.

${ }^{31}$ MacMaolain, C., EU Food Law. Protecting Consumers and Health in a Common Market, Hart Publishers 2007.

${ }^{32} \mathrm{O}^{\prime}$ Rourke, R., European food Law, $3^{\text {rd }}$ ed., Sweet \& Maxwell, 2005.

${ }^{33}$ In European Food Law Handbook p.75 he states:' Food Law is a functional part of law that combines parts of several branches of law in a coherent body of law to serve its goals.'

${ }^{34}$ This analysis comprised of a search using search terms such as Internet, digital, online, distance and Consumer Rights Directive.

${ }^{35}$ Search terms included: 'online', 'internet', 'digital' and the like. Hits did not (or only marginally) relate to consumer contract online, but for example advertisement online. See: Susie Stærk Ekstrand and Jacob Thomsen, Online Marketing of Food - The "Internal Market Clause" of the e-Commerce Directive from a Danish Perspective, EFFL 2006, p. 193-202; Susie Stærk Ekstrand and Kristine Lilholt Nilsson, A Danish Clampdown on Marketing on Websites?, EFFL 2010, p. 91-94; Kristine Lilholt Nilsson, Misleading? To whom?, EFFL 2012, p. 2227; Kristine Lilholt Nilsson and Christian Marquard Svane, A Challenge to the Country of Origin-Principle. Website marketing, The Saga Continues, EFFL 2012 p. 201-207; Corrado Finardi and Luis González Vaqué, European Food (Mis)Information to Consumers: Do Safety Risks Lie Just Around the Corner? EFFL 2015, p. 92106; Luis González Vaqué, Directive 2005/29/EC on Unfair Commercial Practices and Its Application to FoodRelated Consumer Protection, EFFL 2015, p. 210-221.
} 


\subsection{KNOWLEDGE GAP AND PROBLEM STATEMENT}

From the above follows that a clear and profound gap in scientific knowledge exists regarding the law of obligations dimension of food law in general and regarding contracts online in particular. This knowledge gap is a problem as it precludes meaningful scholarly debate on the issue and contributions to reflecting on possible improvements of this part of food law.

Because the relevant rules and regulations affecting food online originate from different levels (national and European), different units (Justice and Public Health) and different legal cultures (civil law and public law) it is uncertain to what extent the resulting legal field is coherent and wellbalanced.

\subsection{RESEARCH OBJECTIVE}

The objective of this thesis research is to contribute to closing this knowledge gap by means of legal systematic analysis of this civil law segment of the functional field of food law.

For the purpose of guiding this analysis two research questions and a series of sub-questions have been formulated. The research to answer these questions is set out in the research chapters that are all based on legal research articles published in the European Food and Feed Law Review.

\subsection{RESEARCH QUESTIONS}

The legal systematic nature of the current research is reflected in the main research question:

1) Do the rules and regulations, coming from various heterogeneous sources, that directly affect contractual relations established by digital means between food businesses and food consumers constitute a coherent whole?

Directly related to this exploratory main research question is the normative evaluation question:

2) How should the regulation of contractual relations established by digital means between food businesses and food consumers be valued in light of the interests involved?

Both the main question and the evaluation question are operationalised and subdivided in several sub-questions set out in the table here below. As legal standard setting usually expresses itself in rights and obligations, these sub-questions aim to discover the rights and obligations. A distinction needs to be made in rights and obligations prior to concluding the digital transaction which - by the nature of things - are likely to relate to provision of information; and rights and duties following from the digital transaction. The latter will relate to fulfilment, compliance, annulment and liability.

The table lists the sub-questions designed to systematically map and analyse the civil relation between food businesses and consumers of food products.

\begin{tabular}{|l|l|l|}
\hline & Question & Addressed in chapter \\
\hline 1. & Main research question & \\
\hline
\end{tabular}




\begin{tabular}{|c|c|c|}
\hline 1.1. & $\begin{array}{l}\text { Does the distance contract result from } \\
\text { digital technology? }\end{array}$ & $\begin{array}{l}2,5 \text { (as regards food } \\
\text { boxes) }\end{array}$ \\
\hline 1.2. & $\begin{array}{l}\text { Which are the rights and duties of } \\
\text { consumers? }\end{array}$ & 2 (before 2014) \\
\hline 1.2.1. & $\begin{array}{l}\text { To what extent does the consumer have the } \\
\text { right to annul the distance contract } \\
\text { regarding a food product? }\end{array}$ & 3 \\
\hline 1.2.2. & $\begin{array}{l}\text { To what extent does the consumer have the } \\
\text { option to hold the supplier of food online } \\
\text { product liable? }\end{array}$ & 4 \\
\hline 1.3. & $\begin{array}{l}\text { Which are the rights and duties of the } \\
\text { opposing contract partner of the consumer? }\end{array}$ & \\
\hline 1.3.1. & $\begin{array}{l}\text { Who qualifies as 'trader' (i.e. etailer) in } \\
\text { distance contracts }\end{array}$ & 3 \\
\hline 1.3 .2 . & $\begin{array}{l}\text { Which information requirements apply to } \\
\text { etailers regarding their identity? }\end{array}$ & $\begin{array}{l}2 \text { (before 2014), } 3 \text { (after } \\
\text { 2014) }\end{array}$ \\
\hline 1.3 .3 . & $\begin{array}{l}\text { Which information requirements apply to } \\
\text { etailers regarding the contract? }\end{array}$ & $\begin{array}{l}2 \text { (before 2014), } 3 \text { (after } \\
\text { 2014) }\end{array}$ \\
\hline 1.3.4. & $\begin{array}{l}\text { Which information requirements apply to } \\
\text { etailers regarding the food product at issue? }\end{array}$ & $\begin{array}{l}2 \text { (before 2014), } 3 \text { (after } \\
\text { 2014) }\end{array}$ \\
\hline 1.3.5. & $\begin{array}{l}\text { Can non-compliance with information } \\
\text { requirements cause product liability? }\end{array}$ & 4 \\
\hline 1.3.6. & $\begin{array}{l}\text { Does the etailer qualify as product liable } \\
\text { producer? }\end{array}$ & 4 \\
\hline 1.3.7. & $\begin{array}{l}\text { Who classifies as product liable importer in } \\
\text { the digital food chain? }\end{array}$ & 4 \\
\hline 2. & Evaluation question & \\
\hline 2.1. & $\begin{array}{l}\text { Are the new rules regarding food online } \\
\text { adequate in view of the new market shapes? }\end{array}$ & $\begin{array}{l}3 \text { (as regards Article } 14 \\
\text { FIR) }\end{array}$ \\
\hline 2.2 & $\begin{array}{l}\text { Do the new rules regarding food online } \\
\text { result in a well-balanced distribution in the } \\
\text { digital food chain of rights and duties and } \\
\text { related risks? }\end{array}$ & $\begin{array}{l}3 \text { (as regards Article } 14 \\
\text { FIR) }\end{array}$ \\
\hline
\end{tabular}

In answering these questions, account is taken of the fact that the rules and regulations that are subject to these questions do not amount to a static whole, but rather have been subject to a radical reform in the period between 2014 and 2016. This reform aims to respond to the rapidly spreading digitalisation of contractual relations.

\subsection{THEORETICAL FRAMEWORK AND METHODOLOGY}

Theory and methods in legal research have developed for one and a half millennia. As a consequence it has become uncommon in legal research to explicitly address theoretical assumptions, the nature of data, the way data are collected and the way meaning is given to them. ${ }^{36}$ Engagement in interdisciplinary research and other encounters with natural and social sciences necessitate legal scholars to state the obvious. With this purpose in mind, Van der Meulen has written an essay

\footnotetext{
${ }^{36}$ T.S.A. Ulen, Nobel Prize in Legal Science: Theory, Empirical Work, and the Scientific Method in the Study of the Law, University of Illinois Law Review, 2002.
} 
'Governance in Law' with a telling subtitle: 'Charting legal intuition'. ${ }^{37}$ This publication has been chosen as a starting point in the elaboration of theory and methodology for the current research.

\subsubsection{Theoretical framework}

According to Van der Meulen, in systematic legal research, which is research aiming to answer questions of positive law on what the law 'is', and who has which rights and obligations like the main research question in this study and the related sub-questions, the applicable theory is the system of the law itself. The notion that the legal order can be understood and analysed as a system, is an important theoretical notion in its own right. ${ }^{38}$

If research aims to develop an opinion about the legal system with a view to criticising it or improving it, like in this research the second research question and the related sub-questions, a theoretical yardstick is needed that provides an instrument to distinguish law in its less or more desirable effects in the system. In this research this yardstick is the legal principle requiring the law to be equitable and fair in its results regarding the affected stakeholders.

The notion that legal science should be systematic dates back at least to 1814. In that year one of the most famous of all German legal scholars, Friedrich Carl von Savigny published a booklet ${ }^{39}$ in which he argued that legal science - as opposed to legal craftsmanship - rests on two pillars: the one historic and the other systematic.

According to the most prominent Dutch legal scholar in the $20^{\text {th }}$ Century, Paul Scholten, regardless of the presence or absence of coherence in the design law will always be systematic. The reason is that law always has to rely on language - which in itself is systematic - on established principles and concepts and because the law is endowed with instruments to deal with and eliminate contradictions and internal conflicts. In $1942^{40}$ he made a speech to the Royal Dutch Science Academy in which he argued that law is a science and that systematic analysis is its vocation. ${ }^{41}$ In short, according to

\footnotetext{
${ }^{37}$ The publication is freely accessible at https://www.researchgate.net.

${ }^{38}$ This theory seems generally to be embraced in civil law countries but not in common law countries. M.A, Gledon, M.W. Gordon \& P.G. Carozza (Comparative Legal Traditions $2^{\text {nd }}$ ed. West Nutshell Series, St. Paul, Minn. USA, 1999, pp. 75-76), for example state: 'one of the greatest differences between legal education in common law and civil law systems appears in the manner in which the student is initiated into the study of law. While an American law student typically spends the first days of law school reading cases and having his or her attention directed over and over again to their precise facts, a student of the civil law is provided at the outset with a systematic overview of the framework of the entire legal system. The introductory text (a treatise, not a casebook) may even include a diagram depicting "The Law" as a tree, with its two great divisions, public and private, branching off into all their many subdivisions and categories - each of which will become, in turn, the subject of later study'. Systematisation is not limited to education. Gledon et al. p. 91: 'all other actors in the legal system receive their training from the scholars who transmit to them a comprehensive and highly-ordered model of the system that to a great extent controls how they organise their knowledge, pose their questions and communicate with each other.

${ }^{39}$ F.C. von Savigny, Vom Beruf unserer Zeit für Gesetzgebung und Rechtswissenschaft, Mohr und Zimmer Heidelberg 1814 available at < http://reader.digitale-sammlungen.de/resolve/display/bsb10740690.html > (On our era's call for legislation and legal science; or, in the translation of the Encyclopaedia Britannica: Of the Vocation of Our Age for Legislation and Jurisprudence).

${ }^{40}$ The speech was made on March 17 in 1942. It must have been one of his last public appearances during the war. Around the same time the Nazi occupational force had him step down as professor and placed a ban on him to exercise his profession, for publicly protesting measures taken against the Jewish population.

${ }^{41}$ P. Scholten, De Structuur der Rechtswetenschappen, Mededelingen der Koninklijke Nederlandsche Akademie van Wetenschappen, Afd. Letterkunde, Nieuwe Reeks Deel 8, no. 1, N.V. Noord-Hollandse Uitgevers Maatschappij Amsterdam, 1945.
} 
Scholten legal science is the systematic analysis of a subject matter that is in itself systematic in nature. Based in this assumption about the law, this research sets out in search of a system in a field of law that is fed from different sources and from different levels.

\subsubsection{Data}

Within the Dutch system, general rules that form a basis for rights and obligations can in a legal sense only be derived from sources of law that within the legal system are recognised as such. The Dutch legal system distinguishes written sources (international treaties and derived acts, national legislation) and unwritten sources (case law, legal principles and customary law). ${ }^{42}$

By consequence, the primary data used in the current research are the sources of law that feed into the regulation of food online. Written sources are the Dutch Civil Code, the EU Consumer Rights Directive, the EU product liability directive and the EU regulation on food information to consumers. Unwritten sources are the related case law and legal principles.

Secondary data consist among others of policy documents and academic literature.

\subsubsection{Methodology}

Legal practitioners and legal scholars take opposing points of departure. Legal practitioners who act in the interest of clients, start from the case at hand. They collect facts and evidence and connect those to the legal argument they consider can reasonably advance the interests of the client. ${ }^{43}$ The exchange of opinions is not fully determined by the positive legal requirements but just as much by strategic considerations and procedural aspects. Those who use the law to adjudicate conflicts (like judges and arbiters) also start from the case. Depending on the procedural context they must respect a certain level of passiveness. Room for their own opinion on the case beyond what the parties present them, generally is rather limited.

For those who conduct law as a science, the individual case is a mere illustration of how the law or envisaged legal development do or will work out; i.e. an indication or counter indication. The scholar needs a methodology that abstracts from the individual cases to a meta level. ${ }^{44}$

For the purpose of legal scientific research, in 2013 Van der Meulen drafted a map setting out the different levels of legal analysis and the related legal methods. Van der Meulen argues that a simplified model distinguishing three level (micro (the case), meso (the rule) and macro (the legal order)) suffices for educational purposes, but that for scientific purposes more detail is needed. He proposes a matrix - which he calls the COBRA-C matrix - encompassing six levels each covering some

\footnotetext{
42 J.W.P. Verheugt, Inleiding in het Nederlands recht, Uitgeverij de Zuidas, 2015.

${ }^{43}$ P. Wahlgren, Legal Reasoning: A Jurisprudential Description, ICAIL '89 Proceedings of the 2nd International Conference on Artificial Intelligence and Law, New York, ACM, 1989; IRI (Institutet för Rättsinformatik) Automation of Legal Reasoning: A Study on Artificial Intelligence and Law, Deventer, Boston, Stockholm, Kluwer/Juristförlaget, 1992; P. Wahlgren, A General Theory of Artificial Intelligence and Law, in A. Soeteman (Eds.), Legal knowledge based systems JURIX 94: The Foundation for Legal Knowledge Systems, Lelystad, Koninklijke Vermande, 1994, pp. 79-92; G.N. Yannopoulos, Modelling the Legal Decision Process for Information Technology Applications, in Law, Kluwer Law International, 1998.

${ }^{44}$ P. Wahlgren, Legal Reasoning: A Jurisprudential Model, <http://www.scandinavianlaw.se/pdf/40-10.pdf>. Wahlgren subdivides the legal reasoning process into six interrelated steps: identification, law-search, interpretation, evaluation, formulation and learning.
} 
ten aspects. In this way, this matrix provides a categorisation that enables to see all possible spectra at all possible levels.

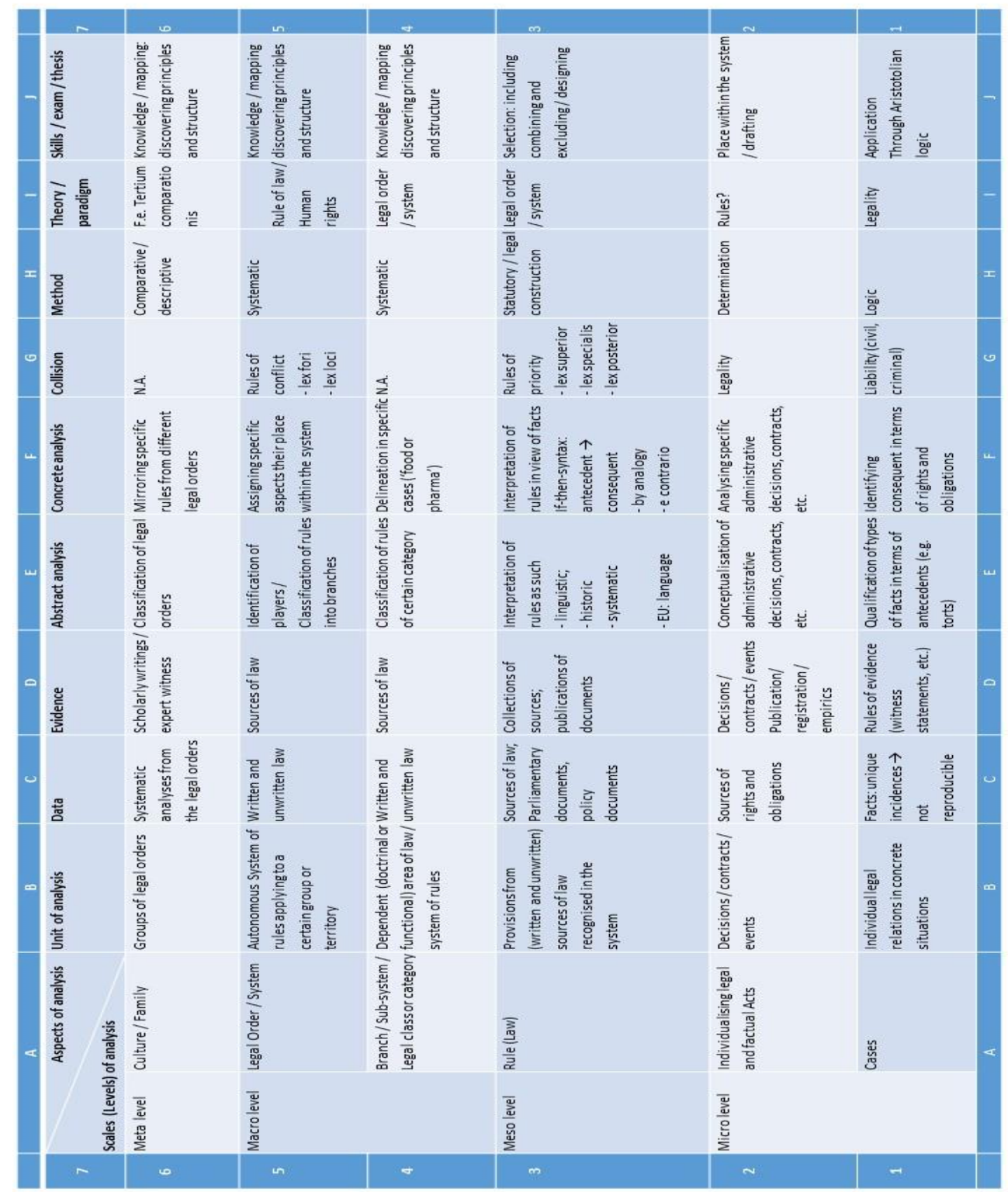


Chapter2 'Real Food from Virtual Shops: the situation before 2014' assesses at meso-level how more general legislation (legi generali) relate to the legi speciali of consumer law (3G). Unlike the heading 'collision' above column $\mathrm{G}$ in the matrix and the reference to rules of priority in window $3 \mathrm{G}$ seem to imply, the chapter shows that in concurrence between these two fields of law, the special law does not automatically take priority. Rather, the chapter shows that in case of distance sales of food the consumer derives better protection from general contract law than from specific consumer law.

Another element of the analysis - in the final chapter - relates to the competent forum and the law it has to apply. Among the so-called rules of conflict, are the lex fori - the law of the forum - and the lex loci - the law of the place where the contract was concluded. While the EU is a huge market with close to 750 million consumers who are all parties to many contracts, increasingly contracts are of an extraterritorial nature. In trade online the statutory seat of the business and the location of the contract become random aspects of the relation. In terms of the matrix (5G) a reorientation is required on the competence of fora and the ruling law of the contract. In other words a reorientation is required on the rules of conflict such as the lex fori and the lex loci. The concluding chapter contributes to this reorientation.

The different types of legal analysis as guided by the matrix, needs to be informed by data. In this research these data are provided by the four research chapters that each highlight an aspect of the research theme as delineated by the problem statement.

In scientific doctrinal legal research data, by definition, consist of texts. These text are sources of law (primary data), or provide knowledge on the sources of law (secondary data). Even the content of socalled unwritten sources of law (legal principles, legal custom and case law) usually must be derived from texts. The most important sources of law in this research are the Dutch Civil Code (CC) and the related law; ${ }^{45}$ including European directives. Directives must be implemented in national law. ${ }^{46}$ By consequence also the rules derived from these directives present themselves to stakeholders as national law. This is different for regulations. Regulations apply directly in the legal orders of the EU Member States. ${ }^{47}$ Their applicability and interpretation is independent from national implementation and interpretation. In terms of the matrix, EU directives and regulations are 'lex superior' in relation to legislation crafted by national legislators.

Because law expresses itself through text, legal scholarship must resort to analysis, explanation and interpretation of text. To this end, each legal system recognises certain methods of interpretation (or 'construction'). Usually, interpretation starts from the wording chosen by the authority expressing the rule. The assumption is that people laying down rules and requirements choose to the best of their ability the words to express their meaning. On the basis of this assumption one can then assume that the legislature actually meant what is being said in its literal meaning. In many situations, these assumptions do not hold or lead to absurd outcomes. The text may be ambiguous maybe as a consequence of political compromise during the drafting, or the legislator did not think of the particular circumstances of the case to which the rule must be applied. For such situations, other methods of interpretation are available. For example, the discussion out of which the text emerged may shed light on the reasons why a particular wording has been chosen (text historic method) or one may take into consideration the objective the legislator aimed to achieve and understand the text in such a way that it best contributes to achieving that objective (teleological method). The

\footnotetext{
${ }^{45}$ Where 'law' is a broader concept than just 'legislation'.

${ }^{46}$ Treaty on the Functioning of the European Union (TFEU).

${ }^{47}$ Article 288 TFEU.
} 
objective can often be deduced from the recitals to the text and also from the discussions during its drafting. ${ }^{48}$

In the following research chapters first the applicable legislation is laid out. Then this legislation is construed using methods of interpretation that are recognised in Dutch and EU legal doctrine. This is done using parliamentary documents and other accessible considerations of the legislature. This is then followed by an analysis of the likely consequences on legal and trade practice. This analysis feeds into value judgements regarding desirable and undesirable effects of the law at issue. Desirability depends on the fairness of the balance of burdens and benefits in light of the objectives pursued by the legislature. Each time when more general elements of civil law are discussed, it is highlighted how this specifically applies in case the merchandise is food. Each time when more general elements of food law are discussed, it is highlighted how this specifically applies in case the food is purchased online. In this way a distinct sub-area of law emerges; an area that this thesis labels as: food online. This area of law shows the characteristics of a functional field of law in that it is cross cutting through civil law and public law and through national law and European Union law. ${ }^{49}$

\subsection{OUTLINE}

This thesis is organised as follows. Chapter 2 "Real Food from Virtual Shops: the situation before 2014' reports on research performed before the entry into force of the national implementation of the Consumer Rights Directive ${ }^{50}$ (to be discussed in detail hereafter) and of the Food information to consumers regulation. ${ }^{51}$ An earlier version of that chapter was published in that time in the European Food and Feed Law Review. This chapter provides the historical baseline to this research. The research in this chapter shows that the instruments to be handed to the consumers to compensate their weakened position as online buyers, cannot function as intended in case the merchandise is food. It is argued that consumers derive more bite from general provisions of contract law than from the provisions specifically addressing distance contracts.

The third chapter, 'Food Online, Radical Changes to the Digital Shop Window after 2014' continuous the argument by addressing in detail the implementation of the Consumer Rights Directive in the Netherlands and the entry into force of the Food information to consumers regulation. It is here in particular that the differences become visible between civil law and food law in the manner in which they envisage to protect the consumer. Civil law is remarkably scarce in requiring provision of information to consumers. In his attempt to ensure that consumers are only bound to purchase foods they actually want, the European legislator has chosen a rather draconic instrument. The consumer has been given the right to withdraw from the contract altogether after the etailer has already fulfilled his side of the agreement. Despite the logistic nightmare for etailers, the legislature has preferred this instrument over elaborate information requirements regarding the product to be purchased. The available data do not show that the legislature balanced these two instruments, but the arguments in favour of a withdrawal right for the consumer rather than an information obligation

\footnotetext{
${ }^{48}$ For example there is no specific provision in legislation answering the question whether a street vendor selling a food box should provide a list of ingredients. The Food information regulation aims to ensure that consumers have access to ingredients information prior to purchase. This objective is best served when we read the requirements in the regulation in such a way that the street vendor is covered.

${ }^{49}$ On the concept of a functional field of law, see: B.M.J. van der Meulen, B.M.J., 'Levensmiddelenrecht, een functioneel rechtsgebied in opkomst' Ars Aequi 2014 and the sources there quoted.

${ }^{50}$ Directive 2011/83/EU.

${ }^{51}$ Regulation (EU) 1169/2011.
} 
must have been compelling for the legislature to accept the considerable disadvantage for the supplier in having to deal return shipments.

Whatever these reasons have been, they seem to have been less compelling in the case of food products. The vast majority of foods is exempted from the right to withdraw. This leaves a considerable gap in the civil law protection of consumers of food online. They can benefit neither from the right to withdraw nor from a right to be adequately informed. This gap has recently been filled by the Food Information Regulation. This regulation does put in place a considerable obligation to supply the consumer online with information prior to the purchase decision. Again the legislator chooses a solution that creates a large burden for the etailer. The etailer has to provide online all the information that the producer is required to provide on the food label. In one seemingly small provision the entire and complex burden the Food Information Regulation places on the food industry, is placed with the etailer as well. This is in addition to the de facto obligation to have the logistics in place to deal with the exercise by consumers of the right to withdraw where (they think that) this applies.

Chapter 4 'Product Liability for Online Food Suppliers' addresses the increased risks for the etailer of foods to become product liable. Due to the very wide scope of the definition of 'producer' in product liability law, the risk for the etailer to be considered the liable producer is rather high. Furthermore, as a consequence of the Consumer Rights Directive and its implementation in national law, of all the players in the chain the etailer is easiest to identify for the consumer. The etailer is lacking all the additional legal tools that have been created for consumers to enable them to successfully claim from their suppliers. Etailers have to push their claims further up the hill without any recourse to facilities regarding burden of proof or liability. Both the Consumer Rights Directive and the Food Information Regulation have been designed to reinforce the consumers' position with a view to ensuring that consumers will no longer be the weakest link in the value chain. Their backlog in legal power is compensated through a veritable arsenal of legal tools and legal assumptions. Backlog in knowledge is compensated through obligations of suppliers to provide detailed information regarding themselves and regarding the products.

Within the food chains from farm to fork risk are handed around like hand-grenades. When the legislators succeed in reinforcing the consumers' position with legal tools and information up to the point where they are no longer the weakest party, a new weakest party is likely to emerge. In the chapter it is shown that probably it is the etailer at whom all other players in the chain will aim their legal arrows.

The last of the four research chapters, chapter 5 'The Lucky Bag for Meals' uses the case of the emerging market for food-boxes ${ }^{52}$ to assess if indeed all information requirements that are imposed upon the etailer actually conform to the needs as perceived by consumers. Food-boxes embody the dream of every etailer. Not the consumers decide what they buy, but the retailers decide what they supply. Business economic advantages of this model in terms of stock management, logistics and marketing are obviously enormous.

An important marketing proposition is this modern day 'lucky bag' is the surprise. It appears that consumers love to be surprised. Despite all requirements regarding transparency and information provision imposed by legislators upon the etailer with a view to protecting consumers, a part of the market seems to prefer to be kept in blissful ignorance. The chapter shows that a relevant group of

\footnotetext{
${ }^{52}$ See p. 125 for a list of boxes that are currently available on the market in the Netherlands.
} 
consumers is actually willing to pay a price premium to businesses for infringing upon their legal obligations and for being kept out of their rights.

The research chapter have in common that they analyse the relevant legal requirements in light of their effect on the legal relation between the actors that together form the last link in the often very long food chains: the consumers and the etailers.

The final chapter, chapter 6 , synthesises the findings of the research chapters and thus answers the research questions set out above. However, in no branch of scholarship do final answers exist. From the answers found a higher level of ignorance emerges. This higher level of ignorance is captured in recommendations for research questions for a future generation of researchers. These open ends show how the legal field of food online in legal development and legal scholarship is just as young as the technology that sparked its emergence. 


\section{REAL FOOD FROM VIRTUAL SHOPS: THE SITUATION BEFORE $2014^{53}$}

\subsection{INTRODUCTION}

The concept of distance contract, defined as a contract entered into by parties who did not physically come together for this purpose, has a long history. In 1744, Benjamin Franklin published a catalogue in colonial North America from which readers could order scientific books through mail; the first mail-order delivery firm was born. ${ }^{54}$

Apparently, Franklin thought that an agreement that was entered into without the parties being physically near one another entailed risks for purchasers, and they had to be protected from the possibility that the suppliers' anonymity would make it possible for them not to fulfil their obligations. Franklin included a warranty in the catalogue:

'THOSE PERSONS WHO LIVE REMOTE, BY SENDING THEIR ORDERS AND MONEY TO B. FRANKLIN MAY DEPEND ON THE SAME JUSTICE AS IF PRESENT.'

The catalogue constituted the origination of the first mail-order delivery firm as well as the initial rights for the benefit of distance buyers.

Today, a few centuries later, the Pony Express of Franklin's day has developed into an extremely efficient and refined global system of mail delivery. The paper catalogue, however, is on the wane because the Internet has enabled sellers to present their goods in a shop along the digital highway. The purchase agreements entered into in these shops are distance contracts, the same as Franklin entered into. But the technology is new.

As always, legislators follow the technology. Legislators, both European and national, believe that, with the introduction of web shops, a new situation has emerged in legal traffic which deviates from what already existed to such an extent that modification of the law is required.

So legislators apply imperative rules of law to intervene in the contractual relationship between distance sellers and buyers.

The new technology has resulted in the expansion of the world of distance buying to foodstuffs. As long as distance selling depended on paper catalogues, perishable products such as food were not included. In the shadow of the turbulence of food safety crises and related modernisation of public and private food law, a silent modernisation of the food market is taking place. For an everincreasing amount of real food is entering kitchens via virtual shops.

\footnotetext{
${ }^{53}$ Earlier versions of this chapter have been published as Lomme van der Veer, Food Online. Reconnaissance into a consumer protection no-man's land between food law and the Civil Code, chapter 14 in Bernd van der Meulen (ed.) Private food law. Governing food chains through contract law, self-regulation, private standards, audits and certification schemes, Wageningen Academic Publishers 2011, p. 301-318; and Lomme van der Veer, Real Food from Virtual Shops. A case study from the Netherlands, European Food and Feed Law Review 2012, p. 3-13. An earlier version is also in published in Dutch language in Voer voor advocaten, Jonge Balie Congres 2009.

${ }^{54}$ See https://about.usps.com/publications/pub11/pub_007htm.
} 


\subsection{THE DISTANCE CONTRACT, BUYING FOOD ONLINE}

Most considerations of the European Parliament and Council for Directive 97/7/EC $C^{55}$ regarding distance contracts do not in any way consider the element that distinguishes transactions via the Internet from Franklin's 'mail-delivery transactions': digital technology. This is different in the following considerations regarding the provision of information and privacy. The nature of the technology plays a role here:

(13) Whereas information disseminated by certain electronic technologies is often ephemeral in nature insofar as it is not received on a permanent medium; whereas the consumer must therefore receive written notice in good time of the information necessary for proper performance of the contract;

(17) Whereas the principles set out in Articles 8 and 10 of the European Convention for the Protection of Human Rights and Fundamental Freedoms of 4 November 1950 apply; whereas the consumer's right to privacy, particularly as regards freedom from certain particularly intrusive means of communication, should be recognized; whereas specific limits on the use of such means should therefore be stipulated; whereas Member States should take appropriate measures to protect effectively those consumers, who do not wish to be contacted through certain means of communication, against such contacts, without prejudice to the particular safeguards available to the consumer under Community legislation concerning the protection of personal data and privacy;

The European Community is not the only entity with the desire to act in a regulatory manner; Member States also desire this. A motive for the Directive was found in the already existing and mutually differing national rules for distance contracts in the Member States. The Directive intends to remove the detrimental effects arising from this for the competition between businesses in the internal market by implementing a minimum of common rules on a Community level.

(4) Whereas the introduction of new technologies is increasing the number of ways for consumers to obtain information about offers anywhere in the Community and to place orders; whereas some Member States have already taken different or diverging measures to protect consumers in respect of distance selling, which has had a detrimental effect on competition between businesses in the internal market; whereas it is therefore necessary to introduce at Community level a minimum set of common rules in this area;

In the explanatory memorandum to Dutch regulations for the 'Adjustment of Book 7 of the Civil Code to Directive 97/7/EG of the European Parliament and of the Council of the European Union of 20 May 1997 on the protection of consumers in respect of distance contracts', this is formulated as follows:

\footnotetext{
${ }^{55}$ Directive 97/7/EC of the European Parliament and of the Council of 20 May 1997 on the protection of consumers in respect of distance contracts.
} 
Firstly, some Member States had taken various measures with a view to the protection of consumers in respect of distance selling, with detrimental effects on the competition between the businesses in the internal market, while for consumers cross-border distance selling could be one of the main tangible results of the completion of the internal market (considerations 3 and 4.). Secondly, the Council Resolution of 14 April 1975 (OJ C 92) is mentioned where the need to protect consumers from demands for payment for unsolicited goods and from high-pressure selling methods (consideration 5) is highlighted. Furthermore, the use of technology for distance communication must not lead to a reduction in the information provided to the consumer or to the provision of ephemeral (not recorded on a permanent data carrier) information (considerations 11 and 13). It is also important for consumers to actually see the product or ascertain the nature of the service before entering into the contract (consideration 14).

Finally it is pointed out that the consumer's right to protection of his/her privacy should be recognised, particularly as regards freedom from certain particularly intrusive means of communication (consideration 17).

Since 1 February 2001, the Dutch 'Distance contracts' (Civil Code, book 7, title 1, part 9A. Articles 7:46a up to and including $46 \mathrm{j}$ ) is prevailing law.

It is thus the nature and manner in which contracting parties relate, based on which legislators judge that consumers require mandatory protection in addition to general contract law. It is not the object of the agreement, the merchandise, but instead the technology used in the offer and the technology used in the acceptance of the offer that requires modification. There are additional rules in the traffic with consumers on the digital highway.

We consider these additional rules as laid down by the Dutch legislator in part 9A of book 7 Civil Code to be relevant in this scheme.

\section{Article 7:46a CC}

In this part, the following words have the following meanings:

a. distance contract: a contract for which, within the framework of a system organised by the seller or service provider for the purpose of distance selling or service provision, up to and including the conclusion of the contract, exclusive use is made of one or more technologies for distance communication;

b. distance buying: the distance contract which is a consumer purchase;

\section{(...)}

e. technology for distance communication: a means that can be used without simultaneous personal presence of parties for entering the distance contract.

\section{(...)}

g. Directive 97/7/EG: by the European Parliament and the Council of the European Union of 20 May regarding the protection of consumers in respect of distance contracts (OJ L 144); 
The legislator has designed things in such a way that 'distance purchasing' is a subset of the distance contract, where, in addition to the nature of the contract - it is after all a purchase agreement characteristics of the parties involved have been laid down in the contract. After all, a consumer purchase involves a seller who acts within the execution of a profession or business and a buyer, a natural person, who does not act within the execution of a profession or business as parties.

Article 7:46b CC

1. (...).

2. This part does not apply to distance purchasing:

a. concluded by means of automatic vending machines or automated commercial premises;

b. concluded at an auction.

3. Articles 46c-46e and 46f, paragraph 1 do not apply to the distance purchasing of mainly foodstuffs supplied to the home of the buyers, to his/her residence or to his/her workplace by regular roundsmen.

The question of what exactly is meant by vending machines and automated commercial premises arises. Coffee, beverage and sweets vending machines - there are even fruit machines that actually supply fruit - must be considered as vending machines. In the case of an automated commercial premises, people probably think of 'a wall' in which people deposit money and pull out foodstuffs from behind a hatch.

Although these machines can hardly be considered a 'technology for distance communication' as defined in Article 7:46a(a) CC, the legislator has apparently intended to do good by excluding this form of selling with technical tools.

It is also relevant to know whether it is only the baker and milkman who are meant by 'regular roundsmen' i.e. the suppliers who deliver with some frequency at set times. One may even see the occasional cheese and ice cream vendors in rural areas.

Apparently, the legislator has considered the possibility of the buyer and seller not meeting near or in the vending car, but that instead the seller delivers orders to a private address based on a note or e-mail.

The difference between the frequent and punctual roundsman to whom the rule of the distance purchase does not apply, and the roundsman who delivers at the buyer based on an order from a web shop thus lies in the frequency and regularity of deliveries. This difference would be minimised if the buyer frequently orders from a web shop at set times, and the web shop delivers just as frequently and at set times, or if the consumer subscribes to a food box. ${ }^{56}$

\footnotetext{
${ }^{56}$ For the latter, see chapter 5.
} 
The intended distinction is that of the supplier who follows the usual route, contrary to a roundsman who comes by on the occasion of an order. This leads to the curious conclusion that if the sales contract is initiated by the seller, the protective measures of the Distance Purchase do not apply, and do apply in those cases in which the initiative is taken by the purchaser.

Article 7:46c CC deals with the provision of information to which the seller is obliged in case of distance purchases. Contrary to the conformity requirement to be discussed in sections 2.4 and 2.5, this is not mainly about information about the product. As regards the product, only the main characteristics of the item must be named. Usually, this involves information about the identity of the product, price, costs and the seller.

\section{Article 7:46c CC}

1. In good time prior to the conclusion of a distance purchase, the other party shall be provided with the following information using means adapted to distance communication technologies, of which the commercial purpose must explicitly be made clear:

a. the identity of the seller, and, if the distance purchase requires (part) advance payment, the seller's address;

b. the most important characteristics of the item;

c. the price of the item, including any taxes;

d. the costs of delivery, insofar as this applies;

e. the manner of payment, delivery or execution of the distance purchase;

f. the possible application of the option for dissolution in accordance with Articles 46d, paragraph 1 and $46 e$;

g. if the costs for the use of distance communication are calculated on any basis other than the basic rate: the amount of the applicable rate;

$h$. the period for the acceptance of the offer, or the period for the fulfilment of the price

i. where appropriate, in the case of a distance purchase which serves to permanent or periodic delivery of items: the minimum duration of the contract.

Pursuant to Article 7:46c, paragraph 1, the seller is obliged to provide the information meant 'in good time prior to entering into a distance purchase'. The legislator has thus not stipulated to make the information available to the purchaser 'prior to or while entering into the contract', in accordance with the system as formulated in Article 6:234, paragraph 1a CC regarding the applicability of General Terms and Conditions. This difference could be interpreted in wording, but it may also be that the difference is to be explained by causes less relevant for the meaning.

Paragraph 2 of Article 7:46c deals with the way and time at which information is to be provided in the execution insofar as this is not already the case based on paragraph 1. 
2. In good time during the execution of the distance purchase and, as far as this does not concern items to be supplied to third parties, not later than the time of delivery, the buyer must be provided with the following information in a clear and comprehensible manner in writing, or insofar as the information under $a$ and c-e are concerned, in another durable medium available and accessible to him/her, unless this information has already been provided prior to entering into the distance sale:

a. the information meant in part a-f of paragraph 1:

b. the requirements for exercising the right of dissolution in accordance with Articles $46 d$, paragraph 1 and 46e, paragraph 2;

c. the visiting address of the place of business of the seller to which the buyer can submit complaints;

d. insofar as applicable; information concerning the warranty and the services offered within the framework of the distance purchase;

e. if the distance sale has a duration exceeding one year or an indefinite duration: the requirements for dissolution of the contract.

In addition to a general termination option for seven days after receiving an item, the arrangement for the Distance Sale has an extended period in which dissolution is an option if the provisions are not fulfilled as laid down in Article 46c.

\section{Article 7:46d CC}

1. During a period of seven working days after receiving an item, the buyer is entitled to dissolve the distance purchase without stating the reasons. If all requirements of Article 46c, paragraph 2 are not met, this term is three months. The first sentence applies accordingly as from the moment all requirements of Article 46c, paragraph 2 have been met within the period meant in the second sentence.

2. In the case of dissolution pursuant to paragraph 1, the seller cannot charge compensation from the buyer, except for the direct costs for returning the item.

3. In the case of a dissolution pursuant to paragraph 1, the buyer is entitled to the free refund of what he/she has paid to the seller. The reimbursement shall be carried out as soon as possible and in any case within thirty days after the dissolution.

4. Paragraphs 1-3 do not apply to the distance purchase:

a. in the case of items of which the price is bound to fluctuations in the financial market over which the seller has no control;

b. in the case of items that:

$1^{\text {st }}$. have been produced according to the buyer's specifications;

$2^{\text {nd }}$. are clearly personal;

$3^{\text {rd }}$. cannot be returned by reason of their nature; 


\section{$4^{\text {th }}$. are susceptible to rapid decay or ageing;}

c. of audio and video recordings and computer software if the buyer has broken the seal;

d. of newspapers and magazines.

Despite the fact that the arrangement for Distance Purchasing applies unimpaired to the distance purchasing of foodstuffs, the exception as formulated in Article $46 \mathrm{~d}$, paragraph 4 , under $\mathrm{b}, 3^{\text {rd }}$ and $4^{\text {th }}$ appears to result in that a violation of the provisions in Article 46c, paragraph 2 remains without any threat for dissolution for many foodstuffs. After all, it must be stated of many foodstuffs that, because of their nature, they cannot be returned, or that they may decay or age rapidly.

In early 2008, the European Commission published a proposal for a Directive regarding consumer rights. ${ }^{57}$ In this Directive, the exceptions to the right to revoke are somewhat extended. Deliveries of wine if the delivery takes place after thirty days and agreements concluded in a sale by auction were added.

For the time being, it must be established that the legislator intends to provide consumers in distance selling with additional protection by ordering the provision of information which is not aimed at the product as much, but instead at the supplier and the costs involved in the contract; after all, Article 7:46c, paragraph $1 \mathrm{~b}$ CC provides only the marginal order to state 'the most important characteristics of the item'. It must also be established that the violation of this limited obligation will regularly fail to lead to the option to avail of the dissolution options as formulated in Article 7:46d relating to the exceptions as presented in paragraph 4.

In relation to the fact that consumers are not in the physical vicinity of the article to be purchased in the distance purchasing, the legislator has provided them with ample opportunity without putting forward arguments to dissolve the contract during a period in which they have been in the physical vicinity of the product. This is impossible in the case of products such as foodstuffs that can decay or age rapidly. The provision of information about products prior to the purchase is thus of significant importance in the case of foodstuffs.

\subsection{INFORMATION AND EXPECTATIONS ABOUT THE PRODUCT}

Where foodstuffs are concerned, the European and national legislators attach sufficient importance to proper information about products that the provision of information on foodstuffs is regulated in a special way. Directive 2000/13/EC ${ }^{58}$ orders Member States to harmonise legislation where labelling is concerned, which in the Netherlands was realised through the Food Labelling Decree. The Netherlands has entirely included the Directive into national legislation, so if the labelling of foodstuffs complies with the provisions of the Food Labelling Decree, these foodstuffs can be traded freely in other European Union Member States, provided that the indications and notifications on the packaging are stated in the language of the country where the foodstuff is marketed.

\footnotetext{
${ }^{57}$ Commission of the European Communities, Brussels 8.10.2008 COM (2008) 614 final. Proposal for a Directive of the European Parliament and of the Council on consumer rights.

${ }^{58}$ Directive 2000/13/EC of the European Parliament and of the Council of 20 March 2000 on the approximation of the laws of the Member States relating to the labelling, presentation and advertising of foodstuffs.
} 
In distance contracts, the merchandise is presented in a digital display case. A brief survey performed by my students and me suggests that foodstuffs are hardly ever displayed in such a way that the label is legible, and the accompanying text hardly ever provides the information prescribed by labelling law.

The buyers cannot examine the label prior to or during the purchase and are therefore unable to base their expectations on this. Subject of further research could be whether national and European legislators intended to have buyers take cognizance of the label prior to or during the purchase, or prior to or during consumption..$^{59}$ If the outcome would be that the law orders that buyers must be able to take cognizance of the label prior to the purchase, almost every Internet foodstuff provider will be forced to modify their website. In addition, the texts on labels must be legible in all of the languages of the Member States from which people can buy digital products in the web shop.

Questions that require elaboration within this framework not only see to the readability of labels, but also whether labels can be exemplary or that people need to be able to take note of the actual labels of the product that is to be delivered after purchase. The difference between both variants is expressed most tersely in the notification of the best-before date and use-by date.

It has been determined that, pursuant to Article 7:46c, paragraph $1 \mathrm{CC}$, the seller is obliged to make the information regarding the most important characteristics of the product ${ }^{\prime 60}$ known prior to the purchase. Assuming that the mandatory information on a label contains more than 'the most important characteristics of the product', the buyer of foodstuffs must first avail of the information legislators consider necessary after they have been purchased and delivered. As regards products which cannot be returned due to their nature or to the fact that they may decay or age rapidly, this means that the buyers can take cognizance of the properties of a product at a time when they can no longer return it based on the provisions of Distance Purchase. In fact, the seller can even limit the options for return by placing the best-before or use-by date presented close to the date of delivery. ${ }^{61}$

The legislator appears to think that the impossibility of coming into physical contact with a product in the case of Distance Purchasing is to be compensated with additional options for dissolution. The legislator also appears to think that the provision of information as regards foodstuffs must take place extremely precisely and carefully through mandatory statements on labels. For many foodstuffs, distance buyers have to do without the information on the label and without the options of dissolution as laid down in the Distance Contracts section in the Civil Code. None of the arrangements stated provide protection in the areas in which the legislator has considered that additional protection is required. Do distance buyers of foodstuffs have any instruments to make up for this?

\subsection{CONFORMITY}

\footnotetext{
${ }^{59}$ A strong indication in the direction of the former - though postdating current food labelling law and not entirely unambiguous in its wording - is Article 8(1) of the General Food Law (Regulation (EC) 178/2002) setting as objective for food law to enable consumers to make informed choices ('Food law shall aim at the protection of the interests of consumers and shall provide a basis for consumers to make informed choices in relation to the foods they consume...').

${ }^{60}$ Article 7:46c, paragraph 1 b CC.

${ }^{61}$ The seller who labels has a margin in choosing the date. Sellers of pre-labelled foodstuffs may choose to send the oldest stock first.
} 
The item delivered must comply with the agreement. The conformity requirement as general principle of contract law, is no more complicated than this. In fact, it simply is the application of the Latin adage pacta sunt servanda on purchase agreements.

The question whether that which has been delivered complies with the agreement proves to require more elaboration. The Dutch legislator answers the question e contrario:

\section{Article 7:17 CC}

1. The supplied product must be in conformity with the agreement.

2. A product does not meet the agreement if, also in view of the nature of the product and the statements the seller has made about it, it does not have the properties the buyer could have expected based on the agreement. The buyer may expect the product to have the properties necessary for normal use and the presence of which he/she does not need to question, as well as the properties that are required for a particular use as provided for in the agreement.

3. A product that differs from that which has been agreed or a product of another type does not meet the agreement. The same applies if that which has been delivered differs in number, weight or measure from what has been agreed.

4. If a sample or model has been shown or given to the buyer, the product is to correspond with this unless it was provided merely as an indication without the product having to correspond with it.

5. The buyer cannot rely on the fact that the product does not meet the agreement if he/she was informed or reasonably could have been informed of this at the time of the conclusion of the agreement. The same applies if this is due to defects in or the unsuitability of raw materials originating from the buyer, unless the seller should have warned him/her about these defects or unsuitability.

6. (...)

This Dutch law that prevails since 1 May 2003 is the implementation of Directive 99/44/EC. ${ }^{62}$

In this Directive, the requirement for conformity is expressed as follows:

Article 2 Directive 99/44

1. The seller must deliver goods to the consumer which are in conformity with the contract of sale.

2. Consumer goods are presumed to be in conformity with the contract if they:

(a) comply with the description given by the seller and possess the qualities of the goods which the seller has held out to the consumer as a sample or model;

\footnotetext{
${ }^{62}$ Directive 1999/44/EC of the European Parliament and of the Council of 25 May 1999 on certain aspects of the sale of consumer goods and associated guarantees.
} 
(b) are fit for any particular purpose for which the consumer requires them and which he made known to the seller at the time of conclusion of the contract and which the seller has accepted;

(c) are fit for the purposes for which goods of the same type are normally used;

(d) show the quality and performance which are normal in goods of the same type and which the consumer can reasonably expect, given the nature of the goods and taking into account any public statements on the specific characteristics of the goods made about them by the seller, the producer or his representative, particularly in advertising or on labelling.

3. There shall be deemed not to be a lack of conformity for the purposes of this Article if, at the time the contract was concluded, the consumer was aware, or could not reasonably be unaware of, the lack of conformity, or if the lack of conformity has its origin in materials supplied by the consumer.

4. The seller shall not be bound by public statements, as referred to in paragraph 2(d) if he:

- shows that he was not, and could not reasonably have been, aware of the statement in question,

- shows that by the time of conclusion of the contract the statement had been corrected, or

- shows that the decision to buy the consumer goods could not have been influenced by the statement.

5. Any lack of conformity resulting from incorrect installation of the consumer goods shall be deemed to be equivalent to lack of conformity of the goods if installation forms part of the contract of sale of the goods and the goods were installed by the seller or under his responsibility. This shall apply equally if the product, intended to be installed by the consumer, is installed by the consumer and the incorrect installation is due to a shortcoming in the installation instructions.

In his article, entitled 'De koopregeling in het richtlijnvoorstel consumentenrecht' ${ }^{63}$ (The purchase scheme in the consumer law Directive proposal), Hijma observes a difference in meaning between both arrangements as a result of a free translation of the Dutch legislator:

"One more peculiarity can be observed. Article 2, paragraph 3 of Directive 99/44 determines that there is no non-conformity if, at the time of entering the contract, the consumer 'was aware, or could not reasonably be unaware of, the lack of conformity'. In the implementation, the Dutch legislator has translated this text in a peculiar manner: 'was aware or reasonably could be aware' (Article7:17, paragraph 5 CC)."

A less free translation, however, would have resulted in the Dutch text being as introverted as the English text: there is no non-conformity if the buyer was aware or should have been aware of the lack of conformity.

Hijma states that, as evidenced by the explanatory memorandum, the Dutch 'implementation text' does not intend to result in a buyer's obligation to examine. The formula merely prevents buyers from relying on the fact that the defect was unknown to them, while it is virtually impossible that it would have escaped them.

\footnotetext{
${ }^{63}$ De koopregeling in het richtlijnvoorstel consumentenrecht, prof. dr. Jac. Hijma, included in the 'Het voorstel voor een Europese richtlijn consumentenrecht' collection, The Hague, Boom Juridische uitgevers, 2009 p. 171.
} 
In the Dutch version of the applicable text, the Vienna Sales Convention ${ }^{64}$ is translated just as roughly. In the English text, Article 35, paragraph 3 reads as follows:

The seller is not liable under subparagrpaphs (a) to (d) of the preceding paragraph for any lack of conformity of the goods if at the time of the conclusion of the contract the buyer knew of could not have been unaware of such lack of conformity.

The German text is just as firm:

Der Verkäufer haftet nach Absatz 2 Buchstabe a) bis d) nicht für eine Vertragswidrigkeit der Ware, wenn der Käufer bei Vertragsabschluss diese Vertragswidrigkeit kannte oder darüber nicht in Unkenntnis sein konnte.

The Dutch text reads:

De verkoper is niet ingevolge het in het voorgaande lid onder a)- $d$ ) bepaalde aansprakelijk voor het niet- beantwoorden van de zaken aan de overeenkomst, indien de koper op het tijdstip van het sluiten van de overeenkomst wist of had behoren te weten dat de zaken niet aan de overeenkomst beantwoorden.

The core issue translates as 'knew or ought to have known', which seems to be markedly wider in scope then 'could not have been unaware'.

On 8 October 2008, the European Commission published the proposal for a Consumer Rights Directive. ${ }^{65}$ The proposal envisages the adoption of a Directive that is to form a recast of the European provisions regarding consumer rights, jointly specified with the term 'consumer acquis'.

The proposal includes a conformity arrangement that provides more room for the statement that there is some obligation to have something examined or investigated on the part of the buyer. Article 24, paragraph 3 reads:

There shall be no lack of conformity for the purposes of this Article if, at the time the contract was concluded, the consumer was aware, or should reasonably have been aware of, the lack of conformity, or if the lack of conformity has its origin in materials supplied by the consumer.

So in fact, with Article 7:17, paragraph 5, CC the Dutch legislator comes closer to the proposal for the Directive than the current Directive.

\footnotetext{
${ }^{64}$ United Nations Convention on contracts for the international sales of goods (CISG).

${ }^{65}$ Proposal for a Directive of the European Parliament and Council regarding consumer rights, Brussels, 8

October 2008, COM (2008)614 final; 2008/0196 (COD).
} 


\subsection{CONFORMITY REQUIREMENT AND DISTANCE CONTRACTS}

It is conceivable that the Dutch or European legislator would be aware of the fact that consumers who become involved in distance purchasing develop expectations about products along routes other than by actually seeing and possibly holding the product. After all, the expectations to be fulfilled for the distance buyer in connection with the conformity requirement are constituted by presentations of the product in the digital shelf. It would have been possible for the legislator to have acted as a controller in the presentation regarding the provision of information.

The legislator decided another road, the road of 'unmotivated' dissolution. After all, based on the Article, the distance buyer can dissolve the agreement without stating reasons for seven days, which can be extended to three months, after receiving the product. The buyer thus has the time to decide whether his/her expectations about the product are met. But it is this instrument a foodstuff buyer will regularly have to do without, pursuant to Article 7:46 d, paragraph 4 CC.

The distance buyer also has to do without the information the label provides. A label can adjust the expectations of foodstuffs. As a result of the lack of corrective action of the label, the seller is fully obliged to comply with that which the buyer may expect from the seller in view of the nature of the product and the statements of the seller.

The above described difference in meaning between Article 7:17, paragraph $5 \mathrm{CC}$, which indicates some level of obligation to have something examined or investigated; and the more reticent Article 2, paragraph 3 Directive 99/44 may have a considerable impact to the question whether the label modifies the buyer's expectations as such that deliveries are always conform if the label provides accurate information. In distance purchasing, the label will play an opposite role; after all, buyers cannot read the label until the product has been bought and delivered, and are not able to determine whether the product is in conformity with the expectations until it has been delivered. So the label cannot contribute to the formation of expectations of the product, but instead to the assessment that the product does not meet the expectations.

What is the set of instruments available to distance buyers of perishable goods if the label forces them to adjust expectations? Actually, the buyer can avail of the entire set of instruments for nonconformity.

Based on Article 7:21 CC, buyers can demand delivery of that which is missing, repair or replacement. For a vegan who reads on the label that the expected vegetarian hamburger contains products of animal origin, these options for demand are no consolation, ${ }^{66}$ as is the case with a buyer of cheeseburgers who reads that there is no cheese in the hamburger. Article 7:22 CC outlines other powers:

Article 7:22 CC

1. If, in the event of a consumer sale agreement, that which has been delivered does not comply with the agreement, the buyer also has the right to:

\footnotetext{
${ }^{66}$ Assuming that a vegan not only wants to avoid eating products of animal origin but also to contribute to their production by buying them. The cheese lover might still be satisfied through replacing the product.
} 
a. dissolve the agreement, unless the deviation of that which has been agreed does not justify this dissolution and its consequences in view of its minor importance;

b. reduce the price in proportion to the degree of deviation of that which has been agreed.

2. The rights meant in paragraph 1 arise only if repair and replacement are impossible or cannot be expected from the seller, or if the seller has failed to perform an obligation as meant in Article 21, paragraph 3.

3. Insofar as this part does not deviate from this, the provisions of part 5 of title 5 of book 6 regarding dissolution of an agreement apply to the authority as meant in paragraph $1 \mathrm{~b}$.

4. The buyer may exercise the rights and authorities stated in paragraph 1 and Article 20 and 21 without prejudice to any other right and claim.

Now that it appears from Article 7:6 CC that Article 7:22 has also a mandatory character, the distance seller will not be able to rule out the option to dissolve in the case of non-conformity, even if the foodstuffs are subject to decay or ageing.

A superficial investigation into what distance sellers of foodstuffs stipulate for themselves provides a curious result. Let us take a little excursion to practice.

In which cases do the Albert Heijn, Etos en Gall \& Gall web shops rule out dissolution in their General Terms and Conditions? They are all part of the Ahold concern and use the same General Terms and Conditions. The key provision are the following:

\section{Web shop General Terms and Conditions}

These General Terms and Conditions of the Nederlandse Thuiswinkel Organisatie (Dutch Homeshopping Organisation) were established in consultation with the Consumers' Association within the framework of the Coördinatiegroep Zelfreguleringsoverleg (CZ; Self-Regulation Coordination Group) of the Social and Economic Council and came into effect as of 1 January 2009.

\section{Article 2 - Identity of the entrepreneur}

- Albert Heijn bv trading under the name/names: Albert

- Business and visiting address: Provincialeweg 111506 HA Zaandam

- Telephone number: $+31(0) 800-2352523$

- Accessibility: from Monday through Friday from 8:30 am until 10:30 pm and Saturday from 8.00 am until $2.30 \mathrm{pm}$

- E-mail address: info@albert.nl

- Chamber of Commerce number: 35012085

- VAT identification number: nl002330884b01 
$(\ldots)$

\section{Article 5 - The agreement}

1. Subject to the provisions of paragraph 4, the agreement is concluded at the time of the consumer's acceptance of the offer and the fulfilment of the conditions set for this purpose.

2. If the consumer has accepted the offer electronically, the entrepreneur will immediately confirm receipt of the acceptance of the offer electronically. As long as the receipt of this acceptance has not been confirmed, the consumer may dissolve the agreement.

3. If the agreement is concluded electronically, the entrepreneur will take appropriate technical and organisational measures to safeguard the electronic transfer of data and ensures a safe web environment. If the consumer has the option of paying electronically, the entrepreneur shall observe appropriate safety measures.

4. Within legal frameworks, the entrepreneur may investigate whether the consumer is able to meet his/her payment obligations and whether all facts and factors that matter in a responsible conclusion of the distance contract. If the entrepreneur has valid grounds not to conclude the agreement based on this investigation, he/she is entitled to refuse an order or application stating reasons or to attach special conditions to the execution.

5. The entrepreneur shall include the following information for the product or service to the consumer, in writing or in such a way that the consumer can save it on a permanent data carrier in an easily accessible manner:

- the visiting address of the business location of the entrepreneur where the consumer can lodge complaints;

- the conditions under which and the way in which the consumer may invoke the right to revoke, or a clear notification of being refused the right to revoke;

- the information about existing service after sale and warranties;

- the information included in Article 4, paragraph 3 of these terms and conditions, unless the entrepreneur has already provided the consumer with this information prior to the execution of the agreement;

- the requirements for dissolution of the agreement if the agreement has a duration of over one year or if the duration is indefinite.

6. If the entrepreneur has committed him/herself to supply a series of products or services, the provision in the above paragraph applies to the first delivery only.

\section{Article 6 - The right to revoke on delivery of products}

1. When purchasing products, the consumer has the option to dissolve the agreement without stating reasons for a period of 14 days. This period comes into effect on the day after receiving the product by or on behalf of the consumer.

2. During this period, the consumer shall handle the product and its packaging with due care. $\mathrm{He} / \mathrm{she}$ shall unwrap or use the product only to such an extent in so far as this is required to be able to assess whether he/she wishes to keep the product. If he/she makes use of the right to revoke, he/she shall return the product and any accessories - if reasonably possible - in the original state and packaging to the entrepreneur, in accordance with the reasonable and clear instructions by the entrepreneur. 


\section{Article 7 - Costs in the event of revocation}

1. If the consumer exercises the right to revoke, the costs for return shipment at the most will be at his/her expense.

2. If the consumer has paid an amount, the entrepreneur shall repay this amount as soon as possible and no later than 30 days after the return shipment or revocation.

\section{Article 8- Exclusion of the right to revoke}

1. If the consumer does not have a right to revoke, this can only be excluded by the entrepreneur if the entrepreneur has clearly stated this in the offer, in any case in good time prior to the conclusion of the agreement.

2. Exclusion of the right to revoke is possible only for products:

- that have been produced by the entrepreneur in accordance with the consumer's specifications;

- which have a distinct personal nature;

- that cannot be returned because of their nature;

- that can decay or age rapidly;

- of which the price is bound to fluctuations in the financial market over which the entrepreneur has no control;

- for single issues of newspapers and magazines;

- for audio and video recordings and computer software of which the consumer has broken the seal.

\section{$(\ldots)$}

As many other distance sellers, Albert.nl derives its General Terms and Conditions to the set of terms and conditions developed by the Dutch Homeshopping Organisation in conjunction with the Consumers' Association within the framework of the Self-Regulation Coordination Group of the Social and Economic Council. ${ }^{67}$

As do many other suppliers, Albert.nl has, as appears from the formulation of its Terms and Conditions, copied the instructions of the Dutch Homeshopping Organisation, which in turn have been copied from Article 7:46d, paragraph 4 CC instead of following them.

Article 8, paragraph 1 is particularly confusing. Which right to revoke has been excluded if the consumer does not avail of a right to revoke?

In Article 8, paragraph 2, Albert.nl does not express the cases in which they avail of the option to exclude the right to revoke. Similar to the legislator, they merely outline the cases in which they are entitled to exclude this right, and as such leave the buyer uncertain about their intentions.

\footnotetext{
${ }^{67}$ The Social and Economic Council is an advisory board to the government and used to be the highest body within the corporatist structure of product boards and industrial boards which existed until its abolishment in January 2015. Members of the Social and Economic Council are appointed by the government, by trade unions and by employers' associations (each one third of the total number). See: < www.SER.nl $>$.
} 


\subsection{CONCLUSIONS}

In digital distance sale the provisions of Directive 2000/13/EG and the Food Labelling Decree miss their objective if the purpose is to inform consumers about foodstuffs before they buy them.

The stipulations in Directive 97/7/EG and part 9A of title 1, book 7 CC miss their objective insofar as these stipulations intend to compensate for the lack of physical contact with ample options for dissolution, now that these options for dissolution may be lacking in the case of foodstuffs.

Ultimately, online buyers of food might know their position is best protected not by a lex specialis of consumer law or food law, but by the legi generali of contract law because these eventually provide an option for dissolution. After all, it is impossible for the distance seller to keep the consumer from the right of dissolution in the case of non-conformity, even if he/she has drafted the General Terms and Conditions correctly. 


\section{RADICAL CHANGES TO THE DIGITAL SHOP WINDOW AFTER $2014^{68}$}

\subsection{INTRODUCTION}

Commercial activities, from wholesale to consumer purchasing, have to a large extent shifted from the physical to the digital world as a result of the opportunities that now exist for making large amounts of information available simply. The migration from 'bricks' to 'clicks' can be seen in the streetscape of every European city. Physical shops - in as much as they are still used - are increasingly often just used as a 'showcase', while the actual transactions take place via the Internet.

Food too is bought and sold on a large scale via the digital superhighway. Often the entire chain from producer to consumer is made up of orders via the Internet. It is not only the number of online food purchasers that is increasing; the number of suppliers is increasing too. There are traditional retailers who are entering the digital market, newcomers who are going online for the first time on a small or large scale, and traditional producers who see an opportunity to become digital retailers themselves, thus affecting their customers' margins.

As a webshop has scarcely any need or no need at all for property, inventories or stocks. Entering the digital market is significantly simpler than opening a physical shop. However, online food retailers will have legal obstacles to overcome that may possibly be higher than the threshold of the physical shop.

These legal obstacles are to be found in Directive 2011/83/EU ${ }^{69}$ (the Consumer Rights Directive) and Regulation (EU) No. $1169 / 2011^{70}$ (the Food Information Regulation).

\subsubsection{The Consumer Rights Directive}

EU member states had to implement the rules and requirements of the Consumer Rights Directive in their own national legislation by the end of 2013. The Dutch legislator did not meet this deadline. The Netherlands did not modify its national legislation in line with the Consumer Rights Directive until mid-2014. The Consumer Rights Directive includes formal and material stipulations that - laid down in the legislation of the member states - include mandatory requirements about the form and content of contracts that are concluded via webshops.

\footnotetext{
${ }^{68}$ An earlier version of this chapter has been published as: Lomme van der Veer, Food Online. Radical Changes to the Digital Shop Window, European Food and Feed Law Review, 2014, p. 78-90.

${ }^{69}$ Directive 2011/83/EU of the European Parliament and of the Council of 25 October 2011 on consumer rights, amending Council Directive 93/13/EEC and Directive 1999/44/EC of the European Parliament and of the Council and repealing Council Directive 85/577/EEC and Directive 97/7/7EC of the European Parliament and of the Council.

${ }^{70}$ Regulation (EU) No 1169/2011 of the European Parliament and of the Council of 25 October 2011 on the provision of food information to consumers, amending Regulation (EC) No 1924/2006 and (EC) No 1925/2006 of the European Parliament and of the Council, and repealing Commission Directive 87/250/EEC, Council Directive 90/496/EEC, Commission Directive 1999/10/EC, Directive 2000/13/EC of the European Parliament and of the Council, Commission Directives 2002/67/EC and 2008/5/EC and Commission Regulation (EC) No $608 / 2004$.
} 


\subsubsection{The Food Information for Consumers Regulation}

The Food Information for Consumers Regulation came into effect on 13 December 2014. This regulation declares, using a simple permissive provision, that the very comprehensive regulations that apply in the field of food information also apply to webshops. As of mid-December 2014 online food retailers are suddenly drawn into a judicial area that they were unfamiliar with that has very radical consequences for their presentation on the web.

This Chapter describes the consequences of the two regulations for food retailers from a Dutch perspective. What do online food retailers have to comply with in order not to be in breach of the law since the end of 2014? What legal and practical problems are they faced with? 2014 was a key year for food online.

\subsection{THE DISTANCE CONTRACT}

\subsubsection{Introduction}

European legislators do not use the term 'webshop'. The legislation in which Europe intends to act as a modifier and which it aims to use to introduce harmonisation between the member states via the Consumer Rights Directive does not cover the 'digital contract' or the 'purchase in the webshop' or the like. Rather it uses the broader term 'distance contract', to which, for example, telephone transactions and mail orders also belong. The explanatory statements to the Directive also indicate that the main reason for the Directive was the greatly expanding trade that is taking place via the Internet.

\subsubsection{Definition}

The definition of the distance contract in the Consumer Rights Directive is (Article 2(7)):

'Any contract concluded between a trader and the consumer under an organised distance sales or service-provision scheme without the simultaneous physical presence of the trader and the consumer with the exclusive use of one more means of distance communication up to and including the time at which the contract is concluded.'

The Dutch Civil Code (CC) defined the distance contract in a broader sense (Art. 7:46a of the Dutch Civil Code): 
'A contract under a distance sales or service-provision scheme organised by the vendor or service provider with the exclusive use of one more techniques for distance communication up to and including the time at which the contract is concluded.'

In the Directive the distance contract is thus always b2c; in the Dutch legislation it could also be b2b. In the bill ${ }^{71}$ to implement the Consumer Rights Directive in The Netherlands this difference has been removed. In the Consumer Rights Directive Implementation Act it is stipulated that Article 6:230g(1e) of the Dutch Civil Code the distance contract is:

'A contract concluded between a trader and the consumer under an organised distance sales or service-provision scheme without the simultaneous personal presence of the trader and the consumer with the exclusive use of one more means of distance communication up to and including the time at which the contract is concluded.'

The matter of whether an online supplier is a trader ${ }^{72}$ - as a result of which they are fully covered by the regime of the regulations referred to - may possibly result in discussion. Somebody who picks berries from their garden and makes jam from them for their cellar will not be a 'trader' if they offer a few jars on the Internet. But what if they do this every year in substantial quantities? Possibly there is the need for a further tightening-up because of the considerable consequences of the applicability of the classification 'trader'.

A previous aid in determining whether one of the parties should be regarded as a 'trader' could be found in the fact that there had to be a sales system organised by them (...). So somebody who sporadically sells goods as a hobby via an existing sales or intermediary site (marktplaats, ebay, etc.) could be distinguished from traders who run their own webshops ${ }^{73}$.

The requirement that the system had to be organised by the trader themselves was dropped in the harmonisation. It is possible that the finding that items are now traded very professionally and with considerable turnover via general sales and intermediary sites resulted in the words 'by the vendor or service provider' not being included.

It is obvious that the soft definition of the term 'trader' will result in a great deal of case law because of the harsh consequences of the applicability of this classification. It would be good if a concrete criterion were introduced now, just as the tax office uses an hourly criterion to distinguish between hobbies and sporadic activities and professional and commercial trading. The determination of the

\footnotetext{
${ }^{71}$ Amendment of Books 6 and 7 of the Dutch Civil Code, the Consumer Protection (Enforcement) Act and some other acts in connection with the implementation of Directive 2011/83/EU of the European Parliament and of the Council dated 25 October 2011 regarding consumer rights amending Directive 93/13/EEG of the Council and of Directive 199/44/EG of the European Parliament and of the Council and repealing Directive 85/577/EEG and Directive 97/7/EG of the European Parliament and of the Council (OJ L 304/64) (Consumer Rights Directive Implementation Act).

${ }^{72}$ Consumer Rights Directive: any natural or legal person, regardless of whether they are private or public, who, in contracts covered by this Directive, trades in part via another person who acts on their behalf or for their account for purposes relating to their trade, business, craft or profession.

Dutch Civil Code (art. 7:5 (1)): vendor who acts in the implementation of a profession or business.

${ }^{73}$ In the concluding Chapter the existence of platforms will be discussed.
} 
tax office that sales tax has to be paid is possibly an aid, but a consideration based purely on turnover is of course also possible. ${ }^{74}$

\subsubsection{Obligations of the webshop}

On the basis of the implementation of the Consumer Rights Directive webshops have to comply with different kinds of obligations. There are a lot of stipulations that have an imperative effect on the content of the contract. But there are also a lot of stipulations that focus on the presentation: the provision of information to the consumer. Both categories are discussed. Wherever meaningful the difference is indicated with the old and the new Dutch legislation.

\subsubsection{Obligations relating to the provision of information in the webshop}

\section{Introduction}

There are considerable differences between the concluding of a contract in a physical shop and the concluding of a contract online. Where these differences are disadvantageous for the consumer the Consumer Rights Directive attempts to offset these disadvantages. One of the tools used for this is the compulsory provision of information to the consumer via the website. Information about the trader, the nature of the product, the price, consumer rights: details that consumers have to be able to familiarise themselves with before they agree to the offer made by online retailers.

\section{Information about the trader}

On the Internet people are able to remain anonymous. Online vendors can hide their identity. Unlike in a physical shop, where consumers can have legal redress using legal remedies, it is possible for a webshop to be untraceable by dissatisfied consumers. Disappointed online consumers can write unfavourable reviews but to take legal action for compensation for poor performance they ultimately need a known (legal) person and an address. The obligation to provide information about the identity of the trader should make it possible for traders to be traced physically and legally.

According to the Dutch Civil Code the obligation to provide information about trader details is very slight $^{75}$. The Consumer Rights Directive fleshes out the obligation.

Before consumers decide to buy, the trader - i.e. the webshop - provides information in a clearly and comprehensive manner about ${ }^{76}$ :

\footnotetext{
${ }^{74}$ In the concluding Chapter this issue will be further discussed.

${ }^{75}$ Article 46c (1a) of the Dutch Civil Code mandates only that 'the identity' of the trader has to be made public in advance. It is not clear if a trademark, a trade name or a registered name is sufficient. Only in the case of an obligation to pay in advance does the address of the vendor also have to be made public in advance. Article 46 (2c) of the Dutch Civil Code mandates that on delivery at the latest a visitors' address to which a customer can submit complaints also has to be made public.

${ }^{76}$ Refer to the Consumer Rights Directive article 6 (1 b, c, d).
} 
- the identity of the trader, such as the trade name;

- their geographical address;

- their telephone number, fax number and e-mail address (if available);

- the geographical address and the identity of the trader on whose account they are acting (if applicable);

- the geographical address of the place of business to which consumers can address any complaints (if different to above).

In making the provision of these details compulsory the Directive aims to actually make it possible for a discussion with the supplier about the implementation to take place other than online, even though the contract was concluded online.

\section{Information about the product}

The Directive is very brief about the obligations of the webshop to provide details about the product. The task is to provide ${ }^{77}$ :

the main characteristics of the goods or services, in as much as these have been modified to suit the carrier used and the goods or services

The aim that the European legislator has set itself is to ensure that consumers have the opportunity to buy only those products that they want to buy, even if as a result of the distance they were not able to view, hold, taste, etc. the product. In order to realise this the Directive could have mandated that very comprehensive information had to be provided about all the characteristics of the product.

The Directive chose to use a different tool to bring about a situation in which consumers are not bound to purchase a product that does not meet their expectations: a broad right of withdrawal. The right of withdrawal belongs to the imperative stipulations relating to the content of the contract and will be covered there. It is already being noted that the system of withdrawal opportunities that is cumbersome for vendors but effective for consumers can fail precisely in the case of food because of hygiene and shelf life.

So for food whose purchase may not be able to be withdrawn the system of a summary obligation to provide information does not work as opposed to a considerable right of withdrawal. However, the Food Information for Consumers Regulation to be discussed below applies to food; this ensures via a simple provision that virtually all the information about food that has to be provided as part of the contract has to be available before purchase.

According to the text of the Directive, the extent to which consumers have to be informed before purchase about the goods (or services) is determined by 'the carrier used' and the goods concerned. The Consumer Rights Directive Implementation Act adopts the formula literally, except for the fact

\footnotetext{
${ }^{77}$ Article 6(1)(a) of the Consumer Rights Directive.
} 
that it refers not to 'goods' but to 'items' in order to anchor the terminology in the system of the Dutch Civil Code.

In Dutch jurisdiction a clear picture has emerged of 'the main characteristics' of an item using the legal question as to whether in a certain case a contract has been concluded ${ }^{78}$. The question regarding the extent to which 'the carrier' affects the detail and number of the characteristics that have to be provided has not yet been answered. It is a fact that the opportunities to provide information on websites are actually and technically unlimited.

The summary instruction relating to the obligation to report the main characteristics of the goods or services is further coloured by the guarantee of conformity. Webshops that overdo the recommendations by creating more or higher expectations in consumers than are suited to the product may be faced with the whole consumer toolkit in the case of non-conformity. So the purchase of food that is possibly not withdrawable can be terminated.

The Directive mandates ${ }^{79}$ that the following be included:

'a reminder of the existence of the statutory guarantee of conformity of goods'

According to Dutch law the conformity requirement states simply that a supplied item has to comply with the contract. A domestic variant of the 'pacta sunt servanda'. ${ }^{80}$

Information about the price ${ }^{81}$

On websites the price of the goods has to be clearly stated, including all taxes, or, if as a result of the nature of the goods the price cannot be reasonably calculated in advance, the way in which the price should be calculated, including all additional freight, delivery or postal charges and any other costs, or, if these costs cannot be reasonably calculated in advance, the fact that such costs could possibly

\footnotetext{
${ }^{78}$ A contract cannot be concluded until there is agreement about the main characteristics of the contract.

${ }^{79}$ Consumer Rights Directive article 5 (1 e).

${ }^{80}$ The question as to whether the goods supplied comply with the contract is more complicated. The Dutch legislator describes whether an item complies with the contract by summarising when that is not the case. Article 7:17( 2) of the Dutch Civil Code An item does not comply with the contract if, taking into account the nature of the item and the communications made by the vendor about the item, it does not have the properties that the purchaser may expect on the basis of the contract. The purchaser may expect that the item has the properties that are required for its normal use and about whose absence there should not be any doubt, as well as the properties that are required for an exceptional use that was provided for in the contract.

${ }^{81}$ Consumer Rights Directive article $6(1 \mathrm{e})$ the total price of the goods or services, including all taxes, or, if as a result of the nature of the good or the service the price cannot be reasonably calculated in advance, the way in which the price should be calculated, and, in this case, all additional freight, delivery or postal charges and any other costs, or, if these costs cannot be reasonably calculated in advance, the fact that such additional costs could possibly be owed. In the case of a contract that includes a subscription the total price includes the total costs for each invoicing period. If a set rate applies for such contracts, the total price also includes the total monthly costs. If the total costs cannot reasonably be calculated in advance, the way in which the price should be calculated should be stated.
} 
be owed. For long-term contracts - for example, the periodic supply of meals to elderly people ${ }^{82}-$ both the costs for each invoice period and the monthly costs should be indicated.

Current Dutch law, which has been fleshed out to a lesser extent, mandates only that the price needs to be stated, including all taxes. ${ }^{83}$

On the basis of both the Directive and the Dutch Civil Code the costs of using distance communication to conclude the contract have to be stated if these costs are calculated on a different basis to the basic rate. ${ }^{84}$

\section{The right of withdrawal}

The right of withdrawal is the subject of discussion in the imperative aspects that determine the content of the contract. Suffice it to say here that on the basis of Article $6(\mathrm{~h})$ of the Directive the right of withdrawal, in as much as it exists, has to be stated, including the applicable conditions, deadline and method for the exercise of this right. A sample form should be available on the website which can be used to exercise the right of withdrawal.

\section{Information about various aspects}

Before consumers commit themselves, they have to be able to read about the method of payment, delivery, implementation, the period within which the trader undertakes to deliver the goods and, if applicable, the trader's policy relating to dealing with complaints. ${ }^{85}$

The following should also be stated (in as much as they are relevant within this context): ${ }^{86}$

- the existence and the conditions linked to after-sales assistance for consumers, after-sales services and commercial guarantees;

- the existence of relevant codes of conduct in the field of unfair trading practices and how to obtain copies of these;

- the duration of the contract, or, if the contract is of variable duration or is automatically extended, the conditions for cancelling the contract;

- the minimum duration of the obligations of consumers by virtue of the contract;

- the existence and the conditions linked to securities or other financial guarantees that consumers have to pay or provide at the request of the trader;

- the possibility of access to out-of-court complaint and dispute resolution procedures to which the trader is subject and the way in which these are accessed.

\footnotetext{
${ }^{82}$ See also chapter 5 .

${ }^{83}$ Article 7:46c (1c) of the Dutch Civil Code.

${ }^{84}$ Article 7:46c (1g) of the Dutch Civil Code and Consumer Rights Directive article 6 (1f ).

${ }^{85}$ Consumer Rights Directive article $6(1 \mathrm{~g})$.

${ }^{86}$ Consumer Rights Directive article $6(1 \mathrm{~m}, \mathrm{n}, \mathrm{o}, \mathrm{p}, \mathrm{q}, \mathrm{t})$.
} 


\section{Design of the webshop}

Traders are obliged, on the basis of the Directive, to provide information that is not fully to the advantage of these traders. The tendency to publish this information in very small print or to hide it a long way behind buttons is understandable but it is also risky. The outcome of this could be that the webshop is treated in law as if it did not at all comply with the obligation to provide information.

After all, the Directive mandates ${ }^{87}$ that the information be provided in a clear, comprehensible manner in a way that suits the communication means used. Immediately before consumers place an order, information has to be provided in a clear, obvious manner about the aspects of characteristics, price and duration covered above.

It is considered important that consumers know exactly when they are bound to a payment obligation. Webshops have to be designed in such a way that consumers expressly recognise, when placing an order, that the order involves a payment obligation. If a button needs to be clicked on to place an order, the button has to be marked clearly 'order with payment obligation' or corresponding unambiguous wording. The button is not allowed to contain a lot more other information as a result of which attention could be diverted from the payment obligation. If the site is not designed properly with regard to this, quite simply no payment obligation arises. ${ }^{88}$ The Directive states that in such a case 'the consumer is not bound by the contract or the order', which raises the question as to whether the supplier is still bound by the contract and the obligation to supply still stands. It is also unclear what the status of the contract is if the consumer truly wants to be bound. The Consumer Rights Directive Implementation Act opts for a system in which such questions are excluded ${ }^{89}$. Trading in violation of the outlined obligation produces a voidable contract. So in the system of the Directive there is no consumer obligation and the status of the contract is uncertain. The Dutch legislator leaves the contract intact, including all the commitments linked to it. The consumer is also entitled to annul the contract, which results in the legal fiction that the contract never existed. Moreover, it should be mentioned here that annulment offers more opportunities than the withdrawal discussed below, as in the case of annulment neither the exceptions nor the deadlines of withdrawal apply.

It cannot be excluded that the wording chosen here by the Dutch legislator is on shaky ground as regards the harmonisation objectives of the Directive and the implementation obligation of the Dutch legislator. However, the Dutch option is so much stronger from a qualitative point of view that the freedom taken is highly defensible.

\section{Obligation to provide information after the purchase}

Once the order has been implemented, the obligation to provide information does not cease. The webshop provides the consumer, using a durable data medium, with the confirmation of the contract concluded within a reasonable period after the concluding of the contract and at the latest on delivery of the goods or before the start of the implementation of the services. The confirmation

\footnotetext{
${ }^{87}$ Consumer Rights Directive article 8 (1 ff).

${ }^{88}$ Consumer Rights Directive article 8 (2): (...) If the stipulations of this paragraph are not complied with, the consumer is not bound by the contract or the order.

${ }^{89}$ Article 6:230v (3) of the Dutch Civil Code (...) A contract that is concluded that violates this section is voidable.
} 
again states all the compulsory information about the webshop, the product, the withdrawal etc., unless the consumer already has this information on a durable data medium ${ }^{90}$.

\subsection{CONTRACT OBLIGATIONS FOR WEBSHOPS}

\subsubsection{Introduction}

Anybody who buys a product in a physical shop can feel, try on, smell, weigh, operate, measure, try out, etc. the product. Online consumers have to make do with a photograph and some text, however advanced these are.

The Consumer Rights Directive has not opted to offset this lack of opportunities with all kinds of instructions about the description of the product ${ }^{91}$. It has opted for a different tool to ensure that consumers are bound to purchase contracts only for products that they actually want to buy: the withdrawal.

\subsubsection{The term 'withdrawal'}

According to Dutch law, violation of a contract results in annulment or termination. Annulment of a contract has a retroactive effect. Termination does not have this retroactive effect ${ }^{92}$. As a result of termination obligations arise to rescind the performances already carried out as part of this terminated contract ${ }^{93}$.

According to Dutch law, the term 'withdrawal' relates not to the contract but rather to the legal act ${ }^{94}$. Withdrawing an offer or an acceptance ${ }^{95}$, for example, prevents a legal effect - the concluding of the contract - taking place. In exceptional cases the offer can still be withdrawn even after it has already been accepted ${ }^{96}$.

The term 'withdrawal' used in the Consumer Rights Directive ${ }^{97}$ relates not to the legal act - the acceptance of the offer by the webshop - but rather to the contract that consequently already exists.

\footnotetext{
${ }^{90}$ A durable data medium (Consumer Rights Directive Article 2(10)) 'Any aid that enables the consumer or the trader to store information that has been given to them personally in a way that makes this information accessible for future use during a period that is appropriate to the purpose for which the information is intended and that enables an unmodified presentation of the stored information.'

${ }^{91}$ The Consumer Rights Directive mandates in article 6 (a) only the mention of 'the main characteristics of the goods and services'.

${ }^{92}$ Article 6:269 of the Dutch Civil Code.

${ }^{93}$ Article 6:271 of the Dutch Civil Code.

${ }^{94}$ For example the withdrawal of an offer as referred to in article 6:219 (1).

${ }^{95}$ Both legal acts; a will which is directed towards a legal consequence and which has been manifested by a declaration ex article 3:33 of the Dutch Civil Code.

${ }^{96}$ Article 6:219 (3).

${ }^{97}$ Consumer Rights Directive article 9 (1): Except when the exceptions referred to in article 16 apply the consumer has a period of 14 days to withdraw from the distance contract (...) without giving reasons and without having to bear costs other than those set out in article 13 (2) and article 14.
} 
After all, Article 6 gives consumers the right, under conditions, to withdraw from the distance contract without giving reasons.

So the term is somewhat strange. Something cannot be withdrawn unless it has previously been commissioned. And that is the acceptance, not the contract. Possibly the European legislator opted to avoid the term 'termination' as this term is linked to deficiencies in the compliance with the contract. The right of withdrawal of consumers is already generating enough resistance among webshops without the association with non-performance too.

In the legal effects to be discussed below the withdrawal described in the Directive is closest to the term termination. This has prompted the Dutch legislator not to adopt the term 'withdrawal' from the Directive but rather to use the term 'termination'.

\subsubsection{The right of withdrawal}

In Article 9(1) of the Consumer Rights Directive the right of withdrawal, the withdrawal deadline, the exceptions to the right of withdrawal and the costs associated with the returned goods are referred to in one sentence. These are then fleshed out in more detail in the subsequent Articles.

\section{The deadline}

The deadline for withdrawal from the contract is 14 days after the day on which the consumer or a third party designated by the consumer who is not the carrier has the goods physically in their possession $^{98}$.

If the consumer orders several goods in one go that are delivered at different times, the deadline is 14 days after the day on which the consumer or a third party designated by the consumer who is not the carrier has the last of the goods physically in their possession ${ }^{99}$.

If the order is for one good but the delivery consists of different consignments or parts, then the deadline is 14 days after the day on which the consumer or a third party designated by the consumer who is not the carrier has the last consignment or the last part physically in their possession ${ }^{100}$.

In the case of the regular delivery of goods during a certain period the deadline is 14 days after the day on which the consumer or a third party designated by the consumer who is not the carrier has the first of the goods physically in their possession ${ }^{101}$.

\section{The exceptions}

Where food is traded at a distance the question as to whether contracts can be withdrawn - and the food can be returned - is highly relevant. After all, with food the matter of hygiene and shelf life and expiring best-before dates plays a major role. So it is amazing that no attention at all is devoted to food in the recitals of the Consumer Rights Directive that relate to the right of withdrawal.

\footnotetext{
${ }^{98}$ Consumer Rights Directive article $9(2 \mathrm{~b})$.

${ }^{99}$ Consumer Rights Directive article 9 (2bi).

${ }^{100}$ Consumer Rights Directive article 9 (2bii).

${ }^{101}$ Consumer Rights Directive article 9 (2bii).
} 
Recital 49) ${ }^{102}$ devotes attention to the fact that the right of withdrawal cannot be appropriate given the nature of some goods. The examples of such goods referred to concern wine if bought in the long term because of the speculative character, curtains because of the fact that these are tailor-made on request, fuel because of mixing. In the preamble no attention was devoted to the special position of webshops that sell food, so there is only the text of the Articles in the Consumer Rights Directive to be used as a basis for the question as to whether the right of withdrawal applies in full to food.

Article 16 of the Consumer Rights Directive mandates that the member states should not provide a right of withdrawal in their national regulations if the distance contract concerns (in as much as this is relevant here):

- the supply or provision of goods or services the price of which is linked to fluctuations on the financial market over which the trader has no influence and that may occur within the withdrawal period;

- the supply of goods that were manufactured in accordance with the consumer's specifications or that are clearly intended for a specific person;

- the supply of goods that are highly perishable or have a limited shelf life;

- the supply of sealed goods that are not suitable for return for reasons of health protection or hygiene and whose seal has been broken after delivery;

- the supply of goods that after delivery have been irrevocably mixed with other products as a result of their nature;

- the supply of alcoholic drinks whose price was agreed when the sales contract was concluded but whose delivery cannot take place for 30 days and the actual value of which is dependent on fluctuations in the market over which the trader has no influence.

\subsubsection{Food and the right of withdrawal}

There is a category of distance contracts for which the lack of a right of withdrawal is obvious. Anybody who orders a pizza, a kebab, sushi, etc. via the Internet will not be surprised that the contract cannot be withdrawn during 14 days after the delivery person has delivered the food. The Dutch website 'thuisbezorg.nl', part of the international Takeaway.com, has, by its own account, 4,500 affiliated restaurants in The Netherlands. In the general terms and conditions of the website the lack of the right of withdrawal is not stated. The affiliated restaurants present themselves in the format of the website, as a result of which they too cannot indicate the right of withdrawal, or the

\footnotetext{
${ }^{102}$ Recital 49) Certain exceptions from the right of withdrawal should exist, both for distance and off-premises contract. A right of withdrawal could be inappropriate, for example given the nature of the particular goods or services. This is the case for example with wine supplied a long time after the conclusion of a contract of a speculative nature where the value is dependent on fluctuations in the market ('vin en primeur'). The right of withdrawal should neither apply to goods made to the consumer's specifications or which are clearly personalized such as tailor-made curtains, nor to the supply of fuel, for example, which is a good, by nature inseparably mixed with other items of delivery (...).
} 
lack of it. Although it is obvious for the parties that these contracts cannot be withdrawn, the Consumer Rights Directive mandate that this must be stated ${ }^{103}$.

From a legal point of view it is of course relevant at what length of shelf life the phrases 'highly perishable' or 'limited shelf life' can no longer be used. The phrase 'goods that are highly perishable or that have a limited shelf life' needs to be explained. If the phrase does not refer to both meanings, 'highly perishable' means something other than 'limited shelf life'.

It is possible that 'highly perishable' means that the food can or does perish in the period between dispatch, withdrawal deadline and return of the goods. If 'limited shelf life' means something other than 'highly perishable', a longer deadline therefore applies for this criterion. Maybe even no deadline at all applies.

A jar of honey, jam or pasta keeps for a long time after it has been opened. A best-before date of several years is no exception. However, the good does not have an unlimited shelf life and so, with a literal interpretation, it comes under the supplies for which the right of withdrawal can be excepted. Tinned food sometimes has an even longer shelf life. But even the shelf life of this food is limited.

The explanatory memorandum of the exception drawn up according to Dutch law in Article 6:230p, f. $2 \mathrm{e}^{104}$ provides a narrow explanation of 'items that are highly perishable or have a limited shelf life'. The explanation states without indication of any doubt:

'Items that perish or age quickly (subsection 2) are also excepted. It is obvious that this concerns items such as meat or other products with a limited shelf life that as a result could perish within the termination period.'

The explanation in a semantic sense devotes more attention to 'highly perishable' than to 'limited shelf life'. In the case of 'highly perishable' seeking a link with the withdrawal deadline (termination deadline in Dutch law) is practical and workable, but there is uncertainty about the rating 'limited shelf life'. A certain explanation for this concept is on the whole not 'obvious'. Both the European and the Dutch legislators have failed to provide any content for this criterion.

If there is a lack of clear regulations, the webshop itself will have to evaluate the question as to whether the traded food can be excepted from the right of withdrawal. The consequences of its decision are considerable. Anybody who has not stated that in the case of withdrawable contracts there is a right of withdrawal that lasts for 14 days will be punished with the exceptionally long withdrawal deadline of 14 days and a year ${ }^{105}$. So if a supplier has not stated anything about withdrawability because they assume that their Articles are covered by the exception, the right of withdrawal will last for a year and 14 days if this assumption turns out to be incorrect.

\footnotetext{
${ }^{103}$ Consumer Rights Directive Art. 6(1)(k) (the trader provides in a clear and comprehensible way) if a right of withdrawal is not provided for in accordance with article 16, the information that the consumer will not benefit from a right of withdrawal or, where applicable, the circumstances under which the consumer loses his right of withdrawal.

${ }^{104}$ Article 6:230p of the Dutch Civil Code: The consumer has no termination right in the case of: f.2e the supply of items that are highly perishable or that have a limited shelf life.

${ }^{105}$ Consumer Rights Directive article 10 (1) If the trader has not provided the consumer with the information on the right of withdrawal is required by point $(\mathrm{h})$ of Article $6(1 \mathrm{~h})$, the withdrawal period shall expire 12 months from the end of the initial withdrawal period, as determined in accordance with Article 9 (2).
} 
Imagine, a webshop carries products that are not highly perishable (not within 14 days) but that have a limited shelf life (six months). Because of this the webshop does not state that there is a right of withdrawal of 14 days. If - in accordance with the explanation - the 14-day deadline is key to the question as to whether the exception ex Article 6:230p f.2e (Directive Article 16(d)) applies, the webshop should have stated the withdrawability.

Where the retailer believed that they needed to conclude non-withdrawable contracts because of the limited shelf life, they are bound by a withdrawal deadline of a year and 14 days. A deadline that is longer than the shelf life period.

Questions about deterioration and shelf life and the possibility of the supplier qualifying the contract as non-withdrawable can arise in the case of all kinds of preserved food, chocolate, vacuum-sealed food, nuts, dried products, deep-frozen food, etc.

At the moment the members of the largest webshop organisation in The Netherlands, the Nederlandse Thuiswinkel Organisatie, refer to the right of withdrawal in standard general conditions that are prescribed by the organisation. It is very much the question whether this complies with the Consumer Rights Directive, which prescribes that the information about this be issued in a clear, comprehensive manner. After all, the Directive prescribes ${ }^{106}$ that consumers be informed in a clear, comprehensive manner about the (possible) fact that consumers have no right of withdrawal (...) or, if applicable, the conditions under which consumers lose their right of withdrawal.

If a webshop presents not just products that come under the exception of Article 16 of the Directive, the webshop has to state that consumers have a right of withdrawal. As a result of this indication the webshop can no longer suffice with the announcement that some products are excepted from this, thus leaving the judgement about the applicability of the exception to the consumer. So the webshop will have to state expressly, clearly and comprehensively for each product that the purchase does not enjoy a right of withdrawal.

Suppliers possibly attempt to obtain more certainty about the non-withdrawability by giving the lid a seal. Assuming that a broken seal means that the jar has been opened, the broken seal means a considerable limitation of the shelf life. Also, the supplier can maybe invoke the exception to the withdrawability for reasons of hygiene or health protection.

\subsubsection{Legal effects of the withdrawal}

As the withdrawal is closest to termination, it is obvious to assume that the withdrawal does not have retroactive effect, just like termination. As the legal effects of the withdrawal are all established, the question about the retroactivity seems somewhat academic. Yet the question is of some importance, including for trading practices.

According to Dutch law, vendors acquire the ownership of the items supplied to them only if the act of delivery takes place on the basis of a valid title ${ }^{107}$. If withdrawal were to have retroactive effect, the legal fiction would apply that a valid title never existed. So the ownership was then never transferred. If there is no retroactive effect, the title is not violated. The ownership is then transferred and the obligation to 'return' comes into being. The difference arises in the case of

\footnotetext{
${ }^{106}$ Consumer Rights Directive Article 6 (1k).

${ }^{107}$ Article 3:84 (1).
} 
bankruptcy of the consumer. If the receiver carries out the withdrawal, the product does not become part of the bankrupt's estate in the first case and does become part of the bankrupt's estate in the second case. The trader will not be able to revindicate, if the product is part of the bankrupt's estate, although their refund obligation remains. On the basis of Article 13(3) of the Consumer Rights Directive ${ }^{108}$ the consumer may also suspend their payment obligation until they have received the goods.

Articles 13 and 14 of the Consumer Rights Directive regulate the obligations that arise repeatedly as a result of the exercise of the right of withdrawal.

The webshop reimburses all the payments received from the consumer, including, where applicable, the delivery costs, at the latest within 14 days of the date on which the withdrawal right is exercised. The consumer pays the costs of retuning the items, if the webshop made them aware of the obligation before purchase.

\subsection{THE FOOD INFORMATION REGULATION}

\subsubsection{Introduction}

The Consumer Rights Directive provides broad instructions relating to the obligation to describe the product. Only the main characteristics of the product have to be presented in a clear, comprehensible manner. The European legislator has not sought the solution to the lack of opportunities for viewing the goods properly before purchase in a far-reaching provision of information about the product. Rather it has opted for the right of withdrawal. So the product can be evaluated, perhaps even more intensively than in a physical shop, before being bound to the contract. Now we have seen that precisely in the case of food the right of withdrawal regularly has exceptions. So the possibility arises that consumers cannot evaluate the product properly before purchase and can no longer affect the contract after purchase.

As of 13 December 2014 this information gap has been closed. On this date the Food Information for Consumers Regulation ${ }^{109}$ came into force. The regulation will have immediate effect and will therefore not have to be implemented in the law of the member states.

The consequences for companies in the food sector are considerable. The consequences for food webshops are huge. Below we attempt to provide an initial picture of the legal context into which food webshops will be placed by the new Food Information for Consumers Regulation.

\footnotetext{
${ }^{108}$ Consumer Rights Directive article 13 (3) Unless the trader has offered to collect the goods himself, with regard to sales contracts, the trader may withhold the reimbursement until he has received the goods back, or until the consumer has supplied evidence of having sent back the goods, whichever is the earliest.

${ }^{109}$ Regulation (EU) No 1169/2011 of the European Parliament and of the Council of 25 October 2011on the provision of food information to consumers, amending Regulation (EC) No 1924/2006 and (EC) No 1925/2006 of the European Parliament and of the Council and repealing Directive 87/250/EEC, Council Directive 90/496/EEC, Council Directive 1999/10/EC, Directive 2000/13/EC of the European Parliament and of the Council, Commission Directives 2002/67/EC and 2008/5/EC of the Commission and Regulation (EG) No $608 / 2004$
} 


\subsubsection{The Food Information Regulation and the responsible operator}

The Food Information Regulation obliges operators of food companies to make detailed information available. For the definition of 'food business' the regulation refers to Regulation (EC) no. 178/2002 Article $3(2)^{110}$.

According to Article 8(1) of the Food Information Regulation ${ }^{111}$ it is not the food business that is responsible for the provision of accurate food information but rather 'the operator of the food business under whose name or trade name the food is traded'. So a distinction is drawn between 'the food business' and 'the operator of the food business'.

For the definition of this operator the Food Regulation also refers to Regulation (EC) no. $178 / 2002^{112}$. The food business operator is denoted as a natural or legal person who 1) manages the food business and 2 ) is responsible for compliance with the food legislation.

The unworkable distinction according to Dutch law between the food business (the company) and its operator (the company management) seems to indicate a kind of liability by managers regarding compliance with food legislation and to exclude the company itself from liability. This liability seems even further enhanced by paragraph 5 .

The Food Information for Consumers Regulation could have injected clarity by not referring to the definition from Regulation (EC) no. 178/2002 but rather by providing a definition itself. Instead, it opted to fit in with the definition and to further clarify an element of this: responsible for. After all, Article 8(1) lays the responsibility for compliance with food legislation with the operator under whose name or trade name the food is traded. ${ }^{113}$

So it is not the food business that bears responsibility for compliance with the regulations referred to, nor is it the operator of that food business (as may be the case in a civil law sense), but it is the operator of the food business that has associated its name with the food ${ }^{114}$.

Recital 15 of the Food Information for Consumers Regulation indicates how the Union regulations 'should' apply ${ }^{115}$. Several examples make it clear that the sporadic, non-commercial processing or sale of food by private individuals should not be subject to the Union regulations. The recital uses the word 'undertaking' not the term 'food business' or 'operator'.

\footnotetext{
${ }^{110}$ Regulation (EG) no. 178/2002, article 3 (2): 'food business' means any undertaking, whether for profit or not and whether public or private, carrying out any of the activities related to any stage of production, processing and distribution of food.

${ }^{111}$ Food Information for Consumers Regulation article 8 (1): The food business operator responsible for the food information shall be the operator under whose name or business name the food is marketed, or, if the operator is not established in the Union, the importer into the Union market.

${ }^{112}$ Regulation (EG) no. 178/2002, article 3 (3): 'food business operators' means the natural or legal persons responsible for ensuring that the requirements of food law are met within the food business under their control.

${ }^{113}$ On the food legal concept of responsibility, see: B.M.J. van der Meulen, Responsibility in EU food law, in: Paul Verbruggen and Tetty Havinga (eds.) Hybridization of Food Governance. Trends, Types and Results, Edward Elgar 2017, p. 121-136.

114 'The importer' is also responsible if the operator is not based in the Union.

${ }^{115}$ Recital 15 of the Food Information for Consumers Regulation: Union rules should apply only to undertakings, the concept of which implies a certain continuity of activities and a certain degree of organisation. Operations such as the occasional handling and delivery of food, the serving of meals and the selling of food by private persons, for example at charity events or at local community fairs and meetings, should not fall within the scope of this Regulation.
} 
So the recital does not shed any light on the person of the party responsible for compliance with the regulation. Other recitals do so even less.

The question arises as to whether the webshop, the distance vendor, is a food business or an operator of the food business or the 'the operator responsible for the food information of a food business under whose name or trade name the food is traded'. And if the latter is the case, does the responsibility concern the availability of the information or also its accuracy?

Whether a webshop, whatever its legal form, can be held to account as 'the responsible operator' therefore depends on whether the food to be marketed bears its name or trade name. The large variety of webshops means that an equally large variety of answers can be given to this question. In a general sense it can be stated that webshops that sell their own products are possibly both food businesses and the responsible operator of these, while webshops that sell branded items by a different proprietor escape this responsibility.

However, the radical character of the Food Regulation does not consist of the above-mentioned allocation of responsibilities. The radical changes for the practices of webshops are presented in an almost casual manner in recital $27^{116}$. The recital states that all the obligations relating to food information naturally also apply to food that is sold via webshops and that this information has to be available before the purchase takes place. The word 'before' has far-reaching consequences not only for the design of webshops but also for the legal relationships in the chain.

\subsubsection{The webshop's obligation to provide food information}

As Article 14 mandates that the information relating to prepacked food be available before purchase, the webshop cannot do anything other than present all the compulsory product information digitally too. In theory the second full sentence of Article 14(1)(a) makes it possible for the information 'to be issued via other suitable, clear means indicated by the operator of the food business'. However, the obligation that the information has to be available before purchase means that information transfer other than via the same website is not really conceivable. Because Article 14 of the Food Information for Consumers Regulation so mandates, the webshop is itself responsible for the availability - and accuracy - of the food information. A responsibility that arises not because this operator links its name or trade name to the food but because they provide the food in a distance contract.

In Article 14 one obligation is excepted from mention if it involves a distance sale: the indication of the date of the minimum durability or use-by date (Article $9(1)(f)$ ). The exception is of a practical nature. After all, in a food webshop the item that is actually sold is seldom shown. Illustrations are shown of an example. A purchaser may expect the recipe and preparation that are presented and suggested. However, the shelf life deadline and the latest use-by date that are linked to the production or packaging date will change so regularly that the webshop cannot be expected to update the digital presentation equally regularly.

\footnotetext{
${ }^{116}$ Recital 27 of the Food Information for Consumers Regulation: In order to ensure the provision of food information, it is necessary to consider all ways of supplying food to consumers, including selling food by means of distance communication. Although it is clear that any food supplied through distance selling should meet the same information requirements as food sold in shops, it is necessary to clarify that in such cases the relevant mandatory food information should also be available before the purchase is concluded.
} 
In the case of non-prepacked food that is delivered following a telephone or digital order only those mentions are obligatory that are referred to in Article $9(1)(c)^{117}$. For the time being pizzerias, etc. that provide their customers with a delivery service are exempt from the extensive obligation to provide information. The exception that relates to non-prepacked food has been generally accepted if there is no packaging for the information to be shown on. However, in the case of the sale of nonprepacked food via webshops the information carrier is not the packaging but the digital shop window. So all food information can in fact be made available, unless consumers can exercise some influence on the composition when ordering. For the time being this possibility has not prompted the legislator to extend the obligation to provide information regarding non-packaged food that is sold via a webshop.

\subsubsection{The presentation of the food information}

Article 13 of the Food Information for Consumers Regulation prescribes, with reference to an Annex IV, the way in which the food information has to be presented on the product. This Article does not apply to the compulsory information that the distance food vendor has to make available. Article 14 mandates only the availability of the compulsory information. There are conceivably two presentation modes.

1) the product can be 'zoomed in on' from all sides

If all the compulsory information is attached to the product and the product can be 'zoomed in on' from all sides in such a way that it is possible read all the information, this probably complies with the obligation to provide information as set out in Article 14 of the Food Information for Consumers Regulation.

2) the information is presented with the product

The obligation to provide information can be complied with by presenting the compulsory information with the product. For the sake of the attractiveness of the website the option can be chosen to present the information when the product is clicked on.

\subsubsection{The last link in the chain}

Both forms of presentation require greater technical effort from webshops than was required previously. In by far the most cases the obligatory information will come from predecessors in the

\footnotetext{
${ }^{117}$ Article 14(2) of the Food Information for Consumers Regulation refers to Article 9(1)(c). 'any ingredient or processing aid listed in Annex II or derived from a substance or product listed in Annex II causing allergies or intolerances used in the manufacture or preparation of a food and still present in the finished product, even if in an altered form:'.
} 
chain. With the new information obligation for distance vendors webshops are dependent on predecessors in the chain not just as regards the provision of information itself but also as regards the digital presentation of this.

In the market there are data pools in which producers store the compulsory details about their products. Only the parties designated by these producers have access to these details. Online retail did not need access to these details as long as the products on offer were already prepacked. After all, the details are shown on the packaging. Because of the Food Information for Consumers Regulation webshops will need to obtain access to these data pools or to digital information for each product so that they can comply with their obligation to provide information.

In the chain the proprietors and the major producers acquired a much greater influence on the presentation of the products a result of this dependence. Also, it is not inconceivable that the increased dependence may involve extra pressure on the margins. After all, the products form not just the commodity but also the presentation.

\subsection{CONCLUSIONS}

Since 2014 food webshops face a very large number of regulations. These stipulations focus on both the content of distance contracts and the presentation.

As regards content the right of withdrawal has the most drastic effect on the autonomy of the parties. If distance vendors do not realise in good time what regulations they need to comply with in this regard, they may be faced with unexpected and drastic legal actions by their purchasers.

More radical are European regulations regarding the presentation of the webshop and the presentation of the food. All things considered, with just one stipulation a very detailed set of obligations to provide information has suddenly been declared to apply to distance vendors.

As a result of these new obligations in the field of product information webshops have to form a lot more partnerships with predecessors in the chain in order to make the right information available and presentable. The market will indicate how this new dependency relationship will take shape in the relationships in the chain.

A regular check ${ }^{118}$ at the webshops shows that the distance contracts have virtually all been concluded in shops that as a whole do not comply with the regulations discussed. Both in front of and behind the counter the realisation does not seem to have dawned that Europe is intervening massively in the digital shop window.

\footnotetext{
${ }^{118}$ For three years 60 students from Windesheim University of Applied Sciences in Zwolle checked all existing food webshops for compliance.
} 


\section{PRODUCT LIABILITY FOR ONLINE FOOD SUPPLIERS ${ }^{119}$}

\subsection{INTRODUCTION}

On a global scale there is an inevitable and drastic shift of activities taking place from the physical world to the virtual world. As the Internet has become available to large groups of people, this has provided a rapid means of communication suitable for social and commercial interaction between anybody online.

Such is the position that the Internet has acquired in trade relations that it is now impossible to image these relations being carried out without the Internet. All along the digital highway there are chains and hubs of parties forming that operate in all sectors, and transactions are taking place without the parties or their representatives ever having met each other physically.

In the food sector too the Internet has become very important. Parties that are involved in the production and trade of food establish contact with each other and maintain commercial relations via the digital highway. This is just as true for the last link in the digital food chain; after all, there are now an infinite number of web shops that supply food, from major supermarkets to the tiniest caterer.

This Chapter looks at the product liability of online food suppliers.

Product liability is a topic that manufacturers and importers feel very strongly about. However, there is a lot less interest among retailers and consumers in the possibility of basing claims on the European Directive of $1985^{120}$ or the implementing Dutch legislation ${ }^{121}$. The rules and requirements are of less importance in practice.

This notion prompts Faure in his article dated February $2004^{122}$ to state in a section entitled 'Much ado about nothing?':

'European law relating to product liability probably provides the best example of a legal area where the major importance that is attached to it in the legal literature and at policy and political level is in stark contrast to the importance of this topic in practice.'

If Faure was referring to the small number of lawsuits where the claim is based on product liability, he was right in 2004, and in 2017 he could repeat the statement with impunity. However, the merits of the requirements in practice should rather be sought in the extent to which they encourage producers and importers not to market any defective products. The effect is, or so one can presume,

\footnotetext{
${ }^{119}$ An earlier version of this chapter has been published as Lomme van der Veer, Product Liability for Online Food Suppliers, European Food and Feed Law Review, 2015, p. 286-303.

${ }^{120}$ Council Directive 85/374/EEC of July 1985 on the approximation of laws, regulations and administrative provisions of the Member States concerning liability for defective products.

${ }^{121}$ Article 6:185 - 6:193 of the Dutch Civil Code.

${ }^{122}$ M.G. Faure 'Product Liability in Europe: critical reflections on law and economics,' AV\&S 2004, 2.
} 
more preventive than corrective. After all, the fear of huge claims is a very strong stimulus to manufacturers to market products that are sufficiently safe.

This Chapter examines the question as to whether the digitisation of the food chains means that food product liability needs to be looked at again, more closely. Special attention should be devoted to the possibility that legal and actual shifts in liability risks could take place upwards or downwards in the food chain as a result of digitisation. After all, for the preventive effects of liability regarding safetyrelated defects in products to work, all the potentially liable parties have to be aware of this risk.

\subsection{PRODUCT LIABILITY}

\subsubsection{Directive and national legislation}

Interest in the issue of product liability arose in The Netherlands in the $1960 \mathrm{~s}$ as a result of several high-profile cases such as the Planta scandal and the thalidomide affair.

Around 1960 over 100,000 people in The Netherlands suffered from swine vesicular disease, a rash that was similar to hives and that was followed by fever. The illness was attributed to an 'anti-spatter emulsifier ME 18' that was added by manufacturer Unilever to its Planta brand margarine. In 1962 the affair was investigated by a parliamentary committee led by Dr. W. Drees. Unilever paid out a total of 1,250,000 guilders in compensation for pain and suffering to over 8,000 people without admitting liability. The Planta brand was replaced by Brio. In 2001 the name Brio was changed to Bertolli.

The thalidomide affair occurred when, following the introduction of thalidomide on the market on 1 October 1957, in 1960 thalidomide became popular in around 40 countries as a sleeping tablet and as an anti-nausea drug. In The Netherlands the drug was known under the brand name 'Softenon'. The substance was teratogenic. Many children of women who took the drug during the early stages of their pregnancy suffered missing or underdeveloped limbs. By the time the drug was taken off the market in 1961, almost 10,000 children had been born with a disability.

This generated interest in product liability in the USA too, where incidentally thalidomide was not authorised because there was lack of evidence concerning its safety. This interest had since resulted in regulations.

The scandals and doctrine that developed in the USA prompted the designers of the New Dutch Civil Code to develop legislation that made it easier to hold manufacturers liable for safety-related defects in their products.

In the USA and Europe, and therefore also in The Netherlands, there was a realisation that parties that had suffered harm as a result of products with a safety-related defect should be given a stronger position with regard to manufacturers, who are a lot more powerful in the legal sense. In addition, consumers by definition have less knowledge about the product compared with manufacturers.

Legislators sought to improve the consumers' position by changing the way in which the burden of proof was apportioned. After all, in practice an injured party had huge problems collecting evidence to substantiate their statement that the manufacturer was liable. The problem of providing evidence of manufacturers' guilt was in particular a insurmountable one. After all, injured parties have no 
insight into the way in which the production process was set up and what raw materials and semi manufactured products were used. Often it is not possible to demonstrate whether the manufacturer could have avoided the occurrence of the safety-related defect.

In case law too there was a realisation of the difficult position of the injured party with regard to proof. According to Dutch law a judge has the authority to decide on a different apportionment of the burden of proof if - in terms of current law ${ }^{123}$ - this would be the result of the requirements of reasonableness and fairness. Dutch case law did not fully and generally reverse the burden of proof in the then Article 1401 of the Dutch Civil Code (on torts). But the judge was able to reinforce the position of the plaintiff by considerably objectifying the requirement for fault in the case of safetyrelated defects. This meant that the defendant could be allowed to prove the absence of fault. The presumption of liability was, depending on the nature of the defect, assumed, with a varying number of requirements attached to the proof of the opposite. The Supreme Court's Leaking Hot Water Bottle ruling of $1973^{124}$, followed by the Amsterdam Court in $1974,{ }^{125}$ is often regarded in the literature ${ }^{126}$ as a tipping point for this notion. In the ruling referred to the Supreme Court ruled that manufacturers have a serious duty of care. Manufacturers have to market products that are safe. They have to take into account the possibility that users of their products will not always take every precaution. If a danger manifests itself, the manufacturer has to demonstrate that they met this considerable duty of care.

At the time a new Civil Code was being prepared. The most important parts came into force in 1992. The original draft of Book 6 of this new Civil Code included an Article that aimed to overcome the objections relating to the burden of proof of injured parties set out in the then Article 1401 of the old Dutch Civil Code by means of a system that included both elements of fault-based liability and elements of strict (no-fault) liability.

In accordance with this Article 6.3.13 (draft) of the New Dutch Civil Code the party that puts a defective product into circulation is liable for damage suffered as a result of this, even if they were unaware of the defect; they can be absolved of their liability only if they demonstrate that the defect cannot be attributed to an error made by them or by a person employed by them, nor to the failure of tools used by them.

This draft was revoked because of the fact that international regulations were being developed to which the Dutch legislator would have to conform at some point.

In 1976 the European Convention on Product Liability in regard to Personal Injury and Death was drawn up within the framework of the Council of Europe. However, the convention was never ratified because in the same year the Commission of the European Communities submitted a proposal for a Directive on product liability to the Council of the European Economic Community. The proposal corresponded for the most part with the convention.

On 25 July 1985 the Directive was agreed by the Council of the European Communities. The aims of the Directive were to both expand the targeted consumer protection and to combat any distortion of competition or impairment of the free movement of goods by harmonising the legislation of the Member States.

\footnotetext{
${ }^{123}$ Article 3:12 Civil Code.

${ }^{124}$ HR 32 February 1973, NJ 1973, 315.

125 District Court of Amsterdam 1 March 1974, NJ 1974, 486.

${ }^{126}$ See for example J. Knottebelt, Hoofdstukken produktaansprakelijkheid. Zwolle: Tjeenk Willink 1991.
} 
The Directive had to be implemented in the legislation of the Member States by 30 July 1988 at the latest. The Netherlands did not manage to do this in time. Not until 1990 did the Articles 1407a 1407i come into force. In the New Dutch Civil Code the Articles 6:185 - 6:193 formed the Dutch doctrine relating to product liability. France was the last country. The French legislator did not bring the national legislation into line with the Directive until 1998.

The injured party of Article 6:185 of the Dutch Civil Code has an easier task than the injured party who suffers harm as a result of an unlawful act (tort) that cannot be attributed to product liability. Whereas an injured party who invokes Article 6:162 of the Dutch Civil Code (on torts) has to prove unlawful conduct that can be attributed to the party that caused the damage, as well as proving damage, a causal link and relativity, ${ }^{127}$ the injured party of Article 6:185 (on product liability) has to prove only damage, defect and causality. The position of the injured party is facilitated in particular as there is no condition that states that they have to prove that there was unlawful conduct that can be attributed to the other party. After all, the statement of attribution can be contested with the defence of the absence of fault. If fault, in terms of 'culpability', is lacking, the defence will succeed if it can also be successfully argued that neither the law nor the prevailing opinion nevertheless provide a reason for attributing unlawful conduct to the party that caused the damage. Such a defence is not available to the producer in Article 6:185 of the Dutch Civil Code.

\subsubsection{The manufacturer}

The manufacturer to be held liable in terms of Article 6:187(2) of the Dutch Civil Code and the Directive referred to is the manufacturer of the end product, the manufacturer of a raw material or the manufacturer of a part, ${ }^{128}$ as well an anybody who presents themselves as a manufacturer by attaching their name, trademark or other distinguishing feature to the product. The party that imports the product into the EU as part of commercial activities can be held to account as a manufacturer. If it cannot be ascertained who the manufacturer or importer is, the supplier can be held to account as if they were the manufacturer, unless they identify the manufacturer or importer. The parties that are liable as manufacturers can each be held to account for the whole of the damage. They are thus jointly and severally liable.

\subsubsection{The damage}

Article 9 of the Directive, Article 6:190 of the Dutch Civil Code, states that the damage as referred to in product liability can consist of damage in the sense of death or bodily injury and damage caused by the product to another item that is usually used or consumed in private life, with the application of an franchise in the amount of $€ 500$.

It appears that the provision relating to the franchise is subject to different interpretations ${ }^{129}$ in the Member States. In most of the Member States, including Denmark, Germany, Finland, Italy and Austria, the franchise is treated as a 'deductible': it is deducted from the amount of damages

\footnotetext{
${ }^{127}$ I.e. the legal rule that was infringed upon intended to prevent damage of the type suffered by the plaintiff.

${ }^{128}$ This concept of 'part' in all likelihood includes 'ingredients' in case the product is a food.

${ }^{129}$ Product liability in the European Union, a report for the European Commission, Study by the European Commission, March/2001/11/D.
} 
awarded to a successful plaintiff. In some other Member States, such as The Netherlands and the UK, the franchise is treated as a minimum amount: if the claim exceeds the franchise, the full amount of damages can be recovered. In Spain the franchise is described as a deductible amount in the transposal legislation, but in practice the courts treat it as a threshold, the result of this being that the franchise has in practice never been deducted from any compensation.

\subsubsection{The defect}

The defect consists of the fact that the product does not provide the safety that can be expected from it, taking all circumstances into consideration. The presentation of the product and the use to which it might reasonably be expected to be put are in particular taken into consideration.

\subsubsection{Disculpation}

Although manufacturers can therefore not invoke the general absence of 'culpability', they can call on several disculpation possibilities. Both Article 6:185 CC and the Directive referred to provide manufacturers with the following possible defences:

- they did not put the product into circulation;

- given the circumstances it is likely that the defect that caused the damage did not exist at the time at which they put the product into circulation, or that the defect occurred at a later date;

- the product was manufactured by the manufacturer neither for sale nor for any other form of distribution with an economic aim, nor was it manufactured or distributed as part of the implementation of their profession or business;

- $\quad$ the defect is the result of the fact that the product complies with mandatory government regulations;

- it was impossible, on the basis of the state of scientific and technical knowledge at the time at which the product was put into circulation, to discover the existence of the defect;

- as far as the manufacturer of a raw material or a manufacturer of a part is concerned, the defect can be attributed to the design of the product of which the raw material or the part forms part, or to the instructions issued by the manufacturer of the product;

- the damage can be fully or partly attributed to the behaviour of the injured party or of people for whom the injured party is liable.

\subsubsection{Liability}

Article 15(1)(b) of the Directive envisages the possibility that the Member States may determine in their national legislation that manufacturers are also liable for defects of the existence of which they 
could not have been aware given the state of scientific knowledge and technical knowledge at the time at which they put the product into circulation. In such cases the development risk is attributed to the manufacturer. The Dutch legislator has not opted for this.

Pursuant to Article 8 of the Directive the liability of the producer cannot be reduced if the damage is caused both by a defect in the product and by the actions of a third party. The liability can however be reduced or even waived if the damage occurred as a result of a defect in the product as well as as a result of culpable actions by the injured party and those people for whom the injured party is responsible. Judges who have to make a decision regarding the extent of the attributable damage consider all the circumstances in this regard. The Dutch legislator has set out the several liability referred to above in Article 6:189 of the Dutch Civil Code. Mitigation on the basis of 'own fault' is set out in Article 6:185 (2) of the Dutch Civil Code.

\subsubsection{Statute of limitations}

Articles 10 and 11 of the Directive, Art. 6:191 of the Dutch Civil Code, provide for a statute of limitations of three years to be calculated from the date on which the injured party is aware of, or at least should have been aware of, the defect, the identity of the manufacturer and the damage. The liability of the manufacturer lapses in any case ten years after the manufacturer has put the defective product into circulation.

\subsubsection{Mandatory nature}

Article 12 of the Directive, Art. 6:192 of the Dutch Civil Code, establishes the mandatory nature of the provisions. Liability cannot be limited or excluded with regard to the injured party.

\subsubsection{Relationship with the law}

Article 13 of the Directive, Art. 6:193 of the Dutch Civil Code, stipulates that the product liability regulation does not replace existing provisions that can be invoked by an injured party. All the contract-law provisions that provide for the possibility of claiming damages and invoking other rights remain in force.

\subsection{PRODUCT LIABILITY FOR FOOD}

Neither the national nor the European legislator has taken special measures regarding damage caused by defective food. This raises the question as to whether the product liability regulation applies in full - and can be applied - to food law. 
In an article written in 1988, the year in which the Dutch legislator should have introduced Directive $85 / 374$, Hummels, Hondius and Snijders ${ }^{130}$ wrote about the consequences of the implementation of the Directive for food law. Hummels et al. stated, in anticipation of the introduction of the Directive into national legislation, that it was very important for Dutch food law as it stood at that time, that agricultural products could in principle not give rise to product liability pursuant to Article 1407a ff of the (old) Dutch Civil Code. The Directive provided that agricultural products come under the regime of the provision only after they have undergone primary treatment or processing. So not all food should be regarded as a 'product' in the meaning of this provision, which means that the damage caused by one food will be controlled by a different liability regime to the damage caused by a different food.

So the question was: where is the boundary; what food is regarded as a product and what is not? A definition of the concept 'primary treatment or processing' was missing in both the Directive and the Dutch bill. The explanatory memorandum to the bill argues that the Dutch legislator did not dare to establish a definition as the meaning of the terms had to be ultimately decided on by the European Court alone.

Hummels et al. judged that the concept 'treatment or processing' meant an action that is carried out following slaughter, milking or harvest. The effect of spraying in the field will not be that the sprayed crop becomes a product (in the sense of product liability). Otherwise it would, after all, be impossible to designate a product that was excluded from product liability as all agricultural products undergo some treatment before slaughter, milking or harvest.

The preamble, generally intended to contribute to the understanding of that which follows, provided no clarity. The preamble to the Directive does not speak of primary treatment or processing but rather of industrial treatment or processing that can result in a defect in the product. If the preamble is pursued, Hummels et al. argued, then shrimps that were peeled by domestic peelers at the kitchen table would not be covered by product liability and shrimps peeled industrially would. ${ }^{131}$

Hummels et al. posed several questions: to what extent can actions such as washing, cutting, drying, blanching, heating, cooling, irradiating, freezing and packaging or actions involving a germ inhibitor be regarded in themselves as primary or industrial treatment or processing?

The formulation in the preamble 'that can result in a defect in the products' is also confusing. Whereas the Directive suggests that any primary treatment or processing turns agricultural raw material into a product, the preamble gives the impression that treatment or processing turns an agricultural raw material into a product - in the sense of product liability - only if this treatment can result in a defect. ${ }^{132}$

Such a condition is problematic, as treatment or processing can be harmless but also extremely unsafe. For example, the cooling or freezing of food in general will be a harmless treatment. But if a nitrite solution gets into the goods to be cooled, as happened in the IGLO case in 1980, the same

\footnotetext{
${ }^{130}$ Hummels, Hondius, Snijders, Food and Product Liability, VMT, 22 December (1988) no. 26.

${ }^{131}$ The choice if this example is significant. The practice of 'home peeling' shrimps was widespread at the time and was known to be hazardous. In 1984 fourteen elderly people died as a consequence of consuming contaminated shrimps that had been 'home peeled'. After a lengthy political discussion, the practice was prohibited from 1 July 1990 onwards. See: https://www.nrc.nl/nieuws/1990/06/29/thuispellen-garnalendefinitief-verboden-6934097-a1221976.

${ }^{132}$ After all, in the case of food much processing is intended to reduce health risks (and thus to extend shelf life). Would such processing have been within the scope in case the intended result of reduction of risk was not sufficiently achieved, or only if a new hazard was introduced?
} 
treatment is very unsafe. ${ }^{133}$ If the objective of the formulation of the preamble is for correct cooling not be regarded as a treatment that results in the qualification 'product' in the sense of product liability, but for incorrect cooling to indeed be regarded as this, then the liability is hardly of a qualitative nature.

Yet the criterion is applied. The Hamm Oberlandesgericht (Higher Regional Court in Germany) ruled in 1972 that the producer of flower pots made from peat whereby it was ascertained that the peat displayed a safety-related defect was not liable as the turf had in fact undergone several treatments but that this 'treatment of the peat was limited (...) to purely mechanical processes which do not give rise to obvious sources of danger ${ }^{134}$.

It was not just the formulation of the exception of agricultural raw materials that raised questions; it was also the reasons. The preamble does not provide any justifications for the exception. According to Article 15(1)(a) of the Directive the Member States have the freedom not to include the exception in their national regulations. Greece, France, Luxemburg, Finland and Sweden decided to include the products referred to under the terms of the product liability. They did not include the exception. The Netherlands did include the exception, despite recommendations to the contrary by the SER (Social and Economic Council) $)^{135}$.

The SER's recommendations include several arguments in favour of the exception then conclude that these arguments do not outweigh arguments against the exception.

According to the SER, the distinction between treated and untreated products is becoming increasingly difficult to apply. There are only very few natural products that have not undergone some form of processing before they are supplied. A clearer distinction is that between unprocessed and processed products. In the case of the latter these are in particular products that are obtained through the processing in a factory of potatoes, cereals, meat, fish, fruit and vegetables, etc. If these products are traded in their original forms, they are unprocessed. In the case of such unprocessed products, particularly potatoes, fruit and vegetables and - to a lesser extent - meat and fish, it will often be difficult to trace where the product originated, as batches are mixed during distribution via intermediary trading. The draft Directive overcomes this difficulty - according to the SER - by deciding, if the manufacturer cannot be determined, that every supplier of the product is treated as a manufacturer, unless the supplier immediately provides the identity of their 'predecessor'. The SER recognises that this will possibly result in a situation in which not just the actual producers but also the various intermediate links will insure themselves against product liability. This insurance will push up costs.

The fact that the government is intensively monitoring the application of quality regulations precisely for agricultural, horticultural and fishery products could argue in favour of these products being made exceptions to the regulations regarding product liability. After all, compliance with these regulations will to a large extent prevent the trading of defective, unsafe products.

The SER also refers to the fact that it is precisely farmers, horticulturists and fishermen who put products into circulation that may have a safety-related defect as a result of the contamination of air, water or soil that they did not cause.

\footnotetext{
${ }^{133}$ At the time, two victims died. See: http://www.gahetna.nl/actueel/nieuws/2015/affaire-om-kriebels-tekrijgen.

${ }^{134}$ OLG Hamm, 23 October 1972, Agrarrecht 1973, pp 51-53 with note by Friedhelm Kieserling.

${ }^{135}$ Recommendations relating to Product Liability issued by the Minister of Justice, Publication no. $4-18$ January 1980.
} 
The SER, taking the above arguments into consideration, nevertheless arrives at the conclusion that an exception for this category of products cannot be justified. The SER argues, when discussing its own arguments in favour of the exception:

'First of all the question of double insurance as an additional cost factor does not play a greater role here than in the case of other raw materials, as the companies in this sector already tend to conclude liability insurance, just as much as other production and trading companies. Information from the insurance sector has shown that no problems are expected regarding the introduction of strict liability for producers and traders of unprocessed products with regard to insurability.

It can also be noted that, with regard to the strict liability, an exception for defects that result from environmental influences (contamination as a result of waste discharges, etc.) would be in conflict with the system of the draft Directive, which does not recognise the fault of third parties as a reason for disculpation. It should also be noted that acceptance of strict liability does not prevent the party held liable from seeking redress from the party that actually caused the defect (for example, the waste-discharging factory).

As regards government checks on compliance with the existing quality regulations it should be pointed out that such checks - whether or not they are carried out randomly - cannot guarantee that no defective products will ever reach consumers, so a system of no-fault liability is of sound benefit for consumers, including for such products that are checked. The Council [=SER] does not consider that in these cases a reduced manufacturer liability would be in keeping with the liability system chosen for the draft Directive simply because of the fact that the government too would take on a certain liability for the soundness of the products concerned by virtue of the check carried out.'

The SER, referring to itself as 'the Council' stresses that a large minority of the Council is against the recommendation in as much as it concerns the rejection of the exception, because - so runs the argument of that part of the Council - the agricultural, horticultural and fishery products in their unprocessed state do not undergo any industrial production method, whereas it is precisely the developments relating to this production method that are the reason for the EU proposing an amendment to the system regarding product liability. They also argue that the recital does not hold true that the manufacturer can easily include their product liability costs in their sales prices and thus spread these over consumers.

The discussion about the desirability of the exception at the level of the Member States was ultimately settled by the EU with Directive $1999 / 34 / \mathrm{EC}^{136}$, which obliged all the Member States to add these agricultural products to the products to which product liability applies with effect from 4 December 2000.

In publications by the EU itself ${ }^{137}$ the rapid introduction of the extension was attributed to the then known problems surrounding the outbreak of the BSE epidemic (bovine spongiform encephalopathy / mad cow disease).

BSE is a disease in cattle that was first found in Great Britain in 1985. The cause is probably an abnormally deformed protein that infects the central nervous system. This causes uncoordinated

\footnotetext{
${ }^{136}$ Directive 1999/34/EC of the European Parliament and the Council of 10 May 1999 amending Council Directive 85/374/EEC on the approximation of the laws, regulations and administrative provisions of the Member States concerning liability for defective products.

${ }^{137}$ http://europa.eu/scadplus/leg/en/lvb/132012.htm.
} 
spastic movements and affects memory. The cattle behave strangely, hence the name. The probable cause of the BSE outbreak is that the cattle were fed meat-and-bone meal.

Creutzfeldt-Jacob's disease is an incurable neurological disease that occurs in humans. It belongs to the group of human spongiform encephalopathies. There is a classic variant and a new variant. The classic variant probably has no link with BSE or with the consumption of a certain food. This is not the case with the new variant discovered in 1995. There are strong indications that the consumption of certain products from BSE-infected cattle such as brains, spinal cord and intestines causes this variant. $^{138}$

\subsubsection{Green Paper}

In accordance with Article 21 of the Directive the Commission has to assess the efficiency of the legislative framework relating to product liability. The first report ${ }^{139}$ was presented in 1995.

According to this report most Member States had taken measures to implement the Directive in their legislation. However, the consequences were still limited.

In anticipation of the second report ${ }^{140}$ the Commission published a Green Paper $^{141}$. Although the Green Paper covers the general working of the Directive, with regard to Directive 1999/34/EC and the BSE problem special attention is devoted to product liability relating to food.

The Commission has this to say on this point:

'The objective of this Green Paper is to prepare for the report on the implementation of the Directive that is scheduled for the end of 2000. More so than the first report in 1995 (published in a period that had little experience with the application) this Green Paper will look at the implementation during the period in which policy was characterised by concern for the protection of health and safety of people following mad cow disease.'

In the first report the Commission concluded that the lessons that can be learned from the implementation were still limited. In 1995 the Member States had only a little experience with the workings of the legislation in practice. In the light of the available information the Commission judged then that there was no reason to suggest amendments. In 1999, following mad cow disease and the extension of the applicable products to include primary agricultural products, the situation was completely different.

The purpose of the Green Paper is twofold. On the one hand the Commission invites manufacturers and consumers to share with the Commission their experiences with the Directive in practice so that

\footnotetext{
${ }^{138}$ See for example the publication of the Food Standards Agency at https://www.food.gov.uk.

${ }^{139} \mathrm{COM}(1995) 617$ Application of Council Directive on the approximation of laws, regulations and administrative provisions of the Member States concerning liability for defective products (85/374/EEC).

${ }^{140} \operatorname{COM}(1999) 396$.

${ }^{141}$ Green Paper of the European Commission 'Liability for defective products' (28 July 1999).
} 
an opinion can be formed on the question as to whether the Directive is achieving its aims. On the other hand the Commission wants to use the parties' practical experience to ascertain what they think about possible amendments to the Directive.

With regard to the requested information the Commission is looking at the question as to whether the Directive provides adequate protection for injured parties, whether it discourages the marketing of dangerous products, whether it stimulates or threatens internal market forces, whether insurers have found a way of covering the risks associated with product liability, whether consumer organisations and authorities have found the Directive to be a useful instrument for achieving their objectives, etc.

With regard to the second aspect - whether it discourages the marketing of dangerous products the Commission wants to initiate an open discussion about possible amendments to the Directive, though without actually intending to draw up amendment proposals.

In her article 'Product Liability in the Food Sector ${ }^{142}$, Nicole Coutrelis looks at the invitation in the Green Paper. The author covers the relevant aspects of product liability for the food sector.

Coutrelis believes that several characteristics of the food sector are important for the applicability of product liability. A brief summary:

- The food sector is highly regulated. Comprehensive food-law regulations apply to composition, presentation, treatment and marketing.

- Consumers see a direct link between food and health and safety as well as with psychological and emotional factors.

- Damage resulting from the consumption of unsafe food can be serious and have major consequences for a lot of people but is more often limited to some physical discomfort without financial consequences.

- It is difficult to chart the consumption of food. The safety defect may have occurred with consumers at home as a result of incorrect or overlong storage. In addition, over a certain period the same person will have eaten not just the product with the safety-related defect but also a lot of other things.

- Food is often made up of a lot of different ingredients of different origins. Highly innovative industrial and (bio)technological processes exist alongside traditional products made by small manufacturers.

- A lot of food gets to consumers via chain stores. This retail plays a major role in the presentation and preservation of food. The chain stores often have their own brand names to distinguish the products.

Coutrelis relates the above characteristics to consumers' position regarding proof and manufacturers' disculpation possibilities within the possibilities set out in the Directive.

\footnotetext{
${ }^{142}$ Product Liability in the Food Sector, Nicole Coutrelis, http://ec.europa.eu/enterprise/regulations/goods/docs/liability/1999-greenpaper-replies/046.pdf.
} 
The fact that a manufacturer complies with all the applicable regulations, states Coutrelis, does not inevitably result in a waiver of liability. However, this can help manufacturers with the position that the product did not have any safety-related defect when it was put into circulation. If a manufacturer can demonstrate that their internal procedures meet the HACCP requirements as referred to in Directive $93 / 43^{143}$, this could in many cases lend support to their position that their product was not defective when they put it into circulation. Complying with the labelling requirements ${ }^{144}$ by displaying ingredients and use-by date can contribute to the position of the manufacturer that the product was not defective when it was put onto the market. The position will be possible that it became defective as a result of the passage of time (and spoilage). A provision that was intended to protect consumers thus ultimately provides manufacturers with an argument for shifting liability.

Some food, such as food additives, novel food and genetically modified food, is subject to authorisation before it can be put onto the market. Permission to market this food will be granted only if safety criteria to be adopted have been met. It is certain that if a product has a safety-related defect, liability cannot be shifted by the invocation of the authorisation referred to ${ }^{145}$. However, it is possible that support can be gained from the authorisation for the position that - in terms of Article 6:185 of the Dutch Civil Code section 1 - on the basis of the state of the scientific and technical knowledge at the time at which the product was put into circulation it was impossible to discover the existence of the defect (Coutrelis calls this 'the development risk defence'). Coutrelis adds that, if such a defence were not to succeed, the possibility exists of holding to account about the consequences the authority that wrongly allowed the product to be put into circulation. In terms of Dutch procedural law the EFSA could be joined in proceedings by the indicted manufacturer.

Coutrelis responds with reservation to the suggestions put forward in the Green Paper of presuming causality between the defect and the damage - the opposite of which has therefore to be proven by the manufacturer - as well as to the suggested possibility of presumption of defect.

For the presumption of a 'causal link' the main argument is the fact that consumers often consume a lot of different foods during the same period. So their position as regards proof is unfavourable with regard to causality. However, Coutrelis believes that this same fact likewise means that there is no certainty at all about the presumed relationship between damage and product, which justifies a burden of proof.

According to Coutrelis. the main objection to introducing the possibility of presuming the safetyrelated defect if the damage has occurred lies in the fact that food often has a limited shelf life and is regularly stored incorrectly or for too long, as a result of which the products, although initially safe, become toxic. Moreover, a product with no safety-related defect can become harmful as a result of the consumption of too great a quantity.

Taking everything into consideration Coutrelis arrives at the conclusion that all the major topics that are particularly important in the food sector are covered by the Directive as amended by the Directive 1999/34, as a result of which no special regulation relating to qualitative liability needs to be introduced for the food sector. However, she does add: 'However, in the day-to-day implementation of the principles laid down in the Directive, as well as upon examination of the

\footnotetext{
${ }^{143}$ Directive 93/43, 14 June 1993 OJ L 175/01, 19 July 1993, now Regulation 852/2004.

${ }^{144}$ The former Directive 79/112 has been replaced, first by Directive 2000/13 and now by Regulation $1169 / 2011$.

${ }^{145}$ The impossibility of exoneration on the basis of a permit is set out, for example, in Regulation 1829/2003, Article 7(7).
} 
questions raised by the Commission in its Green Paper, the specificity of the sector does require specific answers,' thus putting her own conclusion on edge.

Ultimately the reactions to the Green Paper did not result in proposed amendments. The Commission arrived at the conclusion that experience with the Directive was still too limited and the availability of data was too small. The Commission stated that in these circumstances it could not propose any amendment.

\subsection{PRODUCT LIABILITY OF OFFLINE SUPPLIERS FOR FOOD}

Suppliers who supply consumers do not belong to the circle of manufacturers who can be held liable for food with a safety-related defect on the basis of quality. However, these suppliers too can be held to account by an injured party if the manufacturer is 'untraceable'.

Article 3(3) of the Directive states:

If it cannot be ascertained who the manufacturer of the product is, every supplier will be regarded as being a manufacturer of the product, unless they inform the injured party within a reasonable amount of time of the identity of the manufacturer or of the party that supplied the product to them. This also applies to imported products, if the identity of the importer referred to in section 2 is not given, even if the name of the manufacturer is given.

Article 6:187(4) of the Dutch Civil Code states:

If it cannot be ascertained who the manufacturer of the product is, every supplier will be regarded as being a manufacturer of the product, unless they inform the injured party within a reasonable amount of time of the identity of the manufacturer or of the party that supplied the product to them. If with regard to a product imported into the European Economic Area it cannot be ascertained who the importer of the product is, similarly every supplier will be regarded as being a manufacturer of the product, unless they inform the injured party within a reasonable amount of time of the identity of the importer into the European Economic Area or of a supplier within the European Economic Area that supplied the product to them.

In the above-mentioned Green Paper the Commission summarises Article 3(3) of the Directive, stating that if the manufacturer of the defective product cannot be identified, the supplier will be treated as the manufacturer, unless they inform the injured party within a reasonable amount of time of the identity of the manufacturer or their supplier (the person who supplied them with the product). The same applies if a product is imported into the European Union, if the product does not give any indication of the identity of the importer, even if the name of manufacturer is given. 
In this regard, the Commission signals that the injured party has to thus formally inform the supplier, so that the supplier can supply the details of the manufacturer or their supplier within a reasonable amount of time. It is argued in the Green Paper that experience has shown that the method of formally informing the supplier of their liability can vary considerably from member state to member state.

This variation is considered to be undesirable in the light of the objectives of the Directive. The Commission supplies examples. For instance in Italy a supplier has three months to provide the desired information concerning the name and address of the manufacturer. The injured party has to submit a written request and indicate the product and the date and place of purchase. The injured party also has to cooperate with an inspection of the product by the supplier, if the latter wishes to carry this out ${ }^{146}$. In Germany the supplier has a month to provide the information ${ }^{147}$ and in Belgium the court decides on the time period ${ }^{148}$. The Commission invites the parties concerned to share their knowledge on this point.

The Commission thus addresses the variation in the way in which the information has to be requested and the time period within which there has to be a response, but neither the Green Paper nor reactions to this deal with the quality of the response.

The quality of the response with which the supplier can shift their liability onto an earlier link in the chain can be measured by both the quality of the information and the result of the referral.

It is not clear what details are sufficient. What details are meant by 'the identity of the manufacturer', 'the identity of the party that supplied the product to them' or 'the identity of the importer?'

Maybe a small overlap in civil law and food law provides a solution. On 28 January 2002 Regulation (EC) no. $178 / 2002$ came into force ${ }^{149}$. This regulation sets out several general principles relating to food safety. The most commonly used citation internationally is 'General Food Law'. The abbreviation GFL will also be used here.

One of the principles is that of traceability ${ }^{150}$. Article 18 of the GFL states the following:

1. The traceability of food, feed, food-producing animals, and any other substance intended to be, or expected to be, incorporated into a food or feed shall be established at all stages of production, processing and distribution.

2. Food and feed business operators shall be able to identify any person from whom they have been supplied with a food, a feed, a food-producing animal, or any substance intended to be, or expected to be, incorporated into a food or feed. To this end, such operators shall have in place systems and procedures which allow for this information to be made available to the competent authorities on demand.

\footnotetext{
${ }^{146}$ Article 4 of the Decree-Law of 24 May 1988.

${ }^{147}$ Article 4 of the Product Liability Law 1989.

${ }^{148}$ Article 4.2 of the law of 25 February 1991.

${ }^{149}$ Regulation (EC) no. 178/2002 of the European Parliament and the Council of 28 January 2002 setting out the general principles and regulations of the food legislation, setting up a European Authority for food safety and setting up procedures for food-safety matters.

${ }^{150}$ For the definition of 'traceability' see article 3 (15) of the GFL.
} 
3. Food and feed business operators shall have in place systems and procedures to identify the other business to which their products have been supplied. This information shall be made available to the competent authorities on demand.

4. Food or feed which is placed on the market or is likely to be placed on the market in the Community shall be adequately labelled or identified to facilitate its traceability, through relevant documentation or information in accordance with the relevant requirements of more specific provisions.

5. Provisions for the purpose of applying the requirements of this Article in respect of specific sectors may be adopted in accordance with the procedure laid down in Article 58(2).

In the EU Food Law Handbook ${ }^{151}$ Van der Meulen and Szajkowska summarise the traceability obligations as follows:

\section{From farm to fork}

One step up, one step down

Operators have systems in place

Information available for authorities

Adequate identification \& labelling

Food traceability first and foremost provides the possibility of identifying food that has a safetyrelated defect. Without traceability a fast, effective recall is not properly possible. However, in this respect there is an important side-effect of traceability: the identification of the food with the safetyrelated defect may also result in the supplier being identified. Article 18(2) of the regulation even states explicitly that the food operator should be able to find out who supplied them.

The question arises: what does ' $w h o^{\prime 152}$ mean? Does the identification of the party who has supplied the product mean this party's trade name, or the legal person with their registered name? With the focus of the GFL on 'food business operators' and 'persons', it is conceivable that the company has indeed been identified but not the precise legal person who formed the opposite contract party of the next party in the chain.

The question is not without significance when one considers that the injured party (the consumer), possibly following a referral by their online supplier, holds a manufacturer to account who, by invoking Article 6:185 of the Dutch Civil Code, states that it was not they who put the product into circulation but rather a - possibly already bankrupt - operating company.

In the apportionment of liability it is not the food chain as such that is relevant but rather the chain of legal parties that have traded the food. The question thus arises as to what details are sufficient to count as an identification in the sense of Article 3(3) of the Directive and Article 6:187(4) of the Dutch Civil Code. How exactly should 'the identity' of the manufacturer be reported?

\footnotetext{
${ }^{151}$ EU Food Law Handbook, Bernd van der Meulen (ed.), Wageningen Academic Publishers, 2014, p.241.

${ }^{152}$ The English text of the regulation states 'operators shall be able to identify any person from whom they have been supplied ...'.
} 
The answer prompts a more difficult question. It is in keeping with the goal of the doctrine of product liability that the details to be provided should be concrete enough for a manufacturer to be able to be held to account and summoned on the basis of these details. Therefore, it concerns the 'registered' identity.

Corporate law provides a great many possibilities for incorporating risky activities with legal entities that offer little redress. So an entrepreneur does not have to be liable for their entire capital for claims arising from damages or otherwise. There is no reason to assume this corporate-law risk spreading does not work in the case of claims based on a safety-related defect in food.

So it is highly possible that a supplier provides very accurate details to an injured party which the injured party then cannot benefit from. In the first liability claim the manufacturer goes into liquidation, then the claim is put on the list of provisionally admitted creditors by the receiver.

In the absence of case law on this matter it is not clear which way this will go. It is possible that such a referral is regarded as being sufficient to shift the liability. In this case a lot of the preventive effect of the liability for food with a safety-related defect will be lost. After all, the financial risk can be 'encapsulated'. The preventive effect resulting from the fear of reputational damage will of course not be affected by this.

It is also possible that case law will show that a referral that does not result in possibilities for redress will not be regarded as a 'notification' that absolves the supplier of liability. In this case suppliers with a sufficient negotiating position will only want to purchase products from parties that provide substantial redress.

Until case law has been developed on this matter, the question remains as to what requirements need to be set for the quality of a referral that will absolve the supplier of their liability.

Maybe the following is appropriate as a provisional answer. Every manufacturer in the chain of food with a safety-related defect is liable, regardless of whether they caused the defect. So it is a considerable extension of liability compared with that of normal tort law in a vertical line, for which the chain runs from top to bottom.

For those who argue that it is not just the designated legal person who is liable but also the other legal persons who belong to the group of corporations that belong to one single company, there is actually a horizontal extension of the liability that is considerably less far-reaching than the vertical one. In this respect there are few arguments not to adopt this piercing of the 'corporate veil'.

In the period between the second report by the Commission and the third report the Council assumes a resolution ${ }^{153}$ that concerns the supplier. The Council states that the system in which the legislators of Member States cannot hold any other parties - read: suppliers - liable for the damage resulting from a product with a safety-related defect is a cause for concern. The Council adopted the position that the possibility of drawing up provisions regarding supplier liability, including provisions regarding objective liability (in The Netherlands it is more usual to refer to this as 'qualitative liability'), can provide benefits to consumers, regardless of whether these provisions are drawn up nationally or at community level. In the cases concerned consumers would then be able to submit a legal claim against the manufacturer, the subsequent supplier, including the vendor of the product, or against all of them. This would give consumers more possibilities for actually obtaining compensation.

\footnotetext{
${ }^{153}$ Resolution of the Council dated 19 December 2002 on amendments to the Directive regarding liability for defective products (Official Journal c 26 dated 4.2.2003).
} 
The resolution ends with the judgement that against this background there is a requirement to ascertain whether Directive 85/374/EG, as amended by Directive 1999/34/EG, should be amended such that it creates the possibility of national provisions relating to supplier liability that are based on the same foundation as the liability system in the Directive relating to manufacturer liability.

According to the text of the resolution the Council is concerned about the question of whether the manufacturer held to account provides sufficient redress. Also introducing the supplier as a qualitatively liable party increases the number of parties from whom redress can be obtained. The resolution devotes no attention to the 'traceability' of the manufacturers in the food chain, although this may be a major argument for expanding the circle of manufacturers to include the supplier. After all, it is the supplier, and no other party in the chain, with whom the consumer had contact.

The Commission's third report ${ }^{154}$ once again concludes 'that it is not necessary at this stage to submit a proposal to amend the Directive'. The Commission thus does not address the suggestion as formulated in the resolution. The Commission states in one simple sentence that it does not need to act upon the resolution as this would deviate from the objective of the Directive to harmonise product liability legislation.

As the resolution does indeed suggest that the Directive be amended such that the Member States are given the opportunity to include suppliers in the circle of liable manufacturers, the proposed amendment could indeed prevent the harmonisation of the regulations. The optional character would probably result in legal diversity.

As a result of the text of the resolution the Commission rejected the suggestion without formulating a contextual judgement about the concern expressed by the Council. If the resolution had suggested that the supplier should be included in the Directive itself as a qualitatively liable party, it would then have been conceivable that a contextual comment would have been issued.

The text of Article 3(3) of the Directive therefore remained unchanged.

In the case of a referral upwards in the food chain a special food characteristic that other products do not have, or have to a much lesser extent, plays a role: a limited shelf life. More than in the case of other products an initially safe product can become defective over time, possibly in combination with other factors. A manufacturer designated by the supplier will possibly be able to successfully state that the defective product was not defective at the time that the manufacturer put the product into circulation. In the terms of Article $7(b)$ of the Directive: the manufacturer is not liable if, given all the circumstances, it is likely that the defect that caused the damage did not exist at the time at which the manufacturer put the product into circulation or that the defect occurred at a later stage.

Manufacturers can possibly even use the use-by date displayed on the product in the form of a quality date or a safety date as proof for the position that the product was not defective when they put it into circulation. The obligation of manufacturers to display the use-by date on their product was of course introduced to protect consumers. However, it is conceivable that a claim based on a safety-related defect will rebound off the manufacturer's position that the safety-related defect did not occur until after the use-by date. In this case the supplier - even if they bought the food on a date after the use-by date - can refer to the manufacturer in order to shift their own liability for the

\footnotetext{
${ }^{154} \operatorname{COM}(2006) 496$ Report from the Commission to the Council, the European Parliament and the European Economic and Social Committee - Third Report on the application of Council Directive on the approximation of laws, regulations and administrative provisions of the Member States concerning liability for defective product (85/374/EEC of 25 July 1985, amended by Directive 1999/34/EC of the Parliament and of the Council of 10 May 1999).
} 
safety-related defect. Manufacturers will be able to exonerate themselves. All that is left for the consumer is to invoke non-conformity with all the associated problems relating to the burden of proof.

\subsection{PRODUCT LIABILITY OF ONLINE SUPPLIERS FOR FOOD}

Vendors of food via webshops are currently facing a lot of legislative changes. Two major sets of European regulations are currently determining the content of their digital shop window. These are Directive 2011/83/EU ${ }^{155}$ (the Consumer Rights Directive) and Regulation (EU) No. 1169/2011 ${ }^{156}$ (the Food Information Regulation).

\subsubsection{The Consumer Rights Directive}

EU Member States had to implement the provisions of the Consumer Rights Directive in their own national legislation by the end of 2013. The Dutch legislator was not able to do this. The national legislation was brought into line with the Consumer Rights Directive on 13 June 2014. The Consumer Rights Directive includes formal and material provisions that - laid down in the legislation of the member states - include regulations about the form and content of contracts that are concluded via webshops.

\subsubsection{The Food Information Regulation}

The Food Information Regulation came into immediate effect on 13 December 2014. This regulation declares, using a simple provision, that the very comprehensive regulations that apply in the field of food information also apply to webshops. As of mid-December 2014 online food retailers were suddenly drawn into a judicial area that they were unfamiliar with that has very radical consequences for their presentation on the web.

The question now is whether the fact that the sale of food took place on the basis of a specially referred to contract - the distance contract - affects a supplier's liability for a safety-related defect.

\footnotetext{
${ }^{155}$ Directive 2011/83/EU of the European Parliament and of the Council of 25 October 2011 on consumer rights, amending Council Directive 93/13/EEC and Directive 1999/44/EC of the European Parliament and of the Council and repealing Council Directive 85/577/EEC and Directive 97/7/EC of the European Parliament and of the Council.

${ }^{156}$ Regulation (EU) No. 1169/2011 of the European Parliament and of the Council of 25 October 2011 on the provision of food information to consumers, amending Regulation (EC) No 1924/2006 and (EC) No 1925/2006 of the European Parliament and of the Council, and repealing Commission Directive 87/250/EEC, Council Directive 90/496/EEC, Commission Directive 1999/10/EC, Directive 2000/13/EC of the European Parliament and of the Council, Commission Directives 2002/67/EC and 2008/5/EC, and Commission Regulation (EC) No $608 / 2004$ of the Commission.
} 


\subsubsection{The distance contract}

European legislators do not use the term 'webshop'. The legislation in which Europe intends to act as a modifier and which it aims to use to introduce harmonisation between the Member States via the Consumer Rights Directive does not cover the 'digital contract' or the 'purchase in the webshop' or the like. Rather it uses the broader term 'distance contract', to which, for example, telephone transactions and mail orders also belong. The explanatory recitals to the Directive also indicate that the main reason for the Directive was the greatly expanding trade that is taking place via the Internet.

The definition of the distance contract in the Consumer Rights Directive is (Article 2 (7)):

'distance contract' means any contract concluded between the trader and the consumer under an organised distance sales or service-provision scheme without the simultaneous physical presence of the trader and the consumer with the exclusive use of one or more means of distance communication up to and including the time at which the contract is concluded.'

The matter of whether an online supplier is a trader ${ }^{157}$ - as a result of which they are fully covered by the regime of the regulations referred to - may possibly result in discussion. Somebody who picks berries from their garden and makes jam from them for their cellar will not be a 'trader' if they offer a few jars on the Internet. But what if they do this every year in substantial quantities? Possibly there is the need for a further tightening-up because of the considerable consequences of the applicability of the classification 'trader'.

A previous aid in determining whether one of the parties should be regarded as a 'trader' could be found in the fact that there had to be a sales system organised by them (...). ${ }^{158}$ So somebody who sporadically sells goods as a hobby via an existing sales or intermediary site (marktplaats, ebay, etc.) could be distinguished from traders who run their own webshops.

The requirement that the system had to be organised by the trader themselves was dropped in the harmonisation. It is possible that the finding that items are now traded very professionally and with considerable turnover via general sales and intermediary sites resulted in the words 'by the vendor or service provider' not being included.

It is obvious that the soft definition of the term 'trader' will result in a great deal of case law because of the harsh consequences of the applicability of this classification. It would be good if a concrete criterion were introduced now, just as the tax office uses an hourly criterion to distinguish between hobbies and sporadic activities and professional and commercial trading. The determination of the tax office that sales tax has to be paid is possibly an aid, but an independent consideration based purely on turnover is of course also possible. The issue will be discussed further in the final Chapter.

\footnotetext{
${ }^{157}$ Consumer Rights Directive Art. 2(2): any natural or legal person, irrespective of whether privately or publicly owned, who is acting including trough any other person acting in his name or on his behalf, for the purposes relating to his trade, business, craft or profession in relation to contracts covered by this Directive; Dutch Civil Code (art. 7:5 (1)): vendor who acts in the implementation of a profession or business.

${ }^{158}$ Article 7:46a (a) CC.
} 


\subsubsection{Obligations of the webshop}

On the basis of the implementation of the Consumer Rights Directive in national legislation webshops will have to comply with different kinds of obligations. There are many provisions that have an imperative effect on the content of the contract. But there are also many provisions that focus on the presentation: the provision of information to the consumer.

The most obvious information obligation concerns not the product to be sold but the person of the trader. After all, online vendors can hide their identity. Unlike in a physical shop, where consumers can have legal redress using legal remedies, it is possible for a webshop to be untraceable by dissatisfied consumers. Disappointed online consumers can write unfavourable reviews but to take legal action for compensation for poor performance they ultimately need a known (legal) person and an address. The obligation to provide information about the identity of the trader should make it possible for traders to be traced physically and legally. Attempts are thus made to frustrate a 'sell and run strategy'.

\subsubsection{Information about the trader}

Before consumers decide to buy, the trader - i.e. the webshop - provides information in a clearly and comprehensive manner about ${ }^{159}$ :

- the identity of the trader, such as the trade name;

- their geographical address;

- their telephone number, fax number and e-mail address (if available);

- the geographical address and the identity of the trader on whose account they are acting (if applicable);

- the geographical address of the place of business to which consumers can address any complaints (if different to above).

In making the provision of these details compulsory the Directive aims to actually make it possible for a discussion with the supplier about the implementation to take place other than online, even though the contract was concluded online.

For product liability claims the traceability of the supplier is important. After all, suppliers are the people who have to refer the consumer to the manufacturer under penalty of liability. The obligation regarding information relating to the identity of the trader does not work higher up in the chain after all, it concerns consumer law. If the supplier too has purchased along the digital chain, they will possibly not be able to refer the consumer in a manner than absolves them of liability. In the case of a safety-related defect it will be possible to declare them liable, although they do not have to be blamed in this respect.

\footnotetext{
${ }^{159}$ Referring to the Consumer Rights Directive Article 6(1)(b), (c), (d).
} 


\subsubsection{Information about the product}

The Directive is very brief about the obligations of the webshop to provide details about the product. The task is to provide ${ }^{160}$ :

the main characteristics of the goods or services, in as much as these have been modified to suit the carrier used and the goods or services

The aim that the European legislator has set itself is to ensure that consumers have the opportunity to buy only those products that they want to buy, even if as a result of the distance they were not able to view, hold, taste, etc. the product. In order to realise this the Directive could have mandated that very comprehensive information had to be provided about all the characteristics of the product. It did not choose to do this.

The Directive chose to use a different tool to bring about a situation in which consumers are not bound to purchase a product that does not meet their expectations: a broad right of withdrawal. However, food suppliers have the right to deny consumers the right of withdrawal for reasons of hygiene and shelf life. So on the basis of the Consumer Rights Directive foods only have to be briefly described, while it may possibly not be possible to return food that has been purchased. The Consumer Rights Directive thus creates a legal vacuum that needs to be filled by food legislation.

The Food Information Regulation instructs operators of food companies to make detailed information available. For the definition of 'food business the regulation refers to Regulation (EC) no. 178/2002 Article $3(2)^{161}$.

The far-reaching amendments for the practice of webshops are presented in an almost casual way in recital $27^{162}$. The recital states simply that all obligations relating to food information of course also apply to food that is sold via webshops and that this information has to be available before the purchase takes place. The word 'before' has far-reaching consequences not only for the structure of the webshops but also for the legal relations in the chain.

As a result of the requirement contained in Article 14 of the Food Information Regulation the webshop is burdened with its own responsibility for the availability - and accuracy - of the food information. A responsibility that arises not because this operator links their name or trade name to the food but because they provide the food in a distance contract.

\footnotetext{
${ }^{160}$ Article 6 (1) a of the Consumer Rights Directive.

${ }^{161}$ Regulation (EC) no. 178/2002, article 3 (2): 'food business' means any undertaking, whether for profit or not and whether public or private, carrying out any of the activities related to any stage of production, processing and distribution of food;

${ }^{162}$ Recital 27 of the Food Information Regulation: In order to ensure the provision of food information, is is necessary to consider all ways of supplying food to consumers, including selling food by means of distance communication. Although it is clear that any food supplied through distance selling should meet the same information requirements as food sold in shops, it is necessary to clarify that in such cases the relevant mandatory food information should also be available before the purchase is concluded.
} 
Article 14 includes one exception regarding what has to be indicated in the case of a distance sale: the indication of the best-before date or use-by date (Article 9(1)(f)). The exception is of a practical nature. After all, in the digital shop window of a food webshop the item that is actually sold is seldom shown. Illustrations are shown of an example. A purchaser may expect the recipe and preparation that are presented and suggested. However, the best-before date and the use-by date that are linked to the production or packaging date will change so regularly that the webshop cannot be expected to update the digital presentation just as regularly.

The question arises as to whether not providing accurate label information can cause a safety-related defect. The answer is fully affirmative. After all, a product is defective in the context of product liability if it does not provide the safety that can be expected of it, with all circumstances being taken into consideration, and in particular:

a) the presentation of the product;

b) the use of the product that can be reasonably expected;

c) the time at which the product was put into circulation.

A label is nothing more than a very detailed presentation of the product.

The obligation to put all the label details on the website before the purchase creates the possibility that all the manufacturers as referred to in Article 6:187(2) CC, as well as the importer referred to in section 3 , are liable if the online retailer has implemented this requirement so poorly that a safetyrelated defect occurs. Retailers themselves are possibly also liable if they cannot discharge their liability through a referral.

The provision that harshly involves online retailers in very complicated label law therefore has another far-reaching consequence: if retailers act in violation of this, this can suddenly have consequences for the liability of all the parties in the chain.

Who exactly is the liable party?

Pursuant to Article 9(1)(h) of the Food Information Regulation online retailers are obliged to report the name or the trade name and the address of the operator referred to in Article 8(1). According to this Article it is not the food business that is responsible for the provision of accurate food information but rather 'the operator of the food company under whose name or trade name the food is traded'. So a distinction is drawn between 'the food business' and 'the operator of the food business'. This distinction is maintained in paragraph 5 giving the operators a general compliance responsibility. 
For the definition of this operator the Food Regulation also refers to Regulation (EC) no. 178/2002 ${ }^{163}$. The food business operator is denoted as a natural or legal person who is responsible for ensuring that the requirements of food law are met within the food business under their control.

The unworkable distinction according to Dutch law between the food business (the company) and its operator (the company management or owner) appears to indicate a kind of liability by managers regarding compliance with food legislation and to exclude the company itself from liability. These managers can themselves also be legal entities. This also applies to the manager of this manager, etc.

The Food Information Regulation could have injected clarity by not referring to the definition from Regulation (EC) no. 178/2002 but rather by providing a definition itself. Instead, it opted to fit in with the definition and to further clarify an element of this: responsible for. Article 8(1) lays the responsibility for compliance with food information legislation with the operator under whose name or trade name the food is traded.

So it is not the food business that bears responsibility for compliance with the provisions referred to, nor is it the operator of that food business (as may be the case in a civil law sense), but it is the operator of the food business that has associated its name with the food ${ }^{164}$. The formulation may possibly also mean that the operator who has linked their name to 'the vehicle' along which the sale took place is liable. In this case it is not only the food websites that need to be concerned but also all the general sales sites on which third parties can offer their food.

Recital 15 of the Food Information Regulation indicates how the Union regulations 'should' apply ${ }^{165}$. Several examples make it clear that the sporadic, non-commercial processing or sale of food by private individuals should not be subject to the Union regulations. The recital uses the word 'company', not the term 'food business' or 'operator'.

So the recital does not shed any light on the person of the party responsible for compliance with the regulation. Other recitals do so even less.

The question arises as to whether the webshop, the distance vendor, is a food business or an operator of the food business or the 'the operator responsible for the food information of a food business under whose name or trade name the food is traded'.

Whether a webshop, whatever its legal form, can be held to account as 'the responsible operator' therefore depends on whether the food to be marketed bears its name or trade name. The large variety of webshops means that an equally large variety of answers can be given to this question. In a general sense it can be stated that webshops that sell their own products are possibly both food businesses and the responsible operator of these, while webshops that sell branded items by a different proprietor avoid this responsibility.

It is curious that the European legislator with one sweeping gesture makes all the links in a product chain potentially liable but that neither the Food Information Regulation nor the Consumer Rights

\footnotetext{
${ }^{163}$ Regulation (EC) no. 178/2002, Article 3(3): 'food business operators' means the natural or legal persons responsible for ensuring that the requirements of food law are met within the food business under their control.

164 'The importer' is also responsible if the operator is not based in the Union.

${ }^{165}$ Recital 15 of the Food Information for Consumers Regulation: Union rules should apply only to undertakings, the concept of which implies a certain continuity of activities and a certain degree of organisation. Operations such as the occasional handling and delivery of food, the serving of meals and the selling of food by private persons, for example at charity events or at local community fairs and meetings, should not fall within the scope of this Regulation.
} 
Directive includes a useful provision regarding the definition of this link itself. In the definition of the 'operator of a food company responsible for the food information' it appears that a rough connection is sought with the parties designated for product liability by designating them as the parties that put the food into circulation, or, if the operator of a food company is not based in the Union, the importer who imports the food into the Union. But the opportunity to firmly qualify the responsible operator was left unused.

As the injured party (consumer) of a food with a safety-related defect will very quickly be discouraged in their quest for a party that actually provides redress on the basis of product liability, they will probably quickly abandon this legal basis and hold to account the online supplier on the basis of non-conformity.

\subsubsection{Online food retailers as importers}

The globalisation of the effect of digital interactions represents an additional expansion of the product liability risks for online food suppliers. The digitalisation of food chains has resulted in a situation in which it is highly possible for smaller retailers too to maintain global business contacts. However, the logistically completely arbitrary external border of the 'European Economic Area' represents a significant barrier as regards liability risks. A delicatessen webshop that imports products from Greece will not be liable if a safety-related risk manifests itself. Pursuant to Article 6:187 (3) of the Dutch Civil Code the same webshop is suddenly liable for the same products if these are bought not from Greece but from Turkey.

\subsection{FROM LIABILITY TO THE OBLIGATION TO PAY COMPENSATION}

In liability law the legislator's first concern does not inevitably have to be that the party that caused the damage should pay compensation for this. It is rather the concern that the injured party should receive compensation. The party that pays the compensation is by no means always the party that caused the damage. It is its quality (capacity) ${ }^{166}$ that makes it liable. It is then up to this liable party to seek redress from the party to which blame can be attributed, so that ultimately the damage lies with the party that caused the damage.

In the case of product liability relating to food this is no different. The circle of liable parties is a large one. And none of the liable parties has to be the party actually responsible for the safety-related defect. If lawfulness and fairness are to be combined, the damage should ultimately be reimbursed by the party that can be blamed for the damage. The culpable party that caused the damage should pay compensation.

In the case of some forms of qualitative liability the Dutch legislator has given some direction to the obligation to pay compensation. In these cases the legislator provides tools for apportioning the costs to be borne among the severally liable parties. One example is Article 6:166 of the Dutch Civil

\footnotetext{
${ }^{166}$ For example as a parent (6:169 of the Dutch Civil Code), as an employer (6:170 of the Dutch Civil Code), as an owner $(6: 173,174,175,179$ of the Dutch Civil Code), as an operator (6:176, 177 of the Dutch Civil Code), as a member of a group (6:166 of the Dutch Civil Code).
} 
$\operatorname{Code}^{167}$. In section 1 it is stated that under certain circumstances members of a group are severally liable for unlawful damage caused by a member of the group. Section 2 states:

They each have to contribute to the compensation in equal parts, unless in the circumstances of the case reasonableness demands a different apportionment.

The Dutch Civil Code also has several general provisions relating to own fault and contributory fault/negligence ${ }^{168}$ that actually contain an apportionment of the obligation to pay compensation. Product liability has two rules relating to the obligation to pay compensation that are in keeping with this. According to Dutch law Art. 6:185(2) and (3)

The liability of the manufacturer is reduced or waived, taking into consideration all the circumstances, if the damage was caused both by a product defect and by the negligence of the injured party or a person for whom the injured party is liable.

The liability of the manufacturer is not reduced, if the damage was caused both by a product defect and by the conduct of a third party.

The circle of liable parties is large for the injured party. If none of the parties can be identified, the injured party still always has the supplier who is known to them from the shop or webshop. In the latter case provisions relating to distance contracts help the injured party to find the retailer. This retailer has to make a referral - the quality of the referral is not clear - or shoulder the damage.

After the injured party has held a party in the chain to account, mandatory law is exhausted and the relationships in the chain are controlled by the contracts between the parties. Manufacturers can exonerate themselves with regard to consumers who have suffered damage as a result of a safetyrelated defect only using the defences set out in the law. However the party in the chain with the greatest negotiating power will easily be able to absolve themselves of their obligation to pay compensation. In this way this obligation will trickle down to the link in the chain that has the weakest negotiating position.

\subsection{CONCLUSIONS}

This Chapter has set out to identify the product liability risks for online food retailers. The underlying question is whether the far-reaching digitisation of the entire food chain means that at the end of this chain there is now a greater product liability risk.

\footnotetext{
${ }^{167}$ For another example see 6:170 (3) of the Dutch Civil Code.

${ }^{168}$ Articles 6:101 and 6:102 of the Dutch Civil Code.
} 


\subsubsection{Distance contract}

The objective of the Consumer Rights Directive is to make online suppliers just as 'traceable' as traditional retailers for legal claims by consumers. All the arrows point to the legal party behind the webshop. Consumer law is then exhausted. Retailers do not have the tools that are available to consumers. Retailers have to push the claim up the hill towards the liable - and maybe even culpable - party without the tool of the distance contract.

\subsubsection{Food Information Regulation}

The Food Information Regulation requires online suppliers to make available all the information online that the label requires. They have an independent responsibility, although they may lack the knowledge for collecting or verifying this information. If the information is incorrect in such a way that it forms a safety-related defect, all the parties in the chain are liable. They may possibly refer to predecessors in the chain to absolve themselves of liability, but these predecessors will first reimburse the consumer then seek redress with the suppliers. Online suppliers also run a great risk of being held independently to account on the basis of non-conformity, if the mandatory label information generated incorrect expectations in the consumer.

It is also conceivable that their predecessor limited the liability risks via corporate law. It is possible that a referral to a bankrupt predecessor will not absolve the retailer of liability.

\subsubsection{Importers' liability}

Apart from a few trading obstacles, online retailers buy just as easily outside the EEA as within. The consequences of choosing to buy outside the EEA are far-reaching. Suddenly they are fully liable for safety-related defects in the food without the possibility of using a referral to absolve themselves of liability.

\subsubsection{Increasing risk of liability as a result of non-conformity}

For the food industry there is the special risk linked to the passage of time. The risk of harmful spoilage becomes increasingly great on the journey from source to consumer. The exoneration possibility linked to the position that the product was still safe when it was marketed means that it may be a lot more attractive for consumers to leave the path of product liability and to claim compensation from the retailer known to them.

\subsubsection{Obligation to pay compensation}

The provisions discussed impose product liability on a lot of parties in the chain. The objective of all the tools that are provided to consumers by the modified regulations is to strengthen the legal 
position of the injured party. If European and national legislators succeed in this aim, the consumer will no longer be the weakest link. Automatically and inevitably the risks will then lie with the party that then forms the weakest link in terms of negotiating and process power. This means that the assumed low threshold for access to the digital market is completely illusory for online retailers.

Huge number of retailers are seeking refuge in digitisation. But those who want to sell food via the web can be sure that all the arrows from above and from below are aimed at them. 


\section{THE LUCKY BAG FOR MEALS ${ }^{169}$}

\section{Since 13 December 2016 it is obligatory to state the nutritional value on food labels ${ }^{170}$, but consumers are more willing than ever to pay for ignorance.}

\subsection{INTRODUCTION}

Since time immemorial, charity, churches, homes and welfare organisations provide meals at home locally to those who are not able to buy and prepare their own meals because of old age or a disability. In the Netherlands this service has become known as 'Tafeltje-dek-je' (the Wishing-Table) after the fairy-tale by Grimm. Similar services are provided in surrounding countries: in England it is referred to as 'Meals on Wheels', and in Germany as, somewhat less poetic, as 'Essen auf Rädern'.

With the advent of web shops selling food, a modern and commercial variant of the old charity service has been introduced: the food box. The target group, however, has shifted from those in need to the wealthy with limited time, and emphasis has been changed from 'care provision' to 'making life easier'.

Food boxes provide food retailers with substantial advantages in the area of purchase. After all, it are not the buyers who determine what they buy, but instead the sellers determine what they sell. Indeed, the fact that consumers are told what to buy is used as the main sales argument. Consumers save themselves the trouble of physical shopping as well as the question of what to buy. Food boxes provide the answer to the obviously troubling and recurrent question of: 'What are we having for dinner today?' The answer to that question is provided as a service.

Googling in the Netherlands will easily result in 40 suppliers of - usually themed - food boxes in a matter of seconds. ${ }^{171}$ Legislators have not anticipated this development.

\subsection{DISTANCE CONTRACTS}

Ordering a food box involves a distance contract; a contract in which a seller and consumer are not simultaneously in a sales area designed for that purpose. The parties involved therefore make use of distance communication resources in order to enter into the contract. On 13 June 2014, the

\footnotetext{
${ }^{169}$ An earlier version of this chapter has been published as; Lomme van der Veer, The Lucky Bag for Meals, European Food and Feed Law Review, 2017, p. 151-156.

${ }^{170}$ Point (I) of Article 9 (1) of (EU) Regulation No 1169/2011 of the European Parliament and of the Council of 25 October 2011 on the provision of food information to consumers, amending Regulations (EC) regulations No 1924/2006 and (EC) No 1925/2006 of the European Parliament and of the Council, and repealing Commission Directive 87/250/EEC, Council Directive 90/496/EEC, Commission Directive 1999/10/EC, Directive 2000/13/EC of the European Parliament and of the Council, Commission Directives 2002/67/EC and 2008/5/EC and Commission Regulation (EC) No 608/2004.

${ }^{171}$ See p. 125.
} 
consumer rights directive ${ }^{172}$, which provides this contract of mandatory content, was implemented in Dutch $\operatorname{law}^{173}$.

Some food companies started providing their food boxes online as well as physically in shopping streets, using a form of vending. In this case there is no question of a 'distance contract' but instead of an 'off-premises contracts' ${ }^{174}$.

Any provisions that use the qualification of 'distance contract' or 'off-premises contract' to enter the agreements between the parties is focused on reinforcing the position of the consumers vis-à-vis their supplier.

Although distance contracts have been entered into since halfway the $18^{\text {th }}$ century ${ }^{175}$, it is modern technology that enables online sales which has led legislators to try and use regulations in order to try and neutralise the consequences of the fact that buyers and sellers are not in the same space when the transaction is realised.

The anonymous character of digital contacts in which sellers can apply a 'sell and run/hide-strategy' is thus compensated for with the obligation to publish address details on the website, thus allowing consumers to literally plant their foot in the physical doorway ${ }^{176}$.

\subsection{BRICKS, CLICKS AND CONFORMITY}

If people buy something in a stone shop (bricks), they can cancel the purchase if they can make a reasonable case that the product purchased does not comply with the expectations they could reasonably have ${ }^{177}$. This is referred to as the conformity principle. For a consumer to cancel their

\footnotetext{
${ }^{172}$ Directive 2011/83/EU of the European Parliament and of the Council on consumer rights, amending Council Directive 93/13/EEC and Directive 1999/44/EC of the European Parliament and of the Council and repealing Council Directive 85/577/EEC and Directive 97/7/EC of the European Parliament and of the Council.

${ }^{173}$ Articles 6:230g under e CC, distance contract: the contract entered between the trader and consumer within the framework of an organised system for distance sales and services without the simultaneous personal presence of the trader and consumer and for which, up to the moment of entering the contract, exclusive use is made of one or several distance communication means.

${ }^{174}$ Article 2, paragraph 8 of the consumers' rights directive: 'off-premises contract' means any contract between the trader and the consumer: a) concluded in the simultaneous physical presence of the trader and the consumer, in a place which is not the business premises of the trader; $b$ ) for which an offer was made by the consumer in the same circumstances as referred to in point $(a)$; c) concluded on the business premises of the trader or through any means of distance communication immediately after the consumer was personally and individually addressed in a place which is not the business premises of the trader in the simultaneous physical presence of the trader and the consumer; or d) concluded during an excursion organised by the trader with the aim or effect of promoting and selling goods or services to the consumer.

${ }^{175}$ In 1744, Benjamin Franklin published a catalogue in colonial North America from which scientific books could be ordered and delivered by mail. See chapter 2 .

${ }^{176}$ Article 6, paragraph 1 of the consumers' rights directive: Before the consumer is bound by a distance or offpremises contract, or any corresponding offer, the trader shall provide the consumer with the following information in a clear and comprehensible manner: (...) c) the geographical address at which the trader is established and the trader's telephone number, fax number and e-mail address, where available, to enable the consumer to contact the trader quickly and communicate with him efficiently and, where applicable, the geographical address and identity of the trader on whose behalf he is acting:

${ }_{177}$ Article 7:17, paragraph 2: An item does not comply with the contract if - also in view of the nature of the item and the statements the seller has made about the item - it does not have the properties the buyer could
} 
purchase, they must demonstrate that the product bought differs from what they might have expected based on appearance or commendation; they must prove the non-conformity. Regulations focus on motivating sellers not to sell inadequate products and to somewhat control their natural urge to celebrate their goods. If sellers go too far in their sales efforts, they risk the dissolution of the contract.

Things are easier for those who buy articles in a digital shop (clicks). They can also dissolve the purchase based on the fact that the product does not comply with their reasonable expectations. However, they are not required to advance any argument for returning the goods bought and have the purchase price refunded during the first fourteen days following receipt ${ }^{178}$. The legislator has accomplished that no consumer is bound to a purchase they do not want, not by providing them with the opportunity to be properly informed prior to the purchase, but instead by providing them with the right to return the item after the purchase.

In an attempt to provide consumers in clicks with the same position as those in bricks, the right has been granted to feel, weigh or put on the merchandise as customers can do in an actual physical shop and putting it back on the shelf. This constitutes a nightmare for most web shops, which obviously are not at all sure of a successful transaction after selling and shipping their products.

\subsection{FOODS IN THE WEBSHOP.}

If you imagine what a bag of lettuce or a bunch of smoked eels will look like after it has been sent and returned unmotivated after a week or more, everyone will understand that the arrangement for return must make an exception for perishables. The Consumer Rights Directive formulates the exception for 'goods which are liable to deteriorate or expire rapidly. ${ }^{179}$ The Dutch legislator has chosen almost an identical confusing ${ }^{180}$ formulation of the exception for 'goods which deteriorate rapidly or have limited shelf life' ${ }^{181}$. The solution the legislator has come up with to protect consumers from making overly impulsive purchases or from purchasing goods that differ from what was expected does not work in the case of food.

expect based on the contract. The buyer may expect the item to have the properties for normal use and that he/she does not have to question the presence, as well as the properties required, for a special use that has been anticipated in the contract.

${ }^{178}$ Article 9, paragraph 1 of the consumers' rights directive: Save where the exceptions provided for in Article 16 apply, the consumer shall have a period of 14 days to withdraw from a distance or off-premises contract, without giving any reason, and without incurring any costs other than those provided for in Article 13(2) and Article 14. See chapter 3.

${ }^{179}$ Article 16 of the consumers' rights directive: Member States shall not provide for the right of withdrawal as set out in Articles 9 to 15 in respect of distance and off-premises contracts as regards the following: (...) d) the supply of goods which are liable to deteriorate or expire rapidly.

${ }^{180}$ The confusion is created by the fact that it is difficult to ascribe an independent meaning to the 'collection' of goods that are liable to deteriorate quickly if those that expire quickly are excluded.

${ }^{181}$ Article 6:230p, under f. $2^{\text {nd }}:$ : goods that deteriorate rapidly or have limited shelf life. 
A gaping cleft resulted in the protection of consumers' rights when buying food online; suppliers were not obliged to provide comprehensive information ${ }^{182}$ or to take goods back. ${ }^{183}$

On 13 December 2014 the Food Information Regulation came into effect. This regulation, which does not require an implementation into Dutch law in order to be effective, includes a clause which stipulates that the greatly elaborated system of mandatory information about food applies to labels as well as websites ${ }^{184}$. All of the mandatory information about contents and composition of food must be available to consumers before they purchase it. The legislator has thus decided to provide consumers with the online opportunity to read all of the label information at a time when they have not yet bought the food, primarily in connection with the fact that they cannot put the food back on the digital shelf.

On 13 December 2016 the information obligations were substantially increased ${ }^{185}$. From that date onwards, stating the nutritional value ${ }^{186}$ has become mandatory for all prepacked foods. Web shops are exempt only of the obligation to express the durability date in the digital shop-window. This is probably based on the consideration that a similar article to the article photographed in the digital shop-window is shipped.

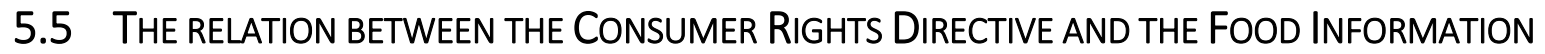 REGULATION}

In the Food Information Regulation, 'protection of consumers' health' and 'right to information' are bracketed together and next to one another. This is logical for those who consider that the health of individual consumers may involve them making a special selection from what they eat, based on the

\footnotetext{
${ }^{182}$ Article 6, paragraph 1 of the consumers' rights directive: Before the consumer is bound by a distance or offpremises contract, or any corresponding offer, the trader shall provide the consumer with the following information in a clear and comprehensible manner: a) the main characteristics of the goods or services, to the extent appropriate to the medium and to the goods or services.

${ }^{183}$ See chapter 2.

${ }^{184}$ Article 14 of the food information regulation, paragraph 1: Without prejudice to the information requirements laid down in Article 9, in the case of prepacked foods offered for sale by means of distance communication: a) mandatory food information, except the particulars provided in point (f) of Article 9 (1), shall be available before the purchase is concluded and shall appear on the material supporting the distance selling or be provided through other appropriate means clearly identified by the food business operator. When other appropriate means are used, the mandatory food information shall be provided without the food business operator charging consumers supplementary costs; (b) all mandatory particulars shall be available at the moment of delivery. paragraph 2: In the case of non-prepacked foods offered for sale by means of distance communication, the particulars required under Article 44 shall be made available in accordance with paragraph 1 of this Article. Paragraph 3: Point (a) of paragraph 1 shall not apply to foods offered for sale by means of automatic vending machines or automated commercial premises.

${ }^{185}$ Article 55 of the food information regulation: This Regulation shall enter into force on the $20^{\text {th }}$ day following its publication in the Official Journal of the European Union. It shall apply from 13 December 2014, with the exception of point (I) of Article 9(1), which shall apply from 13 December 2016, and Part B of Annex VI, which shall apply from 1 January 2014.

${ }^{186}$ Article 9 of the food information regulation, paragraph 1: In accordance with Articles 10 to 35 and subject to the exceptions contained in this Chapter, indication of the following particulars shall be mandatory: (...) (I) a nutrition declaration.
} 
information provided. However, the information can also lead them to make economic, social, ethic or environmental assessments ${ }^{187}$.

The obligatory expressions thus serve to allow consumers to make a well-informed choice about what they eat; an objective that considerably justifies regulatory burden. In which other manner than through label information can consumers inform themselves about what they intend to eat?

Article 14 of the Food Information Regulation also puts this regulatory burden on the shoulders of online food retailers. The justification for this information requirement is not found in creating food safety; in health. After all, the online information does not prevent them from eating food that is unhealthy (for them); it merely prevents them from buying the food ${ }^{188}$. The regulations thus only prevent bad buys. Article 14 ensures that consumers are prevented from having to give or throw away a product after reading the label - after all, they cannot return it - because they could take cognizance of all expressions before they bought it.

Things may be somewhat more subtle for other choices stated by the legislator in the third recital. Although the topic of the consideration certainly is 'consuming', it is conceivable that social, ethnic of environmental considerations have to be made at the time of purchase and not later at the time of consumption ${ }^{189}$.

Because Article 14 does not pertain to food safety, the objective is more likely to pertain to civil law: the aim that consumers are not obliged to buy things they do not want. The information obligation from the food law thus compensates for the lack of the consumer rights' instrument of revocation where goods that expire quickly are concerned.

In this light, it is surprising that the directive and regulation do not fit seamlessly. In the regulation, the obligation to express applies if the prepacked food is offered using techniques for distance communication. In the Consumer Rights Directive, the right of withdrawal applies to distance contracts $^{190}$ as well as off-premises contracts ${ }^{191}$.

In the recitals concerning Article 14, no food is provided to the supposition that the obligation to express intends to fill the hiatus in consumer protection. Consideration 27 of the Food Information Regulation substantiates the choice for the implementation of the intervention of food laws in the distance contract in a very curious manner. The obligation to make the information available to potential online buyers prior to purchase would merely be a specification of the general obligation as

\footnotetext{
${ }^{187}$ Recital 3 of the food information regulation: In order to achieve a high level of health protection for consumers and to guarantee their right to information, it should be ensured that consumers are appropriately informed as regards the food they consume. Consumers' choices can be influenced by, inter alia, health, economic, environmental, social and ethical considerations.

${ }^{188}$ The food information regulation neglects no opportunity to emphasise that the obligations of the retailer online do not alter the obligatory expressions on the packaging.

${ }^{189}$ If a vegetarian does not consume animal products for fundamental reasons, he/she will probably not want to buy them for similar reasons.

${ }^{190}$ In other words, for contracts that are entered into using techniques for distance communication.

${ }^{191}$ This difference is less academic than it possibly seems. In many shopping streets consumers are addressed by food box providers. The sale of a food box subscription takes place in the street and therefore does not involve a distance contract. Revoking was thus possible based on the consumers' rights directive, were it not for the fact that the goods concerned expire quickly. The obligation to express does not apply because no use was made of a technique for distance communication. Ergo, there is no information requirement other than on the label and no option for revocation.
} 
stipulated in Article $9^{192}$. In this recital, the legislator does not seem very aware of the fact that the specification of existing legal context is not concerned here, but instead the introduction of a complex legal area in an entirely new trade.

\subsection{THE FOOD BOX MARKET}

The legitimacy for the application of the integral food information obligation ${ }^{193}$ to online food retailers should therefore be found in the object, that is presented as obvious, to bring about that the information is available 'before the purchase takes place' ${ }^{194}$. This assessment raises two questions. The first one concerns the consumers' requirement. Do the consumers actually have the desire to take cognizance of all of the mandatory information at a time prior to the purchase, or does the option to take cognizance of the label information at the time when they have purchased and received the items suffice? ${ }^{195}$ The second question focuses on the mechanism to meet this possible need. Because it is not the food safety that is at issue, but instead the risk of a bad bargain, it might be that less draconian measures than the radical modifying action by the legislator would have been sufficient. Maybe the market itself could act in a self-regulating manner in this.

It appears from the introduction of the information obligation for online retailers that the legislator considers this need to be so great and the capability of the market to provide this need to be so limited that modifying action is required. No study is known in which the results support both assumptions. Because the online market for food in the Netherlands meanwhile covers $5 \%$ of the supermarket turnover and two million Dutch citizens buy food online ${ }^{196}$, there is growing reason to carry out this study.

\footnotetext{
${ }^{192}$ For the benefit of providing food information, attention must be devoted to all manners in which food is delivered to users, including the sale of food through techniques for distance communication. Although it is clear that food delivered through distance sale must comply to the same information rules as food bought in a shop, it also has to be specified that in these cases the accompanying mandatory food information has to be available before the purchase takes place.

${ }^{193}$ The mandatory notification of the minimum durability or 'use by 'date stipulated in in point (f) of Article 9 (1) is exempt from application.

${ }^{194}$ In Lebensmittelinformationsverordnung, Kommentar (2013), Voit and Grube specify the latest date on which the information must be known during the ordering process. Abs. 1 verlangt die Informationsgewährung vor dem Abschluss des Kaufvertrages. Es ist also nicht erforderlich, dass die Angaben bereits in dem Zeitpunkt zur Verfügung stehen, in dem das Lebensmittel angeboten wird. Es reicht deshalb aus, wenn die Angaben erst in einem zweiten Schritt zur Verfügung stehen. Daher kann eine Internetseite etwa so gestaltet werden, dass die Pflichtangaben erst nach dem Anklicken des Buttons 'in den Warenkorb' erscheinen, solange nach der Gewährung der Information die Bestellung ohne Weiteres angebrochen bzw. auf ihre Fortsetzung verzichtet werden kann. Bei einer sehr engen Auslegung des Wortlauts der Bestimmung wäre es sogar möglich, die Angabe erst i einem Zeitpunkt zur Verfügung zu stellen, in welchem die Bestellung des Verbrauchers bindend geworden ist, aber vom Verkäufer noch nicht angenommen wurde. Eine solche Auslegung würde aber der Zielsetzung der LMIV nicht gerecht, denn diese will gerade dem Verbraucher eine bewusste und informierte Kaufentscheidung ermöglichen. Deshalb muss die Bestimmung so verstanden werden, dass die Information dem Verbraucher in einem Zeitpunkt vorliegen muss, in welchem seine Bestellung noch nicht bindend geworden ist.

${ }_{195}$ I invite the reader to some introspection. If you read a food label, does this usually happen in the shop before purchase or at home after purchase?

${ }^{196}$ Smart Food Monitor, figures and trends in food retail (15 September 2016). In 2016, Multiscope carried out a study among 7000 consumers.
} 
Because scientific research is not yet available, currently the consumers' need for the mandatory online information can only be speculated.

A substantial contraindication for the desire to be well-informed about the food to be bought is the considerable growth in food boxes. It is easy to find twenty companies or more when browsing Dutch sites. The HelloFresh company, which was established in 2011, says that currently they monthly provide 4 million meals to 250,000 clients worldwide. Their Dutch database has 75,000 subscribers ${ }^{197} ; 11 \%$ of all Dutch households have meanwhile sampled a meal box and one third continues ordering meal boxes ${ }^{198}$.

Not a single Dutch website that provides food boxes actually states the information that is obliged based on Article 9 in conjunction with Article 14 Food Information Regulation. Based on false grounds, food business operators apparently believe that they are exempt of this information obligation. Indeed, often they provide no information at all about the contents of the box; worse still, concealing the contents is a marketing tool and a sales argument. Food boxes present the fact that they leave consumers in blissful ignorance about what they buy as a selling point. It is not only the nutritional values that are withheld as a service; the food itself remains a secret up to the bottom of the lucky bag.

Some quotes from websites that provide food boxes:

Jamie's food box:

The contents of Jamie's food box varies, but is always surprising and crammed full of products you can use.

Foodelicious:

I opened the package with anticipation and was very curious about what I would find.

Tasty food box:

A very complete box filled with delicious surprises.

Mathijs Maaltijdbox:

The various fruits received are a weekly surprise.

FoodWeLove:

The contents of the box remain a surprise up to the moment they are shipped.

\footnotetext{
${ }^{197}$ Specification by HelloFresh.

${ }^{198}$ Study by Multiscope (2016) among 1,013 Dutch citizens.
} 


\section{Zoyummy:}

The recipes remain a surprise for clients until they receive the box.

The Authority for Consumers \& Markets actively imposes fines on websites that fail to comply with the consumers' right directive implemented to Dutch law in the area of revocation ${ }^{199}$. The ACM, however, is not likely to check labels or the identical obligation to express ${ }^{200}$ for websites. The enforcement of these stipulations is part of the NVWA (Netherlands Food and Consumer Product Safety Authority) domain, but this authority will not enforce them either. In the description of their actions, their website starts by indicating that they avail of limited capacity and are therefore unable to structurally monitor the correctness of labels. Monitoring will remain limited to labelling topics with the greatest health risks ${ }^{201}$.

There is a large and increasing group of consumers that like to be surprised by the contents of the food box and therefore have no interest in detailed information about the food they are buying. The growing market share that acts according to the consumers' wishes yet contrary to the Food Information Regulation, is not likely to be corrected by the NVWA.

Although this development is indicative of the limited desire of consumers to be informed according to the current obligations, it does not give a decisive answer about the magnitude of the category of consumers who do wish to be informed before purchasing.

The second question concerns the instrument that is best used to meet the information requirements.

Consumers have a very powerful and efficient instrument to induce online retailers to desired behaviour. They might choose to buy only from web shops that voluntarily provide the label information in their digital shop-window. The market may look for a perfect match with consumers' needs, because supply and demand are concerned here instead of food safety.

The opinion that legislators merely have a leading role if the market is unable to come to the desired result by itself also prevails outside the rabid liberal circle. The European legislator has obviously considered that online retailers will not voluntarily comply with the information obligation; not even if consumers ask for this. This assumption would, if correct, legitimise the regulations.

It however remains unclear what the legislator based himself on in the implementation of these draconian measures. I consider it desirable for thorough research to be carried out into the consumers' need to take cognizance of the information referred to in Article 9 prior to a purchase. I also believe that, in the case of an urgent need to that effect, suppliers on the fluctuating market of the Internet will be willing to voluntarily comply with this in order to secure or increase their market share.

\footnotetext{
${ }^{199}$ Recent fines for Bever (198,000.00 euro), Coolcat (220,000.00 euro), Bhsupport (50,000.00 euro), Hipvoordeheb (50,000.00 euro), Shoebaloo (72,000.00 euro). See https://www.acm.nl/nl/publicaties/16508/ ${ }^{200}$ With the exception of the mandatory indication of the minimum durability or 'use by' date stipulated in point (f) of Article 9 (1).

${ }^{201}$ The Netherlands Food and Consumer Product Safety Authority (NVWA) website: The NVWA is the obvious authority for the assessment of labelling of foods. Because of their limited capacity, the NVWA is forced to make choices when monitoring labelling. Labelling topics with the largest health risks have a higher priority than other labelling aspects, which means that the NVWA does not structurally monitor the entire correctness of the label, but instead specifically focuses on label components.
} 


\subsection{TO CONCLUDE}

The market share of food boxes continues to increase. The mass violation of the Food Information Regulation is increasing just as rapidly, and along with it an entirely new toleration area for the lucky bag for food.

It is possible that further research and evaluation of current law will involve a reconsideration of Article 14. 


\section{CONCLUSIONS AND DISCUSSION}

\subsection{INTRODUCTION}

Through modifying legislation ${ }^{202}$, the national and European legislature have set out to overcome the negative consequences it may have when purchaser and seller are not in the same room at the moment of conclusion of their transaction. The anonymous character of contact online - enabling the seller to put in place a strategy of 'sell and run/hide' - is counterbalanced by obligations for etailers to provide information about their personal identity.

Again through modifying legislation ${ }^{203}$ the legislatures have set out to overcome the negative consequences it may have when purchaser and product are not in the same room the moment of conclusion of the transaction. Departing from the general approach, in case the product consists of food products with limited shelf-life the instrument of choice is not imposing on the contractual relation a right of withdrawal for the consumer - including the right to return the product - but demanding that all labelling information be available to consumers prior to purchase.

As a consequence, etailers are confronted with far reaching information requirements. These encompass information regarding themselves on the basis of consumer law and information regarding the product on the basis of food law.

In the previous chapters the effects have been discussed of the new legislation on the position of etailers who are caught in the middle between their suppliers and their customers: the consumers. The findings in these chapters now enable is to answer the research questions set out in chapter 1.

The main research questions are:

1) Do the rules and regulations, coming from various heterogeneous sources, that directly affect contractual relations established by digital means between food business and food consumers constitute a coherent whole?

and related to this exploratory main question the normative question

2) How should the regulation of contractual relations established by digital means between food businesses and food consumers be valued in light of the interests involved?

\footnotetext{
${ }^{202}$ Directive 2011/83/EU of the European Parliament and of the Council of 25 October 2011 on consumer rights, amending Council Directive 93/13/EEC and Directive 1999/44/EC of the European Parliament and of the Council and repealing Council Directive 85/577/EEC and Directive 97/7/EC of the European Parliament and of the Council.

${ }^{203}$ Regulation (EU) No 1169/2011 of the European Parliament and of the Council of 25 October 2011 on the provision of food information to consumers, amending Regulation (EC) No 1924/2006 and (EC) No 1925/2006 of the European Parliament and of the Council and repealing Commission Directive 87/250/EEC, Council Directive 90/496/EEC , Commission Directive 1999/10/EC, Directive 2000/13/EC of the European Parliament and of the Council, Commission Directives 2002/67/EC and 2008/5/EC and Commission Regulation (EC) No $608 / 2004$.
} 
By way of roadmap to answering these questions, further sub-questions have been formulated.

The first sub-question:

1.1. Does the distance contract result from digital technology?

The answer turns out not to be a simple 'yes' or 'no'.

\subsection{THE DISTANCE CONTRACT}

In chapter 2 it is argued that the concept of distance contract, defined as a contract entered into by parties who did not physically come together for this purpose, has a long history dating back at least to 1744. In that year, Benjamin Franklin published a catalogue in colonial North America from which readers could order books by mail.

Already Franklin felt that the situation where seller and buyer do not meet in person requires additional protection. In his catalogue, he included the warranty:

"Those persons who live remote, by sending their orders and money to B. Franklin may depend on the same justice as if present."

Thus, the distance contract is far from new. And neither is the law that aims to regulate it.

Current legislation regarding distance contracts does not as such mention digital communication. Franklin's printed catalogue would still fit the concept of this classified contract. The incentive for the legislator to intervene in a prescriptive manner was therefore not prompted by the emergence of a new - digital - technology directly, but rather by the explosive expansion it brought of distance contracting in economic relations.

Prior to the implementation of the Consumer directive the distance contract was defined as:

\section{Article 7:46a CC}

'A contract under a distance sales or service-provision scheme organised by the vendor or service provider with the exclusive use of one more techniques for distance communication up to and including the time at which the contract is concluded.'

Where a 'technique for distance communication' is: 
Article 7:46a(e) CC

'A means suitable for concluding a distance contract without simultaneous presence of the parties in person'.

After implementation of the Consumer directive, the definition of distance contract has been changed to:

Article $6: 230 \mathrm{~g}(1)(\mathrm{e}) \mathrm{CC}$

'A contract concluded between a trader and the consumer under an organised distance sales or service-provision scheme without the simultaneous personal presence of the trader and the consumer with the exclusive use of one more means of distance communication up to and including the time at which the contract is concluded.'

Just like before the implementation, after the implementation reference is made to 'means of distance communication'. Therefore, the scope is beyond digital technology. The fact that parties are not in the same room at the moment of concluding the sale by definition requires a means of communication that bridges the distance. This does not, however, have to be a technologically advanced means. The change the new definition brings, is that it is no longer part of the definition that the scheme is organised by the vendor. This does justice to the emergence and development of online platforms. Also vendors using such platforms come within the scope of the distance contract.

\subsection{THE CONSUMER ONLINE}

The second sub-question reads:

1.2. Which are the rights and duties of consumers online?

This question has been further detailed into:

1.2.1 To what extent does the consumer have the right to annul the distance contract regarding a food product?

And

1.2.2 To what extent does the consumer have the option to hold the supplier of food online product liable?

\subsubsection{The right to know}

The rights of the consumer under the distance contract relate to information prior to concluding the contract and to annulment after the contract. The research chapter show significant development in the consumers' right over time. An important year in this respect is the year 2014. Until 2014 the 
information requirements were codified in Article 7:46c CC $\mathrm{CC}^{204}$ and from 2014 onwards in Article 6:230m CC. Chapter 2 analyses the situation prior to 2014 and chapter 3 the new situation.

Prior to concluding the online sales agreement, the consumer must be informed in ways commensurate to the technology used about the following.

- The identity of the seller. Prior to 2014 indication of the seller's address was only required in case of advance payment. After 2014 all geographical address information must be supplied up front, including the address where complaint can be lodged.

- The most important characteristics of the good. This requirement returns in the CC provision after 2014 in Article 6:230m (1)(a) ${ }^{205}$. However, Article 14 of the Food Information Regulation requires full disclosure of all labelling information expect for the date marking.

- Price, including any taxes, and costs related to the use of distance communication.

- Costs of delivery and manner of payment. Again, Article 6:230m CC goes deeper into detail addressing among others the applicable complaints mechanism.

- Where applicable, the duration of the contract.

Under the pre-2014 provision, consumers needed to be informed about how to exercise their right to withdraw from the contract, ultimately at the time of fulfilment of the contract, i.e. at the delivery. Under the new provision this information must already be available prior to conclusion of the contract.

The requirements regarding provision of address information have been considerably toughened. In the previous legislation no specific reason was stated. In the new, reference is made to complaints procedures. However, it goes without saying that the core issue is to enable consumers to take legal action to uphold their rights. There is no obvious reason to provide this information later than the other information to which the consumer is entitled. The change the legislator introduced in this regard, therefore must be seen as an improvement.

\footnotetext{
${ }^{204}$ Article 7:46 CC

1. In good time prior to the conclusion of a distance purchase, the other party shall be provided with the following information using means adapted to distance communication technologies, of which the commercial purpose must explicitly be made clear:

a. the identity of the seller, and, if the distance purchase requires (part) advance payment, the seller's address;

b. the most important characteristics of the item;

c. the price of the item, including any taxes;

d. the costs of delivery, insofar as this applies;

e. the manner of payment, delivery or execution of the distance purchase;

f. the possible application of the option for dissolution in accordance with articles 46d, paragraph 1 and $46 \mathrm{e}$;

g. if the costs for the use of distance communication are calculated on any basis other than the basic rate: the amount of the applicable rate;

h. the period for the acceptance of the offer, or the period for the fulfilment of the price

i. where appropriate, in the case of a distance purchase which serves to permanent or periodic delivery of items: the minimum duration of the contract.

${ }^{205}$ Article 6:230m (1)(a) CC: the essential features of the goods or services to the extent to which this is appropriate given the medium used and the nature of the goods or services.
} 
Both the old and the new provision in the Civil Code are scarce regarding the obligation to provide information on the product. This makes sense in light of the instrument the Civil Code has chosen in line with the Consumer Rights Directive to protect the consumer. That is to provide the opportunity to examine the product and only then to decide on keeping it or to withdraw from the contract. Initially the consumer was granted a term for this of seven days. This term has been expanded under the new provisions to fourteen days after receipt of the product.

The right to withdraw, or at least the obligation for the etailer to accept withdrawal by the consumer is excluded from certain contracts. Particularly this exception applies to goods that quickly to deteriorate or age. By consequence, the purchase of many foods will be exempted from the right to withdraw.

In the situation prior to 2014, this was awkward. On the one hand the requirement to provide information was limited, but the alternative means that justified this limitation was not available. Therefore, with regard to the situation prior to 2014, chapter 2 found a gap in consumer law. By consequence, consumers had to rely on general contract law. This in turn implied that the consumer had the burden to prove shortcomings by the supplier in the fulfilment of the contractual obligations for the consumer to be able to annul the contract. Given that the problem was not in the nonfulfilment of the obligations but in the lack of clarity of the obligations to be fulfilled, this placed the consumer at a clear disadvantage. This has been straightened out, not by contract law, but by food law.

\subsubsection{The right to withdraw}

The first sub-question further elaborating on the position of the consumer of food online reads:

1.2.1. To what extent does the consumer have the right to annul the distance contract regarding a food product?

The Consumer Rights Directive, requires EU Member States to grant consumers a withdrawal period of fourteen days. For the Netherlands this implied a doubling of the deadline. However, for food online the effect of prolonging the deadline is likely to have limited consequences as many foods will be within the ambit of the exception on the withdrawal right for the supply of goods which are liable to deteriorate or expire rapidly ${ }^{206}$, (in terms of the Consumer Rights Directive) or goods which deteriorate rapidly or have a limited shelf life (in terms of de Dutch Civil Code) ${ }^{207}$

Chapter 3 reflects, among others, on this curious doubling of deterioration and expiration. It seems difficult to assume that a product may be within the scope of deterioration without being within the scope of expiry. After all, is not deterioration just a radical form of expiration? Could not the legislature have limited themselves to exempting 'van the supply of goods which are liable to expire rapidly'? Any other reading would require to somehow distinguish between the two maybe with the help of connecting the term 'rapidly' only to the one and not to the other? Indeed chapter 3 explores possible consequences of this line of thinking. But even seen on itself, the term 'rapidly' deserves more explanation that the legislator gives.

Where the legislator, both European and national, is overbroad in the terminology 'deterioration', they are terse when it comes to 'expiration' or 'limited shelf life. No indication is given about the timeframe. How rapid should a product deteriorate to come within the scope of the exception on the

\footnotetext{
${ }^{206}$ Consumer Rights Directive Article 16(1)(d).

${ }^{207}$ Article 6:230p(f)(2) CC.
} 
withdrawal right? There is no way for etailers to know if they are entitled to exclude for example canned food from the right to withdraw. If, however, they fail to mention the right to withdraw they have to face the consequence of a prolonged deadline. ${ }^{208}$ The legislator did consider the situation where the etailer mentions the withdrawal right belatedly, ${ }^{209}$ but not the applicable durability. One could argue several ways. On the one hand one could frame 'rapidly' in light of the timeframe of the right of withdrawal - i.e. fourteen days. On the other hand, one could focus more on the type of product and opt for a longer period. In chapter 3, a case is made to interpret 'rapidly' as meaning within one year.

\subsubsection{The right to claim for damages}

With rights come remedies. So directly related to the questions about the legal position of the food consumer online is the question what are the instrument these consumers have available to enforce their right.

In this vein sub-question 1.2.2. asks: To what extent does the consumer have the option to hold the supplier of food online product liable? This question focuses the issue on product liability.

The analysis to answer the question is performed in chapter 4 . In product liability specifically and only safety issues are at stake. ${ }^{210}$ The connection to food law seems obvious. Food law focuses on safety from the other direction in the context of a specific - potentially highly hazardous - type of products: food. ${ }^{211}$ Therefore, a rather intensive cross-fertilisation between the areas of law is to be expected. This expectation, however, meets with disappointment. With the exception of some attention dedicated to possible product liability for agricultural products, the legislator did not specifically address food in the context of product liability. Chapter 4 carefully scrutinises the history of product liability law from the perspective of food.

The chapter further assesses whether consumers have more or different possibilities to hold etailers product liable. Or, phrased from the perspective of the etailer, whether the risk to be held product liable increases for a retailers when they decide to switch or expand from offline to online. The evidence set out in chapter 4 shows that, indeed, both the Consumer Protection Directive and the Food Information Regulation contribute to increasing the risk of product liability.

The legislative design is straight forward. It starts by holding the producer liable for all safety defects in a product from which a consumer suffer damages and then goes on to classify ${ }^{212}$ a wide variety of

\footnotetext{
${ }^{208}$ Consumer Rights Directive Article 10 (1) If the trader has not provided the consumer with the information on the right of withdrawal as required by point (h) of Article 6(1), the withdrawal period, shall expire 12 months from the end of the initial withdrawal period, as determined in accordance with Article 9(2).

${ }^{209} 2$ ) If the trader has provided the consumer with the information provided for in paragraph 1 of this Article within 12 months from the day referred to in Article 9(2), the withdrawal period shall expire 14 days after the day upon which the consumer receives that information.

${ }^{210}$ Article 6:186 (1) CC A product is defective, when it does not offer the safety which can be expected, all circumstances considered and especially a) the presentation of the product; $b$ ) the reasonably to be expected use of the product; $c$ ) the time at which the product is brought into circulation.

${ }^{211}$ According to Article 5(1) of Regulation (EC) 178/2002 (GFL): "Food law shall pursue one or more of the general objectives of a high level of protection of human life and health and the protection of consumers' interests, including fair practices in food trade, taking account of, where appropriate, the protection of animal health and welfare, plant health and the environment."

${ }^{212}$ Article 6:187(2) A 'producer' is the manufacturer of the end product, the manufacturer of a raw material or the manufacturer of a part, as well anybody who presents him/herself as a manufacturer by attaching their name, trademark or other distinguishing feature to the product.
} 
businesses as 'producer' in the special meaning attached to this concept, while some other receive similar treatment without actually being classified as producer. ${ }^{213}$

In principle, the etailer as such does not classify as producer. However, etailers are responsible to disclose their supplier to consumers who suffer harm from unsafe products on pain of being held liable themselves. ${ }^{214}$

Digitalisation of contacts in the chain leads to increased anonymity. There is just one player in the chain who is confronted with a legal requirement to expose themselves: the etailer. On the basis of the legislation implementing the Consumer Rights Directive, the etailers must disclose their identity on contact information. As this disclosure has to take place on the Internet, for all practical purposes access to this information is not limited to consumers in their role of chain partners. The information is available to all, regardless the position they hold in the chain. Indeed identity and contact information of etailers are in the public domain. Contrary to what one might expect, the obligations on traceability ${ }^{215}$ do not result in a similar outcome for other food business operators. First of all, the traceability information is only available to the business partners of the operator who supplied or purchased a food producing animal, food ingredient or food. It is available - but only potentially - to public authorities. In case of incidents they can request this information. Traceability information certainly is not within the public domain. Furthermore, traceability is focussed on the flow of products (foods) - in other words on facts. Its purpose is to find and eliminate food safety problems, not to identify legal entities. ${ }^{216}$ Liability is not about who factually handled the food but about the legal entity that can be held accountable. If the traceability information available to the etailer does not match the liability information needed by the damaged consumer, etailers may not be able to escape liability by disclosing the identity of an entity that classifies as 'producer' in the sense of product liability law. In such situation, the consumer can hold the etailer equally liable as the producer.

This is not the only cause for an increased liability risk. Producer within the meaning of product liability law is anyone who attaches their name, trade mark or other distinguishing mark to a product. The way of doing business only almost inevitably leads to a need for the etailer to package and wrap the product for transport to the consumer. If the packaging material, indeed the address label, holds a sign or symbol directly related to the etailer this may already suffice to classify the etailer as producer no matter there was not any actual involvement in production.

In the Internet area, physical distance lost its relevance. Products can be purchased from anywhere on the globe. Etailers as businesses active on the internet may easily bring product from outside into the European Economic Area. If they do, they classify as producer or at least they are equally held liable because importers in the EEA are considered producer for the purpose of product liability.

The most important factor, however, contributing to increase in the liability risk of the etailer is Article 14 of the Food Information Regulation. The etailer is responsible for providing consumers all

\footnotetext{
${ }^{213}$ Article 6:187 (3) Without prejudice to the liability of the producer, the party that imports the product into the EU as part of commercial activities can be liable as a producer.

${ }^{214}$ Article 6:187 (4) If it cannot be ascertained who the manufacturer or importer is, the supplier can be held to account as if he were the manufacturer, unless they identify the manufacturer or importer within reasonable time.

${ }^{215}$ See Article 18 of Regulation (EC) 178/2002.

${ }^{216}$ In European Food Law Handbook p.361 Van der Meulen states: The intention of the traceability system is therefore to enable food safety problems to be identified at the source, and across the food chain. To this end food business operators must keep comprehensive records of exactly where their food material originated and where it went.
} 
information required by the Food Information Regulation. There is no escaping liability in case of any safety relevant mistake or omission. It makes no difference for the liability of the etailer towards the consumer whether the information provided by the etailer was or was not identical to the information provided by the manufacturer. It makes no difference whether the etailer actually could have accessed to correct information regarding the composition and condition of the product, not that the specific health sensitivities of the consumer were unknown to the etailer.

This analysis also implies an affirmative answer to question '1.3.6. Does the etailer qualify as product liable producer?'

Nowhere, the national or European legislature indicate to have considered the consequences discussed in this section. Even less so did they express themselves on the desirability of the resulting distribution of legal risks.

\subsection{THE ETAILER}

\subsubsection{Trader}

In looking at liability, the perspective of the etailer already gained prominence. The next set of research questions directly addresses the etailer. Sub-question 1.3. asks 'Which are the rights and duties of the opposing contract partner of the consumer?' This question has been further sub-divided in seven detail questions. Because legal relations always have at least two sides, much of what can be said about the etailer is the flipside of what has been said about the consumer online.

The first of the detail questions aims to bring the etailer as such into the light. '1.3.1. Who qualifies as 'trader' (i.e. etailer) in distance contracts?'

Through the implementation of the Consumer Rights Directive and the coming into force of the Food Information Regulation, a considerable package of information obligations has descended upon the etailer. Both for the buyer and for the seller of food online it is vital to know if their transaction classifies as a distance contract because they themselves classify as consumer ${ }^{217}$ and $\operatorname{trader}^{218}$ respectively. Because if such is the case, the law imposes a large range of rights for the consumer and corresponding obligations for the etailer.

In the old law -i.e. prior to 2014 - the legal concept of distance purchase was a subcategory to the legal concept of consumer contact. In the context of consumer contracts seller and buyer were defined ${ }^{219}$ as the 'seller who acts in the exercise of a profession or business, and a buyer, a natural person who does not act in the exercise of a profession or business'. This old definition has the charm that it mirrors the element of 'acting in the exercise of a profession or business'. However, neither the old nor the new definition provide a clear delineation.

\footnotetext{
${ }^{217}$ Consumer Rights Directive Article 2 (1) 'consumer' means any natural person who, in contracts covered by this Directive, is acting for purposes which are outside his trade, business, craft or profession:

${ }^{218}$ Consumer Rights Directive Article 2 (2) 'trader' means any natural person or any legal person, irrespective of whether privately or publicly owned, who is acting, including through any other person acting in his name or on his behalf, for purposes relating to his trade, business, craft or profession in relation to contracts covered by this Directive.

${ }^{219}$ Article 7:5 (1) CC (...) a seller who is acting for purposes relating to his trade or profession and a buyer, a natural person, who is not acting for purposes relating to his trade or profession.
} 
The 'soft' delineation becomes the more dissatisfactory with the increase of legal consequences that come with its fulfilment - or lack thereof. At present no yardstick is available to asses when (i.e. at which turnover or which investment ${ }^{220}$ ) the hobby-farmer becomes to be classified as trader with all obligations and risks that come with this classification. In the section on recommendations, I will propose some criteria for an improved delineation. At this point all that can be concluded is that etailers are professional traders.

\subsubsection{Transparency on identity}

Chapter 3 has analysed the etailers' obligations to provide information regarding themselves. Implementing the Consumer Rights Directive, the Dutch legislator has put in place ${ }^{221}$ that traders must in a clear and understandable manner provide information regarding their identity, trade name, geographic address of location, phone and fax number, and - when applicable - identity and geographic address of the party for whom the trader is operating. Further the trader is instructed to provide the geographic address where consumers can submit their complaints if this address differs from the above. In particular the attention given to the situation where the trader is representing another entity is indicative of the legislator's intention to identify the etailer as the party the consumer can engage in litigation.

\subsubsection{Transparency on the contract}

The third detailed question regarding rights and obligations of the etailer focuses on transparency requirements regarding the contract. '1.3.3. Which information requirements apply to etailers regarding the contract?

As regards the content of contract, the etailer must inform the consumer on all aspects of the price. This includes taxes, costs related to the distance communication and costs of shipment - or at least information on how these are calculated in case this cannot be done in advance. In case of contract with a certain duration - like a subscription to food boxes discussed in chapter 5 - the price per invoice period must be indicated.

Further, the consumer must be notified in advance, or at least before the contract is concluded, about the manner of payment, delivery, fulfilment of the contract by the trader, the time limit for the delivery and the complaints policy.

Consumer must be informed about all aspects of their withdrawal rights. ${ }^{222}$ All these obligations are included in Article 6:230m of the Civil Code.

\subsubsection{Transparency regarding food products}

In chapter 3 an answer is provide to the question: '1.3.4 Which information requirements apply to etailers regarding the food product at issue?' It is shown that the gap in consumer law caused by the lack of a detailed information requirement regarding the product in combination with the exemption on the withdrawal right to perishable products (probably including most foods) is healed by the Food Information Regulation. The Food Information Regulation requires the etailer to provide all labelling

\footnotetext{
${ }^{220}$ Many criteria can be made applicable.

${ }^{221}$ Article 6:230m CC.

${ }^{222}$ Article 6:230m(h) CC.
} 
information online prior to the conclusion of the contract. ${ }^{223}$ The mandatory information is listed in Article 9 of the Food Information Regulation and further elaborated in the body and annexes of this regulation. ${ }^{224}$

\subsubsection{Liability for information failures}

The fifth detailed question '1.3.5. Can non-compliance with information requirements cause product liability?' addresses the legal consequence of non-compliance with Article 14 of the Food Information Regulation in terms of liability. As elaborated above in the context of question 1.2.2. consumers may rely on the information the etailer must provide in the basis of Article 14 of the Food Information Regulation. In case mandatory information of high relevance to a particular consumer is missing such as reference to the presence of milk in case of a lactose intolerant consumer - the product although safe for most consumers may become unsafe for this particular consumer. Therefore, the product does not provide the safety this consumer is entitle to expect as expressed in Article 6:186 of the Civil Code. The consumer's expectation may be based - still in the wording of Article 6:186 of the Civil Code - on 'the presentation of the product'. First and foremost in this presentation is the labelling information.

In case consumers lodge claims against an etailer for physical harm suffered as a consequence of the presence of substances in a food they need not have expected on the basis of the information provided, they may expect a number of objections. The etailer may argue that unsafety should be taken in an objective sense disregarding particular personal sensitivities. ${ }^{225}$ Further, the etailer may wish to argue that the lack in information provision has been remedied when the consumer received the actual product displaying the correct labelling information. At the end of this chapter some

\footnotetext{
${ }^{223}$ Article 14 Food Information Regulation:1. Without prejudice to the information requirements laid down in Article 9, in the case of prepacked foods offered for sale by means of distance communication: (a) mandatory food information, except the particulars provided in point (f) of Article 9(1), shall be available before the purchase is concluded and shall appear on the material supporting the distance selling or be provided through other appropriate means clearly identified by the food business operator. When other appropriate means are used, the mandatory food information shall be provided without the food business operator charging consumers supplementary costs; (b) all mandatory particulars shall be available at the moment of delivery. 2 . In the case of non-prepacked foods offered for sale by means of distance communication, the particulars required under Article 44 shall be made available in accordance with paragraph 1 of this Article. 3. Point (a) of paragraph 1 shall not apply to foods offered for sale by means of automatic vending machines or automated commercial premises.

${ }^{224}$ Article 9 Food Information Regulation: 1. In accordance with Articles 10 to 35 and subject to exceptions contained in this Chapter, indication of the following particulars shall be mandatory: (a) the name of the food; (b) the list of ingredients; (c) any ingredient or processing aid listed in Annex II or derived from a substance or product listed in Annex II causing allergies or intolerances used in the manufacture or preparation of food and still present in the finished product, even if in an altered form; (d) the quantity of certain ingredients or categories of ingredients; (e) the net quantity of the food; ( $f$ ) the date of minimum durability or the 'use by' date; (g) any special storage conditions and /or conditions of use; (h) the name or business name and address of the food business operator referred to in Article 8(1); (i) the country of origin or place of provenance where provided for in Article 26; (j) instructions for the use where it would be difficult to make appropriate use of the food in the absence of such instructions; $(k)$ with respect to beverages containing more than $1.2 \%$ by volume of alcohol, the actual alcoholic strength by volume; (I) a nutrition declaration.

${ }^{225}$ Indeed in the context of the unsafety concept in Article 14 of Regulation (EC) 178/2002 it has been argued that the presence of an allergen only makes a food unsafe if the food specifically makes the claim that it is free of this allergen or that it is intended for people suffering from the allergy at issue. For sources see: B.M.J. van der Meulen, The Core of Food Law. A Critical Reflection on the Single Most Important Provision in All of EU Food Law, European Food and Feed Law Review 3/2012, p. 117-125.
} 
further thoughts will be presented. May is suffice at this point to indicate that due to the mandatory character of Article 14 of the Food Information Regulation, such defences will not hold.

\subsubsection{Product Liability}

The etailer as such is not a product liable producer within the meaning of Article 6:187(2) of the Civil Code. This does not mean, however, that the answer to question '1.3.6. Does the etailer qualify as product liable producer?' is always to the negative. As discussed above in section 6.3.3., chapter 4 shows that for several reasons the etailer is easily included into the circle of product liability.

It was argued that for the purpose of shipment the etailer is likely to package and wrap the product and that adding a name, trademark or other distinguishing sign will classify the etailer as product liable producer. The etailer may wish to contest the reasoning that adding their identity to the package is a presentation within the meaning of product liability law. The issue will have to be assessed on a case-by-case basis. In light of the increased role of platform that will certainly desire to exclude or insure product liability, the issue needs further attention in the near future.

\subsubsection{Import}

Digital trade easily becomes international trade. Chapter 4 addresses the internationalisation of trade. In doing so, it answers question '1.3.7. Who classifies as product liable importer in the digital food chain?' Distance has become irrelevant for communication. And costs of transport make an ever decreasing contribution to the overall costs of products. Value chains - also those of foods - have become global. Purchase agreements between etailers and their suppliers bring etailers within the scope of product liability when they cause products to be brought into the European Economic Area. ${ }^{226}$

Etailers may not perceive a whole lot of difference between frozen duck bought in Italy or in China. However, their legal position regarding consumers is largely affected by the country of origin.

\subsection{IS THE NEW LEGAL FRAMEWORK FOR FOOD ONLINE ADEQUATE IN VIEW OF THE NEW MARKET SHAPES?}

\subsubsection{Introduction}

Chapter 5 addresses the emerging market for food boxes. The agreement on the basis of which these boxes are delivered, is a distance contract. ${ }^{227}$

The chapter shows that the food information requirements apply unabridged to etailers selling foods online in compositions for their own choosing. Not a single supplier of food boxes has been found in the Netherlands who actually complies with these requirements. As a matter of fact, absence of information is a large advertised marketing tool. Consumers appear to appreciate surprise more than information.

\footnotetext{
${ }^{226}$ Article 6:187 paragraph 3.

${ }^{227}$ For it meets the criteria set out in Consumer Rights Directive (2) (7) 'Distance contract' means any contract concluded between the trader and the consumer under an organized distance sales or service-provision scheme without the simultaneous physical presence of the trader and the consumer, with the exclusive use of one or more means of distance communication up to and including the time at which the contract is concluded.
} 
The chapter not only draws attention to the magnitude of the obligations and related burdens that Article 14 of the Food Information Regulation brings to etailers, but is also puts these into perspective by highlighting the consumers' limited interest.

The market, the etailer and the consumer they all happily ignore the law and thrive. Due to lack of urgency legal enforcement is not to be expected (as long as no mayor outbreak makes the headlines). A new sector is emerging in shadow of the law enabled by a policy of non-enforcement.

On the basis of the answers found to the sub-questions in this research, it is now possible to answer the main research questions:

1) Do the rules and regulations, coming from various heterogeneous sources, that directly affect contractual relations established by digital means between food businesses and food consumers constitute a coherent whole?

and more normative

2) How should the regulation of contractual relations established by digital means between food businesses and food consumers be valued in light of the interests involved?

\subsubsection{The legal system of food online}

The first research question aims to unravel a coherent system of consumer protection law. In chapter 1 it has been argued that 'regardless of the presence or absence of coherence in the design, law always will be systematic'. There will always inevitably emerge - at least that is the hypothesis - a new system of law. ${ }^{228}$ We view the same in nature where a new equilibrium - a new eco-system emerges after each introduction or appearance of an exotic species. The question remains, however, of the new legal system is fit for purpose or if it brings unanticipated side-effects. To remain with the metaphor: is it a viable new eco-system that emerges or rather a Lake Victoria type of situation.

The legal empowerment of the consumer brings of information obligations to the etailers regarding three elements of the distance contract: information regarding their identity, information regarding the contract and information regarding the product. All this information gets into the public domain. It strongly affects the legal position of etailers not only with consumers, but with their suppliers as well.

An example may serve to elucidate.

Imagine a consumer suffering damages from an adverse physical reaction to a food purchased online. In the webshop no reference was made to the presence of the ingredient that caused this reaction. The supplier had not provided the etailer this information. De consumer suffers bodily harm and loses income.

Obviously, the consumer will direct any legal action towards the etailer invoking the etailers obligation to provide this information in the webshop. The consumer can invoke a variety a legal tools.

\footnotetext{
${ }^{228}$ See Chapter 1 Theoretical framework.
} 
The consumer can reproach the etailer to have supplied a product not conforming to what the consumer was entitled to expect. ${ }^{229}$ In view of the mandatory information requirements the consumer was entitled to expect the non-declared substance to actually be absent. The etailer's performance suffers from non-conformity. It did not provide the safety the consumer was entitled to expect. This makes the etailer product liable towards the consumer.

Simultaneously, supplying this product equals a faulty performance of the contractual obligations. ${ }^{230}$ The legally required information provision is part of the contractual obligation. In all likelihood the etailer cannot take recourse to invoking force majeure. Regardless if the etailer was not aware of the presence of the substance. Indication of the presence of the substance is a legal obligation. Nonfulfilment can therefore be attributed to the etailer also in the absence of fault. ${ }^{231}$

Furthermore the etailers runs a high risk of being considered 'producer' within the meaning of product liability law $w^{232}$, by consequence they are likely to be held liable at the very least for damage to the health of consumers. ${ }^{233}$ The product does not provide the safety consumers were entitled to expect on the basis of the information provided.

To be able to sue the etailer, the consumer needs to be able to trace the etailer. The etailer is under obligation to provide all the required information in the webshop. ${ }^{234}$

Etailers in turn may wish to pass on liability to their supplier who actually made the shortcoming in providing information. Etailers, however, are not endowed with the legal instruments provided to the consumer. If, on top of this, they lack the bargaining position to make up for this through contractual agreements, liability will remain at their side of the legal filter.

From two rather differing legal areas, consumers are empowered through obligations imposed upon their supplier online. This empowerment is such that no-longer the consumer is the weakest link in the chain. As a consequence of the improved position of the consumer and their own unchanged position towards parties upstream the food chain, the position of weakest link has shifted to the etailer. The etailer is a sitting duck for legal actions both from below and from above.

The research question focuses on coherence in the system. This is clearly achieved in the regulation of the relation within the system between consumer and etailer. These two parties are subject to a cluster of rules governing the creation of contractual relations. From the perspective of the functional approach to food law, this entire cluster is to be considered food law.

From the regulatory perspective, however, there are to be distinguished to separate systems; one civil law, the other food legislation. The question of coherence is about the way these two systems

\footnotetext{
${ }^{229}$ Article 7:17 CC.

${ }^{230}$ Article 7:18 CC.

${ }^{231}$ Article 6:75 CC.

${ }^{232}$ Article 6:185 CC.

${ }^{233}$ Article 6:190 CC.

${ }^{234}$ Directive 2011/83/EU, Article 6, 1 Before the consumer is bound by a distance or off-premises contract, or any corresponding offer, the trader shall provide the consumer with the following information in a clear and comprehensible manner: a) the main characteristics of the goods or services; b) the identity of the trader such as his trading name; c) the geographical address at which the trader is established and the trader's telephone number, fax number and e-mail address, where available, to enable the consumer to contact the trader quickly and communicate with him efficiently and, where applicable, the geographical address and identity of the trader on whose behalf he is acting;.
} 
co-exist, cooperate and mutually influence each other. If coherence is measured by the occurrence of conflicting rules and requirements, then we can conclude that a coherent system if consumer protection has emerged. The research did not bring any unresolved conflict of contradictory rules. ${ }^{235}$ If, however, coherence is measured by the harmonious nature of legal instruments, the new system clearly is blatantly incoherent.

In civil law transparency requirements regarding the nature of the product are subordinate. It is only the most important characteristics of the product that must be mentioned. Limited trust in accurate provision of information regarding the product as a basis for a satisfactory contract has induced an alternative which for the market is of a rather far reaching nature. This alternative is endowing consumers with the right to withdraw. This for webshops burdensome provision was considered necessary to provide consumers an adequate level of protection.

The reasons that brought the legislators to this draconian measure, do not lose their relevance in case the products concern food. Yet, in the case of food the legislators embraced the instrument they had previously rejected by imposing a high level of information provision. Not only did they chose the instrument earlier considered not to be good enough, the failed to provide sufficient clarity on its details.

There is a variety of blind spots.

What does expiring rapidly mean?

Which requirements must be met for an etailer to be a trader?

What is the legal position of online platforms?

How do the new types of market fit into the system?

Because the criteria remain rather soft, one cannot conclude that the system shows concrete contradictions. However, it provides too little certainty to allow for adequate legal risk management. It seems plausible that in the long run only those etailers possessing sufficient bargaining power in relation to their predecessors in the food chain, will be able to sustainably provide food products in the shops along the digital highway. Etailers that lack such power survive thanks to the fact - and so long as this situation remains unchanged - that consumers fail to pick up the weapons the legislator provided them and that enforcement agencies like ACM and NVWA largely direct their priorities elsewhere. The mere fact that the new legal system does not do undue harm as long as it is not actually used, however, cannot serve as a basis to applaud the legislators' achievement.

\subsubsection{The quality of the legal system of food online}

This brings us to the second main research question. Did the legislators achieve a fair balanced of interests? More specifically, is the legal burden that the legislation gives the etailer to carry justified by the consumers' interests that they protect?

It is quite possible that a certain preventive effect - difficult to measure - is caused by the legal position imposed upon the etailer. Therefore, the mere fact that so far hardly any legal action neither individual nor collective - has been undertaken by online consumers against their suppliers,

\footnotetext{
${ }^{235}$ Contradictory rules are classified is 'Collision' in the matrix on p.19.
} 
does not inevitably lead to the conclusion that the legislation is superfluous. It is, for example, conceivable that to obligation to provide address information contributes to increasing overall compliance with the Consumer Rights Directive and the Food Information Regulation.

Both the directive and the regulation serve consumers' interests. The information requirements for the etailers from the Consumer Rights Directive focus on their person and the transaction. Those from the Food Information Regulation on the product. It is not difficult to imagine both sets of information requirements to be absent. Would the market function any different? Would the online market not be able to ensure the desired behaviour of etailers? Let us revisit the different requirements.

\section{Information in the identity of the etailer}

The interest consumers have to know in a legal sense who they are dealing with and how they are dealing is so obvious that absence of transparency in these matters is likely to induce consumers to refrain from the transaction altogether. This is no different form a physical shop where appearance greatly contributes to consumers' decision to enter or not to enter. Usually consumers recognise a shady shop as such.

In the physical world with shops of bricks, the legislators do not provide any instructions how businesses should inform about their identity. This should not surprise given the fact that the address is a given for all who enter the shop. With this address and some information from the chamber of commerce it will usually not be difficult to acquire all legal information regarding the seller that the consumer might need.

The online consumer, for reasons of liability or other may need information regarding the physical address and identity of the seller. For that reason, the consumer might decide to forgo the transaction in case the seller does not volunteer such information. These options for the consumer provide an incentive for the etailer.

The motivating factor for the legislator not to rely on market forces may have been - the recitals nor the legislative history provide information - the fear that consumers will only start to look for the legal identity of the seller after a problem has occurred in the transaction. This fear may in many cases be well-founded.

Nevertheless, the strategy consumers apply in the real street when deciding to access a shop or not, can be just as easily applied along the digital highway. In fact, by imposing all these disclosure obligations the legislator may have imposed an uniformity that makes it more difficult rather than more easy for consumers to recognise shady businesses and to become streetwise along the digital highway.

\section{Information regarding the product}

Information on the composition of a food product prior to purchase online, clearly meets a relevant need of consumers. Another matter altogether is whether the need is so great that the legislator must interfere with the contractual freedom of the parties by imposing all kind of obligations.

First of all, the need must be put into perspective. The information as required is not necessary for the decision of the consumer to consume the product or not. After all, the obligation to provide the 
information prior to the purchase does not come in place of the mandatory labelling information, but rather on top of it. Thus, this additional information requirement does not protect a consumers from consuming an unwanted product, but from buying a product that the consumer would not want to consume.

In other words, the information obligation protects a financial interest of the consumer that is no greater than the actual price of the product at issue. The mandatory information may protect consumers from spending this sum - which by definition is relative small: someone who spends a large sum on one type of food, does not act as consumer. Consumers spend large sums on single types of food only due to repeated purchases. However, after the first purchase the information online does not play any role anymore in the consumers' decision to engage in further purchases. The product then is known on the basis of experience.

Maybe one issue should be highlighted. If for the consumer not consuming a certain product is not just a matter of preference, but of principle the importance for the consumer not to buy the product may go beyond its mere costs. Think of a vegetarian or indeed a vegan. Such person may not only want to refrain from consuming products of animal origin but also from supporting the use of animals in preparing such products by buying them. For such a consumer, the assessment that a product contains ingredients of animal origin may after purchase be belated. However, such consumer can decide to buy online from webshops that express the same outlook on life or otherwise provide the required assurances.

Chapter 5 discusses an emerging new market that is highly illustrative of the limited interest online consumers - or at least a group among them - actually show in the mandatory information. The rapid growth of the market for food boxes provides a strong counter-indication for the existence of a strong desire at the part of online consumers to be well-informed about the foods they buy. Those who purchase a food box online - in the Netherlands $11 \%$ of households has done so at least once ${ }^{236}$ - is usually to a larger or lesser degree surprised by the content of the box. In this research, the mandatory food information has not been found at a single website of the suppliers of food boxes assessed. In fact, keeping the information from the consumer has become a marketing tool. Not transparency, but surprise regarding the content is the proposition used to lure the consumer.

By no means is the far reaching range of mandatory requirements imposed upon etailers justifiable in light of the rather limited interests it serves. The mayor burden for etailers protects an interest that is not bigger that the risk of the occasional bad buy - a risk furthermore that in many situations the consumer knowingly accepts.

\subsection{CONCLUSION}

The current research shows that the rules and regulations, coming from various heterogeneous sources, constitute a coherent whole in the sense that while overlapping and sometimes repeating there have not appeared inconsistencies that require immediate action form the legislature to control possible damages. Nevertheless, the instruments chosen for consumer protection are crude and blunt in the one hand and soft and blurry on the other hand.

The obligations imposed upon etailers mount up to an unequally balanced system. The interests of the consumer served by the information obligations for etailers are minor. They do not affect

\footnotetext{
${ }^{236}$ Researched by Multiscope. see: foodboxwijzer.nl/home/blogs/onderzoek/.
} 
consumers' health and do not go beyond the value of the individual purchase. The consequences for the etailer in terms of liability, however, are such that no longer the consumer but the etailer has become the weakest link in the food chain. A weakest link, that so far is lacking in any special legal protection.

\subsection{DISCUSSION AND RECOMMENDATIONS FOR FURTHER RESEARCH}

\subsubsection{Durability}

At present it is unclear which time limit to durability of a product causes the cessation of the consumers' right to withdraw. Prior to the Consumer Rights Directive, Dutch legislation applied the formula 'goods that can rapidly deteriorate or age'. In this formulation it was unclear whether 'rapidly' applied only to deterioration or also to aging; thus if the provision applied only to fast aging or to any aging. After implementation of the directive, the law reads 'goods that deteriorate rapidly or are of limited durability'. It still remains unclear with timeframe is covered by 'rapidly' and 'limited' but it seems to be longer than under the old text. The current wording does not beforehand exclude a durability of - say - twenty years.

Particularly with products that have their expiration marked on the label - i.e. foods - it would have been easy to indicate an exact time limit distinguishing products that are and products that are not considered to be within or outside the category of products of limited durability. So, the question faces us which time limit should be chosen.

Generally speaking, the legislator is inclined to choose open phrasings. Such open phrasings provide discretion to the courts to apply reasonable and fairness to come to conclusions on a case-by-case basis that do justice to all particularities of the case at hand. In the case of durability such elaboration in case law may be long in the waiting. A court case on a jar of jam does not seem likely. By consequence, it is up to legal scholarship to suggest solutions.

Why would products of limited durability be excluded from the right to withdraw in the first place? The only reason would be in the value the returned product might still have for the etailer. In other words, a product that cannot be sold again should be excluded from the right to withdraw. In this line of thinking, one could relate to the timeframe for withdrawal. The timeframe for withdrawal is fourteen days. So a durability should be considerably longer than fourteen days to not be considered limited. How much longer? If we double this term to a month, the following consumer would receive a product of very limited durability indeed.

A considerably longer timeframe seems to make more sense. If the Food Information Regulation by imposing the information requirement on etailers indeed intends - the legislators do not express themselves to this issue - to compensate the absence of the withdrawal right, it stands to reason to avoid as much as possible overlap between categories of products within the ambit of the withdrawal right and categories of goods within the ambit of the increased information obligation.

Furthermore, in choosing a distinguishing time limit it is desirable to opt for a duration that is rarely used. This to avoid a rather arbitrary tilting point between products are just inside or just outside the 
one category or the other. Furthermore, the remaining durability for the second consumer becomes less sensitive. ${ }^{237}$

In view of these considerations, we propose to consider as tilting point to limited or not limited durability the moment of one year until the indicated durability date. With such timeframe fresh products are all clearly within the scope of limited durability and dry products, canned food and other conserves clearly outside. If we accept this starting point for further research and discussion, such research and discussion may yield an even better substantiated choice. Public authorities such as the European Commission in comitology are well advised to take it upon themselves to express a position in a guidance document or other authoritative interpretation of the law.

\subsubsection{Platforms}

In the period covered by this study, the definition of distance contract has been altered. Most striking is that the old phrasing referred to 'a in the context of a sales system organised by the seller or service provider'. Current legislation has abandoned the requirement that the system is organised by the seller or service provider. The EU legislator in the directive has rightfully acknowledged that online trade increasingly takes place through systems organised by a third party. ${ }^{238}$ Small and not so small suppliers of food online increasingly choose to conclude transactions with consumers through large platforms such as 'marktplaat', 'Ebay', 'Just Eat' and 'Thuisbezorgd'.

It is conceivable that such platforms will play a role in ensuring compliance by etailers. In the People's Republic of China the food legal system is adjusted in such a way that platforms can be held accountable for all infringements committed by traders using their system. ${ }^{239}$ To enable platforms to actually bear this responsibility, the Chinese Food and Drug Administration has mandated the platforms to impose binding rules upon traders using their system. Time and further research will have to show what role platforms will ultimately play in food online. It does not seem likely that the Chinese model will be adopted in Europe, but close attention for the role of platforms in the relation between consumer and etailer will become urgent.

\subsubsection{Applicability of the legal framework}

The Internet has reshaped societal roles. Anybody can be supplier just as easily as customer. Via social media everybody both broadcasts and watches/listens. Via platforms everybody is buyer and seller. Many perceive this interchangeability of roles as the single most important contribution the Internet has made to the quality of life. The thought, however, that the market is accessible to all runs into limits through legislation that applies to traders as soon as their activities take on a certain (or rather uncertain) amount of business characteristics. It is important to pinpoint the turning point where the unregulated trade between private persons becomes the heavily regulated distance sales of food.

\footnotetext{
${ }^{237}$ In Article 14 of the Food Information Regulation the information about the date of minimum durability or the 'use by' date is excluded.

${ }^{238}$ Platforms mainly offer a collective marketing and sales vehicle.

${ }^{239}$ Pinghui Xiao, China's Rising Online Food Trading: Its implications for the Rest of the World and Regulation, working paper submitted for publication (2017).
} 
The distinction between trader and trading private person is relevant in several areas of law. Tax authorities in the Netherlands apply an 'hour-criterion' to distinguish the two. ${ }^{240}$ In the years 2016 and 2017 a person spending 1.225 hours or more to business like activities is considered and entrepreneur. However, this policy is subject to criticism. It is suggested to replace it by a turnover criterion. ${ }^{241}$

Possibly such criterion might prove helpful. A curious side effect would be that the legal relation between buyer and seller would completely depend on the frequency and success with which the sellers open their booth on the digital market placed.

Further research or case law needs to provide a suitable model.

\subsubsection{Applicable law}

Globalising communication, decreasing costs and increasing efficiency of transport contribute to lengthening the last link in the food chain - the one between supplier and consumer. Food online will be traded over ever increasing distances. In 2015 at the World Economic Forum in Davos, Jack Ma the founder of Alibaba - the leading platform in China - expressed the expectation that in the near future 400.000 traders will supply a global market with food products via his platforms.

At present the question which law (including the provisions of the Consumer Rights Directive and the Food Information Regulation) applies to these transactions, is answered on the basis of criteria that rapidly decline in relevance. New criteria need to replace them.

In case the Rome Treaty ${ }^{242}$ applies the provisions of this treaty must be consulted to establish if the provisions from consumer law and food law apply that have been discussed in this thesis. The Rome Treaty provides points of departure ${ }^{243}$, but no solid criteria. The second paragraph of Article $4^{244}$ in

\footnotetext{
${ }^{240}$ Besides the requirement of spending 1.225 hours or more to qualify as entrepreneur, it also must be the main activity.

${ }^{241}$ Organized small entrepreneurs have suggested a turnover criterion of 10.000 euro annually.

${ }^{242}$ Convention on the law applicable to contractual obligations: Article1. 1. The rules of this Convention shall apply to contractual obligations in any situation involving a choice between the laws of different countries. 2 . They shall not apply to: (a) questions involving the status or legal capacity of natural persons, without prejudice to Article II; (b) contractual obligations relating to: wills and succession, rights in property arising out of a matrimonial relationship, rights and duties arising out of a family relationship, parentage, marriage of affinity, including maintenance obligations in respect of children who are not legitimate; (c) obligations arising under bills of exchange, cheques and promissory notes and other negotiable instruments arise out of their negotiable character; (d) arbitration agreements and agreements on the choice of court; ( $f$ ) the question whether an agent is able to bind a principle, or an organ to bind a company or body corporate or unincorporate, to a third party; ( $g$ ) the constitution of trust and the relationship between settlers, trustees and beneficiaries; $(\mathrm{h})$ evidence and procedure, without prejudice to Article 14. 3. The rules of this Convention do not apply to contracts of insurance which cover risks situated in the territories of the Member States of the European Economic Community. In order to determine whether a risk is situated in these territories the court shall apply to contracts of re-insurance. Article 2, Any law specified by this Convention shall be applied whether or not it is the law of a Contracting State.

${ }^{243}$ Article 4, 1. To the extent that the law applicable to the contract has not been chosen in accordance with Article 3, the contract shall be governed by the law of the country with which it is most closely connected. Nevertheless, a severable part of the contract which has a closer connection with another country may by way of exception be governed by the law of that other country.

${ }^{244}$ Article 4, 2. Subject to the provisions of paragraph 5 of this Article, it shall be presumed that the contract is most closely connected with the country where the party who is to effect the performance which is characteristic of the contract has, at the time of conclusion of the contract, his habitual residence, or, in the case of a body corporate or unincorporate, its central administration. However, if the contract is entered into in
} 
particular, sparks speculation. This provision connects the applicable law to the location of the trader. In the area of the Internet, this location is just an accidental spot along the digital highway in a just as accidental country. If this criterion survives, for all practical purposes it means that etailers are free to choose the law that suits them best by claiming residence in that country.

It would stand to reason that future law will attach greater significance to the place of residence of the consumer.

\subsubsection{Discrepancies between information online and on the label}

Earlier in the chapter, we touched upon the question whether etailers can defend themselves against product liability claims based on faulty online information by invoking the correctness of the information on the label which came with the product when it was supplied. This information provide the consumer with the possibility to take cognisance of the correct information. If this defence would be allowed, the legal risk for etailers of incorrect food information online would be limited to annulment of contracts that otherwise would be immune from annulment.

Indeed, such defence should be accepted. Such acceptance achieves that consumers who were in the position to correctly inform themselves about the composition of the product they bought, cannot invoke mistakes that were made earlier in the chain but that subsequently were remedied.

There remains just one anomaly in case of acceptance of this defence, which is that the etailer who could have known that the information was wrong (by consulting the label) escapes liability while the etailer who could not have known (because the label did not provide the correct information) remains liable.

\subsubsection{Article 14 of the Food Information Regulation}

The findings in the current research inevitably point towards abolishment of Article 14 of the Food Information Regulation. Balancing the advantages and disadvantages clearly leads to the conclusion that the European legislator failed to strike a fair balance when introducing this provision.

It has to be acknowledged that for political reasons the likelihood of actually abolishing Article 14 of the Food Information Regulation in the near future is slim. At the very least, the scope of Article 14 should be limited to including only the information which is mandatory for non-prepackaged foods. ${ }^{245}$ In that situation, etailers can limit themselves to providing the most relevant information from a health point of view, which relates to the possible presence of ingredients or processing aids that may spark allergies or intolerances. ${ }^{246}$

the course of that party's trade or profession, that country shall be the country in which the principal place of business is situated or, where under the terms of the contract the performance is to be effected through a place of business other than the principal place of business, the country in which that other place of business is situated.

${ }^{245}$ Article 441 . Where foods are offered for sale to the final consumer or to mass caterers without prepackaging, or where foods are packed on the sale premises at the consumer's request or prepacked for direct sale: (a) the provisions of the particulars specified in point (c) of Article 9(1) is mandatory.

${ }^{246}$ Article 91 In accordance with Articles 10 to 35 and subject to the exceptions contained in this Chapter, indication of the following particulars shall be mandatory: (c) any ingredient or processing aid listed in Annex II or derived from a substance or product listed in Annex II causing allergies or intolerances used in the manufacture or preparation of food and still present in the finished product, even if in altered form;. 
The willingness of the European legislators to evaluate the effects of the legislation they have put in place, gives some hope that at some point in the future the consumer protection regarding food online will be reconsidered. 


\section{SUMMARY}

In this thesis the research focuses on the legal rules and regulations in the Netherlands that apply in the context of food purchases by consumers that are concluded online. Sale of food via the Internet takes place in the area of Civil Code requirements on distance selling and public law requirements on food labelling. In four research Chapters (chapters 2-5) the relevant topics are addressed.

In Chapter 1 the legal context to the research is presented leading up to the formulation of the central problem statement and the research questions. The Chapter also provides the theoretical framework and the in this research applied methodology.

Chapter 2 'Real Food from Virtual Shops: the situation before 2014' reports on research performed before the entry into force of the national implementation of the Consumer Rights Directive and of the Food Information Regulation. This chapter provides the historical baseline to this research. The research in this chapter shows that the instruments handed to the consumers to compensate their weakened position as online buyers, cannot function as intended in case the merchandise is food. It is argued that consumers derive more bite from general provisions of contract law than from the provisions specifically addressing distance contracts.

In chapter 3, 'Food Online, Radical Changes to the Digital Shop Window after 2014' the argument is continued by addressing in detail the implementation of the Consumer Rights Directive in the Netherlands and the entry into force of the Food Information Regulation. The differences become visible between civil law and public food legislation in the manner in which they envisage to protect the consumer. Civil law turns out to be rather scarce in requiring information provision to consumers. In his attempt to ensure that consumers are only bound to purchase contracts they actually want, the European legislator has chosen a far more draconic instrument. The consumer has been given the right to withdraw from the contract altogether after the etailer has already fulfilled his side of the agreement. The legislature has preferred this instrument over elaborate information requirements regarding the product to be purchased. The available data do not show that the legislature balanced these two instruments.

Whatever these reasons have been, they seem to have been less compelling in the case of food products. The vast majority of foods is exempted from the consumers' right to withdraw. This leaves a considerable gap in the civil law protection of consumers of food online. This gap has recently been filled by the Food Information Regulation. This regulation does put in place a considerable obligation to supply the consumer online with information prior to the purchase decision. The etailer has to provide online all the information which the producer is required to provide on the food label. In one small provision the entire and complex burden the Food Information Regulation places on the food industry, is placed with the etailer as well.

In Chapter 4 'Product Liability for Online Food Suppliers' the increased risks for the etailer of foods to become product liable is addressed. Due to the wide scope of the definition of 'producer' in product liability law, the risk for the etailer to be considered the liable producer is rather high. Due to the Consumer Rights Directive and its implementation in national law, of all the players in the chain the etailer is easiest to identify for the consumer. Etailers have to push their claims further up the hill without any recourse to facilities regarding burden of proof or liability. Both the Consumer Rights 
Directive and the Food Information Regulation have been designed to reinforce the consumers' position with a view to ensuring that consumers will no longer be the weakest link in the value chain.

In Chapter 5 'The Lucky Bag for Meals' the emerging market for food-boxes is discussed. Food-boxes embody the dream of every etailer. Not the consumers decide what they buy, but the retailers decide what they supply. Business economic advantages of this model in terms of stock management, logistics and marketing are obviously enormous. Apparently an important marketing proposition in this modern day 'lucky bag' is the surprise. It appears that consumers want to be surprised. Despite all requirements regarding transparency and information provision imposed by legislators upon the etailer with a view to protecting consumers, a part of the market seems to prefer to be kept uninformed. The chapter shows that a relevant group of consumers is actually willing to pay a price premium to businesses for infringing upon their legal obligations and for being kept out of their rights.

In Chapter 6 the findings of the research are presented. Besides the answers to the research questions a new series of questions emerge. These openings to further exploration show how the legal field of food online in legal development and legal scholarship is just as young as the technology that sparked its emergence. 


\section{REFERENCES}

Belgian Product Liability Law of 25 February 1991.

Bregstein, H. 1963 Wezen en grondslagen van het recht J.H. Kok, Kampen.

Colombi Ciacchi, A.L.B., M.A. Heldeweg, B.M.J. van der Meulen en A.R. Neerhof, Law \& Governance, Beyond the Public-Private Law Divide, 2013. Eleven International Publishing.

$\operatorname{COM(1995)} 617$ Application of Council Directive on the approximation of laws, regulations and administrative provisions of the Member States concerning liability for defective products (85/374/EEC)

COM (1999) 396 Green paper Liability for Defective Products

COM (2006) 496 Report from the Commission to the Council, the European Parliament and the European Economic and Social Committee - Third Report on the application of Council Directive on the approximation of laws, regulations and administrative provisions of the Member States concerning liability for defective product (85/374/EEC of 25 July 1985, amended by Directive 1999/34/EC of the Parliament and of the Council of 10 May 1999).

COM (2008) 614 def. Proposal for a Directive of the European Parliament and the Council regarding consumer rights.

Council Directive 85/374/EEC of 25 July 1985 on the approximation of laws, regulations and administrative provisions of the Member States concerning liability for defective products

Council Directive 93/43 EEC of 14 June 1993 on the hygiene of foodstuff.

Coutrelis, N. 1999 Product Liability in the Food Sector, http://ec.europa.eu/enterprise/regulations/goods/docs/liability/1999-greenpaper-replies

Directive 97/7/EC of the European Parliament and of the Council of 20 May 1997 on the protection of consumers in respect of distance contracts.

Directive 1999/34/EC of the European Parliament and the Council of 10 May 1999 amending Council Directive 85/374/EEC on the approximation of the laws, regulations and administrative provisions of the Member States concerning liability for defective products

Directive 1999/44/EC of the European Parliament and of the Council of 25 May 1999 on certain aspects of the sale of consumer goods and associated guarantees.

Directive 2000/13/EC of the European Parliament and of the Council of 20 March 2000 on the approximation of the laws of the Member States relating to the labelling, presentation and advertising of foodstuffs.

Directive 2011/83/EU of the European Parliament and of the Council of 25 October 2011 on consumer rights, amending Council Directive 93/13/EEC and Directive 1999/44/EC of the European Parliament and of the Council and repealing Council Directive 85/577/EEC and Directive 97/7/EC of the European Parliament and of the Council.

Dutch Civil Code, Books 3, 6 and 7.

Faure, M.G. 2004. Product Liability in Europe: critical reflections on law and economics, AV\&S, 2. 
German Decree-Law of 24 May 1988

Green Paper of the European Commission 'Liability for defective products' (28 July 1999)

Hamm, O.L.G. 1973, Agrarrecht 1973, pp 51-53 with note by Friedhelm Kieserling

Hijma, J. 2009. De koopregeling in het richtlijnvoorstel consumentenrecht; included in the Het voorstel voor een Europese richtlijn consumentenrecht' collection, The Hague, Boom Juridische uitgevers, 2009 p. 171.

Hummels, Hondius, Snijders, 1988. Food and Product Liability, VMT no. 26

Italian Decree-Law of 24 May 1988.

Kranenburg, R. 1946 De Grondslagen der Rechtswetenschap. Juridische Kennisleer en Methodologie, H.D. Tjeenk Willink, Haarlem.

Offical Journal of the European Union of 4 February 2003 on amendments to the Directive regarding liability for defective products.

Product liability in the European Union, a report for the European Commission, Study by the European Commission, March/2001/11/D.

Proposal for a Directive of the European Parliament and Council regarding consumer rights, Brussels, 8 October 2008, COM (2008)614 def.2008/0196 (COD).

Recommendations relating to Product Liability issued by the Minister of Justice, 1980 Publication no. $4-18$

Regulation (EC) No 178/2002 of the European Parliament and of the Council of 28 January 2002 laying down the general priciples and requirements of food law, establishing the Euopean Food Safety Authority and laying down procedures in matters of food safety.

Regulation (EU) No 1169/2011 of the European Parliament and of the Council of 25 October 2011 on the provision of food information to consumers, amending Regulation (EC) No 1924/2006 and (EC) No 1925/2006 of the European Parliament and of the Council and repealing Commission Directive 87/250/EEC, Council Directive 90/496/EEC , Commission Directive 1999/10/EC, Directive 2000/13/EC of the European Parliament and of the Council, Commission Directives 2002/67/EC and 2008/5/EC and Commission Regulation (EC) No 608/2004.

Scholten, P. De Structuur der Rechtswetenschappen, 1945 Mededelingen der Koninklijke Nederlandsche Akademie van Wetenschappen, Afd. Letterkunde, Nieuwe Reeks Deel 8, no. 1, N.V. Noord-Hollandse Uitgevers Maatschappij Amsterdam.

Smart Food Monitor, figures and trends in food retail (15 September 2016).

Stellinga, J.R. 1946 Systematische Staatsrechtstudie. Rede ter gelegenheid van den zevenden dies natalis der Rijksbelastingacademie te Rotterdam 16 Oktober 1946, 's-Gravenhage

United Nations Convention on contracts for the international sales of goods (CISG)

Van der Meulen, B.M.J. and Van der Velde, 2008. M. European Food Law, handbook, Wageningen Academic Publishers, Wageningen, the Netherlands.

Van der Meulen, B.M.J. Ars Aequi december 2014, 'Levensmiddelenrecht, een functioneel rechtsgebied in opkomst' 
Van der Meulen, B.M.J. Ars Aequi Libri 2017, 'Levensmiddelenrecht, systeem van een gelaagd functioneel rechtsgebied'

Van der Veer, L.C. 2011. Private Food Law, Food Online, Reconnaissance into a consumer protection no-mans's land between food law and the Civil Code, Wageningen Academic Publishers, Wageningen.

Van Zaltbommel L.K. defended in 1993 a PhD thesis on De betekenis van het recht als system, W.E.J. Tjeenk Willink, Zwolle 1993.

Voit and Grube. 2013.Lebensmittelinformationsverortnung, Kommentar VO (EU) Nr. 1169/11 C.H. Beck

Von Savigny, F.C. Vom Beruf unserer Zeit für Gesetzgebung und Rechtswissenschaft, Mohr und Zimmer Heidelberg 1814 available at < http://reader.digitalesammlungen.de/resolve/display/bsb10740690.html

Web shop General Terms and Conditions of the Nederlandse Thuiswinkel Organisatie, established in consultation with the Consumer's Assocation within the framework of the Coördinatiegroep Zelfreguleringsoverleg of the Social and Economic Council, 1 jan.2009.

\section{Websites}

Codex Alimentarius Commission - www.codexalimentarius.net

Commission of the European Communities - http://ec.europa.eu

Council of Europe - www.coe.int

Court of Justice of the European Communities - http://curia.eu.int

European Council - http://www.consilium.europa.eu

European Food Law Association - www.efla-aeda.org

European Food Safety Authority - www.efsa.europa.eu

European Institute for Food Law - www.food-law.nl

European Parliament's legislative Observatory - www.europarl.europa.eu/oeil/index.jsp

European Union - http://europa.eu

European Law and Related Documents - http://eur-lex.europa.eu/legal-content/

Faolex Legal Database - http://faolex.fao.org

Food and Agriculture Organisation - www.fao.org

Foodlaw-Reading - www.rdg.ac.uk/foodlaw

Forum of European Food Law Enforcement Practitioners - www.flep.org

Green Paper Replies - http://ec.europa.eu/enterprise/regulations/goods/docs/liability/1999-

greenpaper-replies 
Institut für Angewandtes Lebensmittel- und Futterrecht - www.ifal.eu

International Food Policy Research Intitute - www.ifpri.org

International Portal on Food Safety, Animal and Plant Health - www.ipfsaph.org

Nederlandse Vereniging voor Levensmiddelenrecht - www.nvlr.nl

Standing Committee on the Food Chain and Animal Health -

http://ec.europa.eu/food/fs/rc/scfcah/index

Survey of EC food legislation - http://europa.eu/eur-lex/en/lif/reg/en_register_133014

Thuiswinkel Waarborg - www.thuiswinkel.org

List of Dutch online food supermarkets

- albert.nl

- allesin1bezorgservice.nl

- appiehein.com

- asiansupermarkt.nl

- bezorgbus.nl

- boodschappenuitholland.nl

- boodschappenbezorgservice.nl

- boodschappenxl.nl

- denederlandsewinkel.com

- dutchfoodshop.nl

- dutschsupermarket.com

- fabulousfood.nl

- heimweewinkel.nl

- hofwebwinkel.nl

- holland-at-home.com

- hollandwebwinkel.nl

- ooms-supermarkt.nl

- orangepackage.com

- realdutchfood.com

- thijl.nl

- tropimar.nl 
- typicaldutchstuff.com

- vegashopping.nl

- vershuys.com

- thevillageshop.nl

- yummydutch.com

- woodleaf.nl

- superbezorger.nl

- cooponline.nl

- superdirect.com

- zorgboodschap.nl

- bonisupermarkt.nl

- ruudmaas.nl

- onlinesuper.nl

- bright.nl

- simonides.nl

- smaak.nl

- koreashop.nl

- coophooghalen.nl

- regiovers.nl

- ekoplaza.nl

- sagramercato.nl

- spar.nl

- sparkramer.nl

- hoogvliet.com

- webwinkel.ah.nl

- ah.nl

- tropimar.nl

- turkse-winkel.nl

- supermarktdelelie.nl

- russischesupermarkt

- biodichtbij.nl 
- deen.nl

- supermarktodoorn.nl

- lalemarket.nl

- natushop.nl

- biologischetoko.nl

- biowaren.nl

- biovoordeel.nl

- bonfood.nl

- cake-releave.eu

- de weehschaal.nl

- ko-kalf.nl

- lekkervega.nl

- odinwinkel.nl

- roseyscupcakes.com

- vanhavertotgort.nl

- vitatas.nl

- zweedse-jam-leveranciers.nl

- ecovlees.nl

- biologischeviswinkel.nl

- hetlekkerstebiologischevleesgratisbijuthuisbezorgd.nl

- okvlees.nl

- vomar.nl

Some Dutch Meals on Wheels

- thuisbezorgd.nl

- hapjesbestellen.nl

- hapsalons.nl

- deliveryexpres.nl

- justeat.nl

- unitedpizza.nl 
- foodconnecy.nl

- kookjijofik.nl

- maaltijdservice.nl

- lekker-thuis.nl

- uitgekookt.nl

- vansmaak.nl

-eet.nu

- apetito.nl

- broodjesdirect.nl

- broodjesexpress.nl

- debezorgbus.nl

- broodjes-amsterdam.nl

- meester.slagerij.nl

- cafewaterloo.nl

- cafetaria-trefpunt.nl

- broodjeslijn.nl

- hoekstrabroodjesexpres.nl

- tuuttuut.com

- stokbroodje.nl

- luckylunch.nl

- lunch-expres.nl

- bakkerwim.nl

- debrunch.nl

- nieuw-china.nl

- chinaexpres.nl

- nieuwchina.nl

- sajaki.nl

- sushihouse.nl

- sushiaanhuis.nl

- sushitotaal.nl

- pizzabestellen.nl 
- newyorkpizza.nl

- gepetto.nl

- pizzaspidi.nl

- roti-expres.nl

- mediterranescorner.nl

- tacomundo.com

- bezorgbeer.nl

- spareribexpress.com

- apetito.nl

- de stamperij.nl

-tacomundo.nl

- taartbezorgers.nl

- taartenland.nl

- taartwinkel.nl

- taartenwinkel.nl

- gefelicitaart.nl

- broekmans.nl

- multivlaai.nl

- palingshop.nl

Some Food boxes delivering in The Netherlands

- Extra Beebox

- AH Allerhande Inspiratiebox

-Vegetarische Beebox

- Ontbijtbox

-AH Allerhande Familiebox

- Mix Box

- Maaltijd Beebox

- Flexitariërbox

- Gemakskrat 
- FruitBox

- Koolhydraatarme Beebox

- Originalbox

- Veggiebox

- Familybox van Marley Spoon

- Gemakskrat Vega

- Familybox van Mathijs Maaltijdbox

- Familybox van Hello Fresh

- Mathijs Variatiebox

- Classic Box

- Maaltijdbox 9 maanden menu

- Maaltijd glutenvrij - lactosevrij

- Maaltijdbox Koolhydraatarm menu

- Maaltijdbox Vegan menu

- Maaltijdbox Vegetarisch menu

- Maaltijdbox Familie menu

- Maatijdbox Variatie menu

- Groente en Fruit Beebox

- Eenpersoons Beebox

- Basis Vers Beebox

- Weekendkrat Extra

- Kratje Slank

- Niven Foodbox

- Foodelicious box

- Sushi Box

- Asian Food Lovers Box

- Mathijs Fruitbox 